"أثر استخدام نموذج الاستقصاء القائم على الجدل في تنمية مهارات التفكير العليا

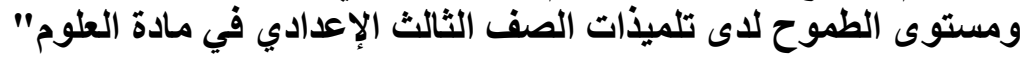

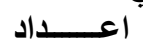

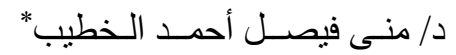

د/ دماح فاروق المرسي الأشقر

مشُكلة الدراسة وأبعادها

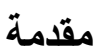

نعيش اليوم عصراً يتميز بالتغيرات السريعة والمتلاحقة في جميع مناحي

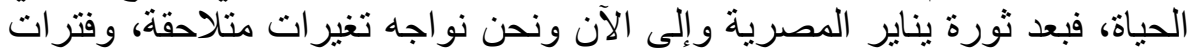

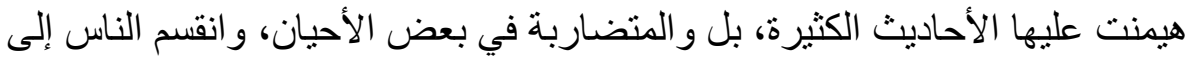

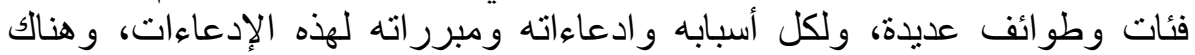
آخرون يتحدثون بلا دليل أو تفسير لما يقول ومون بهابه

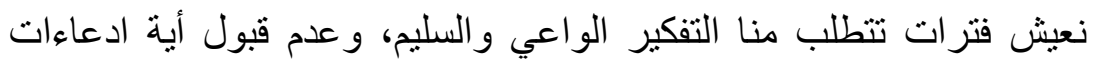

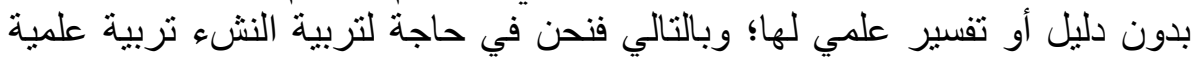

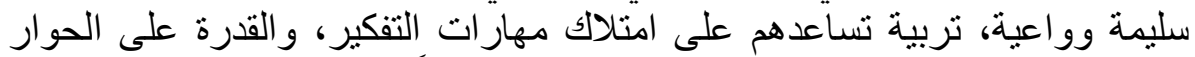

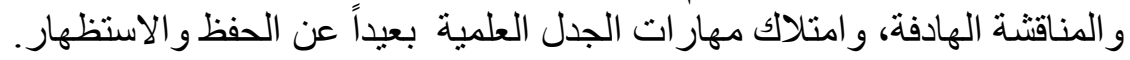

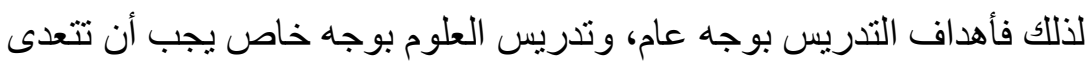

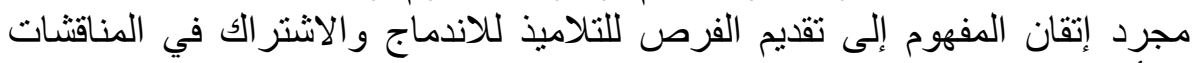
و الأحاديث العلمية الجدلية.

ولكي يتعلم التلاميذ مادة العلوم لا بد وأن يتعلموا الحوارات العلمية

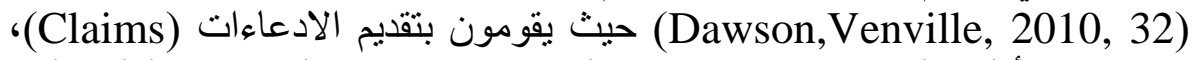

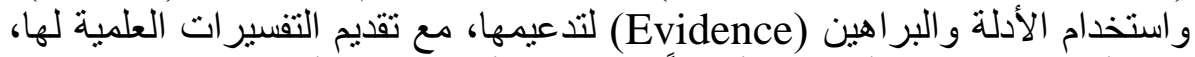

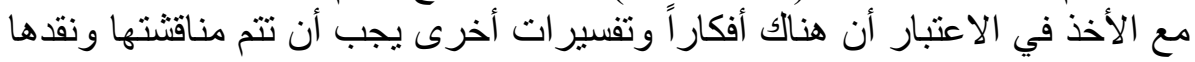
للتوصل إلى التفسير ات الصنبار أن هيحة.

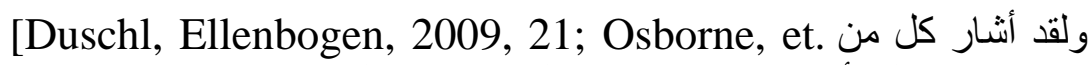

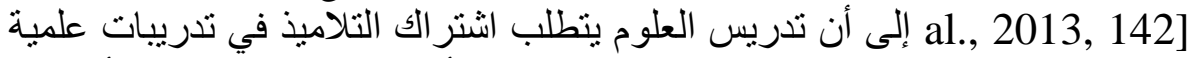

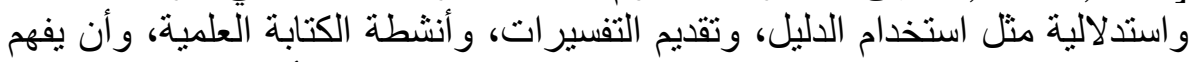

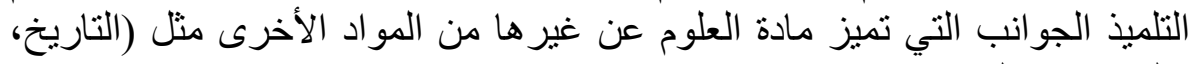
و القانون؛... إلخخ). 


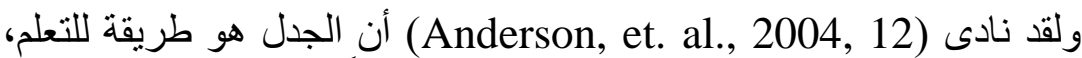

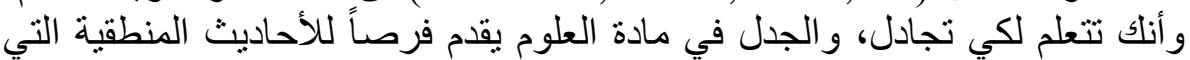
هدفها الإشارة إلى العلاقة بين الأفكار و الدليل العلمي عليها.

والجدل هو نشاط اجتماعي حيث تستكثف الأفكار من خلال المحادثات و المناقتشات الجماعية التي تساعد التناميذ على تقديم وتفسير وتقويم ونقد المعرفة [Driver, et. al. العلمية

2000, 1; Sampson, 2009, 13; Chin, Osborn, 2010; Sampson, Clark, 2011, 22]

و عند اشتراك التلاميذ في عملية الجدل فإنهم يتدربون على استكثاف المعرفة العلمية واستقصائها (Sandoval, Reiser, 2004) وكذلك التدرب على على عادات

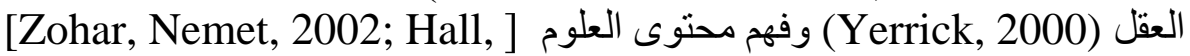
Sampson, 2009 ، وفهم عمليات العلم التي تعد خطوة أساسية لتنمية الثقافة العلمية .(Jimenez-Alexendre, Erduran, 2008)

و الجدل كمفهوم في تدريس العلوم تم تأييده على نطاق و اسع، و لاقى قبو لاً في

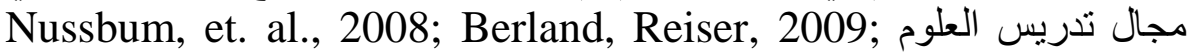
‘Kuhn, 2010 ; Berland, Hammer, 2012;] [Bricker, Bell, 2008;

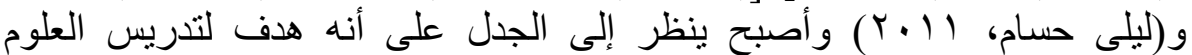
(Kelly, Bazerman, 2003, 17)

و استخدام الجدل في تدريس العلوم يتطلب تغيير اللاتجاهات و المداخل التقليدية التانية

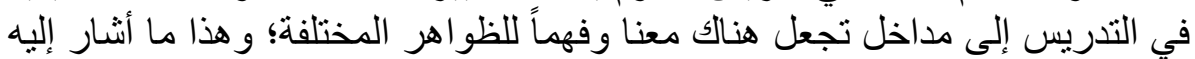

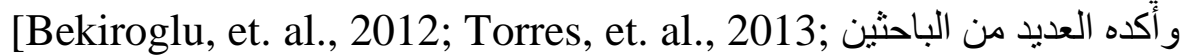
Sampson, Enderle, Grooms, 2013] من النماذج التي تؤكد على نقل المعرفة من المعلم إلى التلميذ إلى نماذج الاستقصاء التي تؤكد على بناء المعرفة و ور اجعتها ونقد ها.

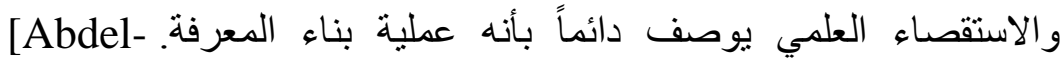
ل2004; Çalık, 2013] khalick, et. al, للبيانات، ثم تقدم لمجتمع الأقران لنقدها ومر اجعتها.

و القدرة على خلق حجة مقنعة، واستخدام الدليل مع تقديم التفسير ات هو مكون

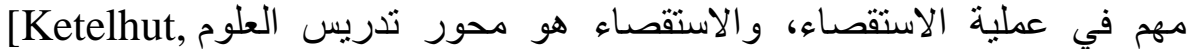
] Nelson, 2010; 56; Yeh, 2012, 24] وما العلوم إلا عملية استقصاء مفتوح. نتيجة لذلك ظهرت العديد من النماذج التدريسية ومنها النماذج القائمة على wallace, Hand, prian, 2004; Lee, Science Writing Heuristic الكتابة

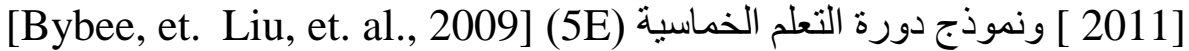
al., 2006, والتدريس باستخدام النماذج Models (Gunckel, 2013)، ونموذج (e) 
بناء المعرفة المشتركة Common Knowledge Construction Model . (Ebenenzer, et. al., 2010)

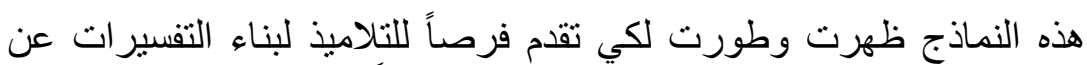

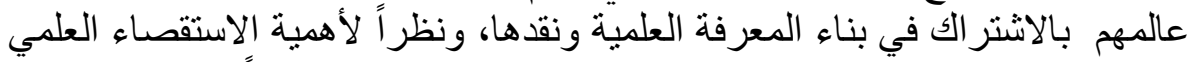
و الجدل في تدريس التعلوم، ظهرت بعض الناء النماذج التي تقدم فرصاً للتعلم من خلال

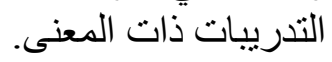

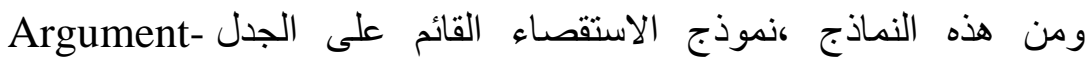

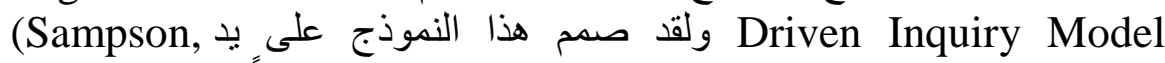
Grooms, Walker, 2009)

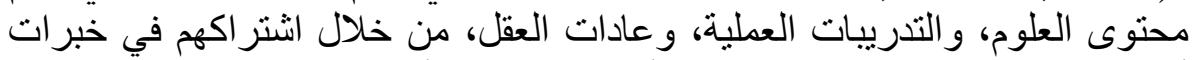

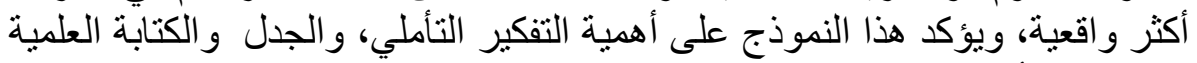
ومر اجعة الأقران من خلال الاستقصاء العلمي.

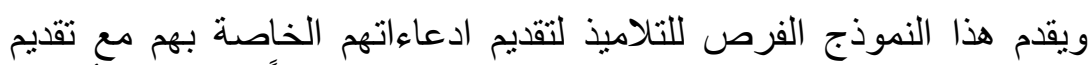

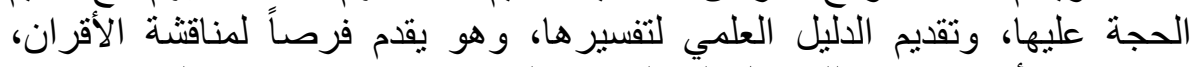

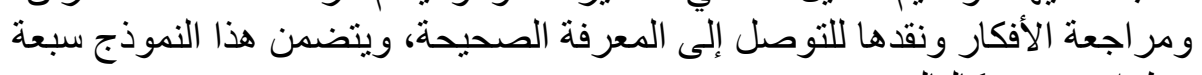

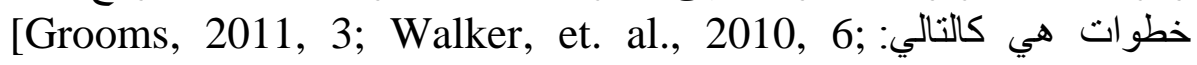
Walker, Sampson, 2013, 8]

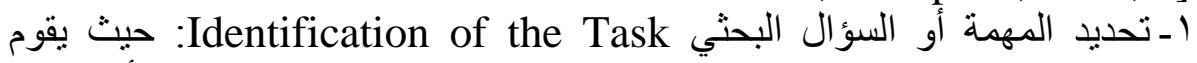

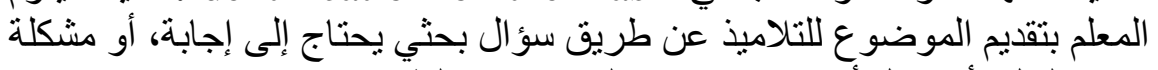

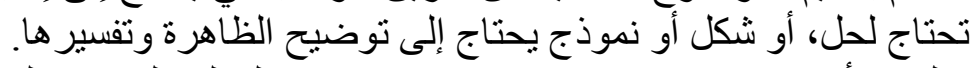

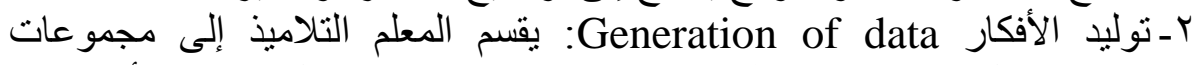

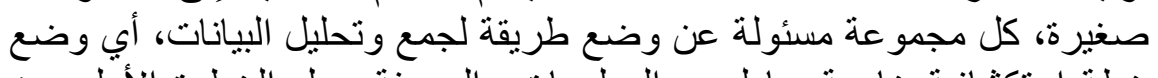

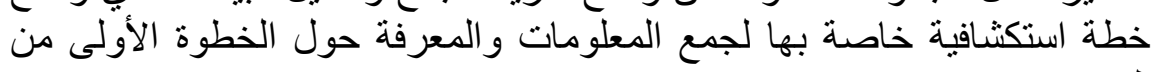

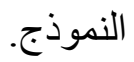

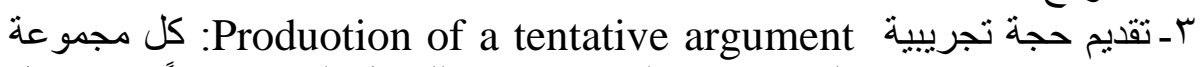

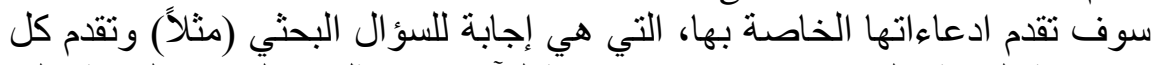

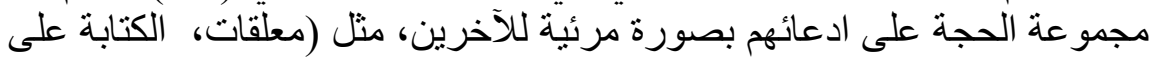

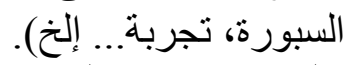

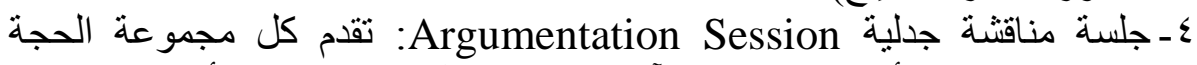
الخاصة بها، وتبدأ بمناقتتها مع الآخرين من خلال النقد وتقديم الأسئلة المرتبطة بها.

هـ تقديم تقرير استكثافي مكتوب Creation of a written investigation Report

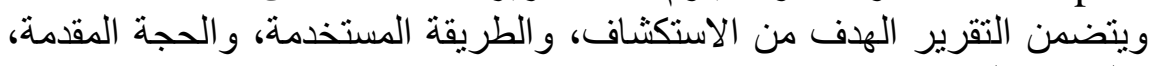
و المبرر عليها، وتفسير ها. 


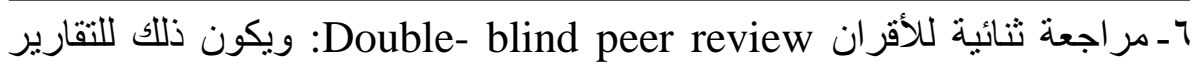

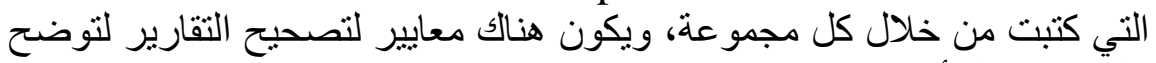

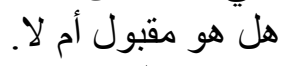

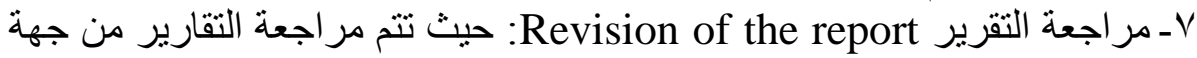

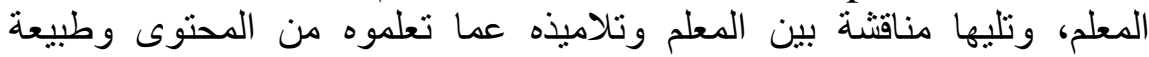
الاستقصاء العلمي، وما الجديد الذي تعلموه كي يفيدهم في المرات اتلهي القادمة.

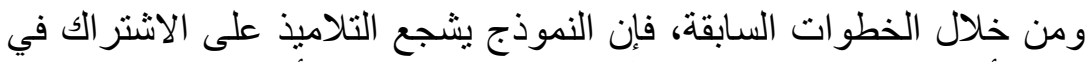

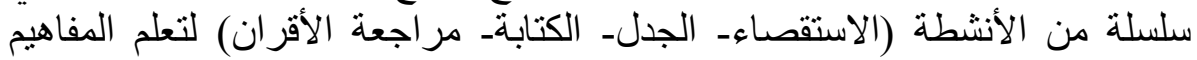
و التدريبات في العلوم، وتنمية مهار ات التفكير لديهم.

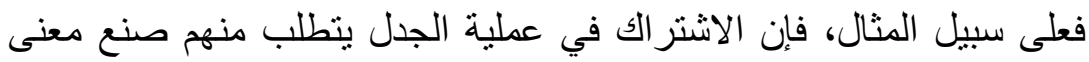

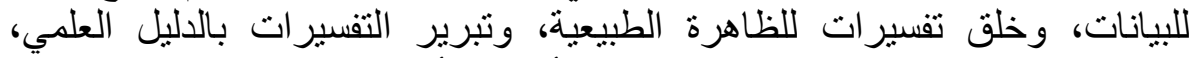

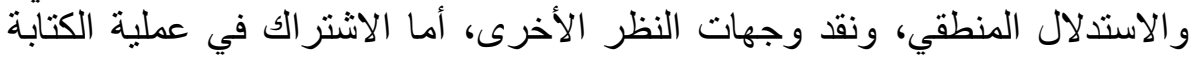

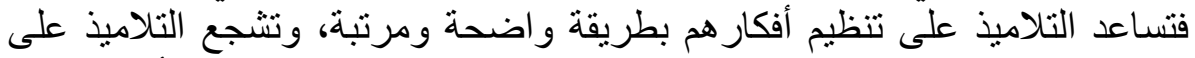

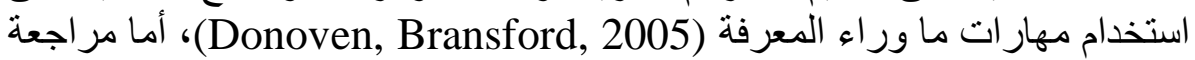

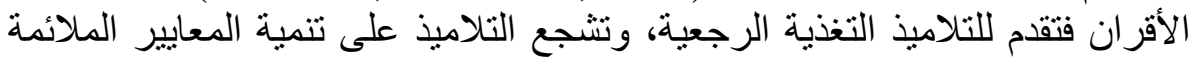

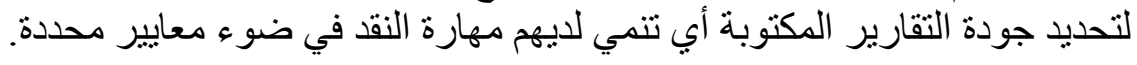

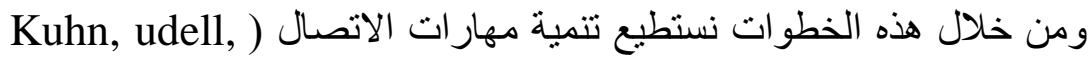

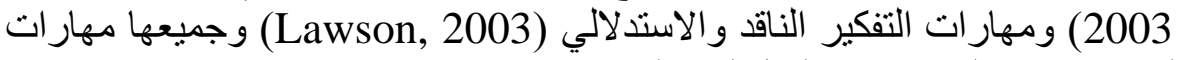
للتفكير تحتاج إلى تنميتها بالفعل لدى التنلاميذ.

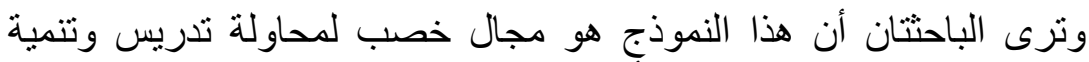

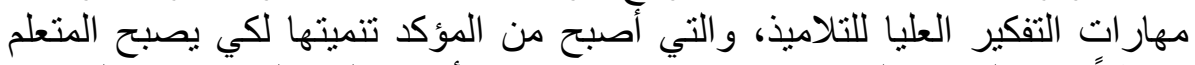

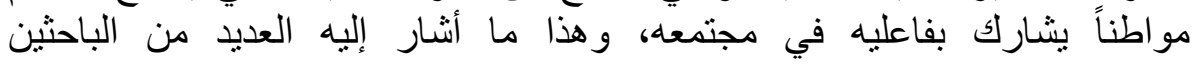
[Hanneke, 2010; Hoffman, 2010; Adeymi, 2012]

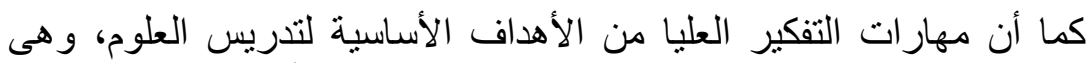

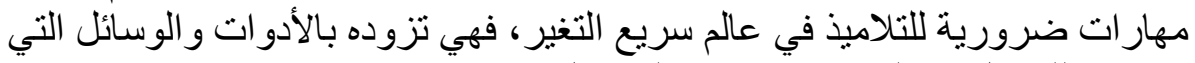

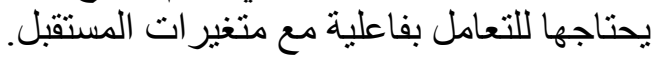

وتتفق معظم الدراسات في التربية العلمية وتدريس العلوم على التعلى أهمية تنمية

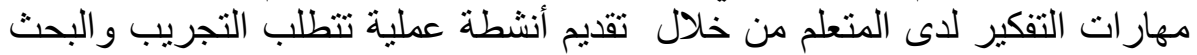

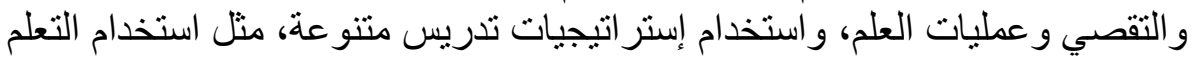

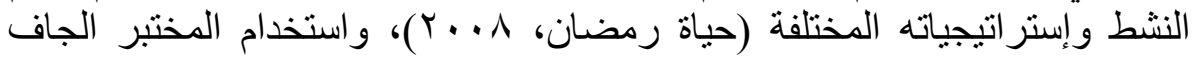

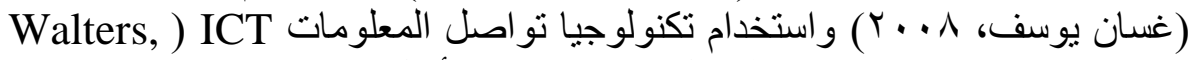

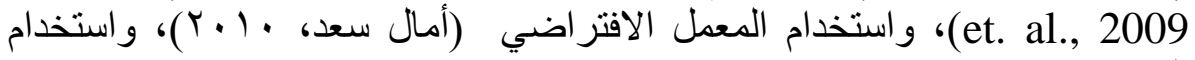

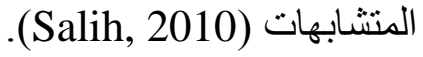




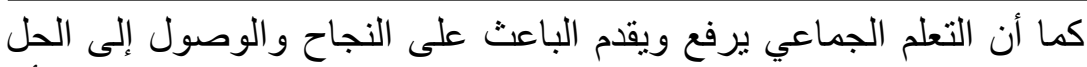

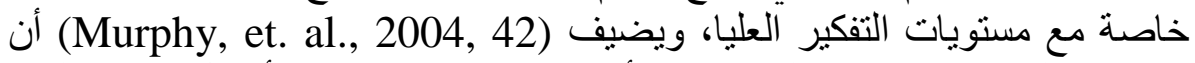
التلاميذ الذين يشاركون المعلم في أثناء التدريس يكونون أفضات التضل في تعلمهر و استمتاعهم من التلاميذ الذين لا يشاركون في في عملية التعلم.

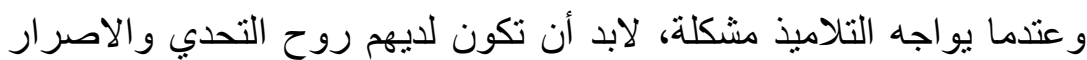

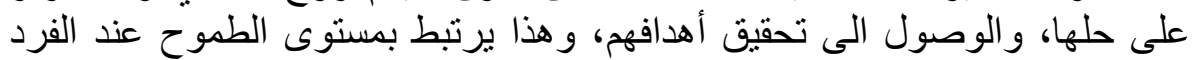

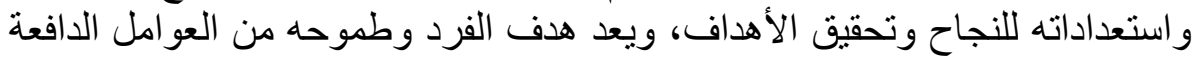

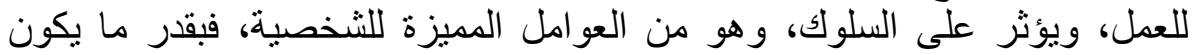

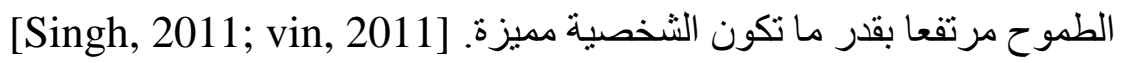
مثكلة الدراسة مرئة

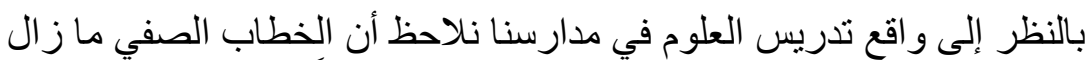

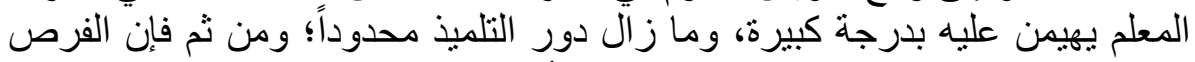

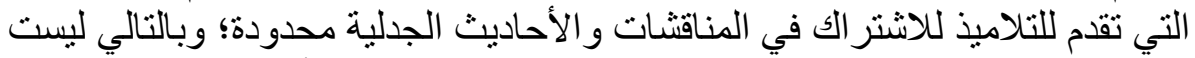

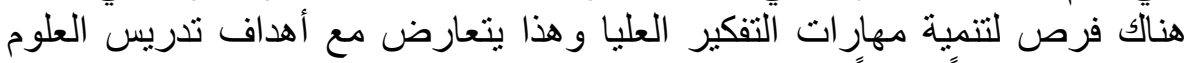

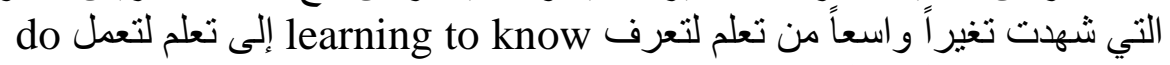

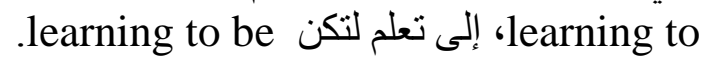

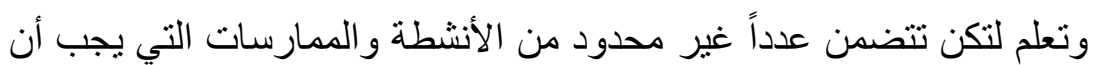

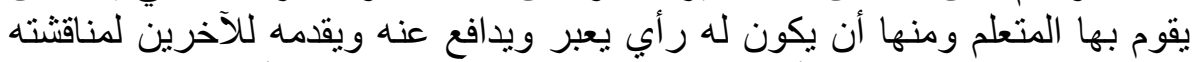

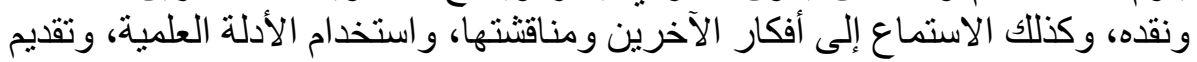

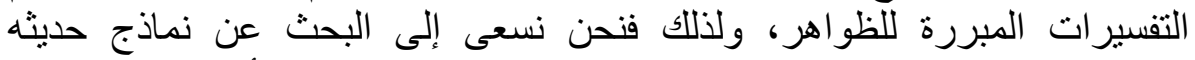

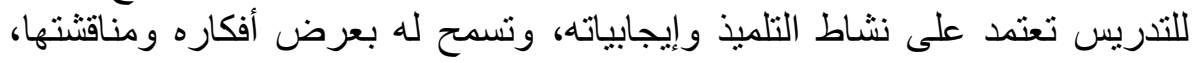

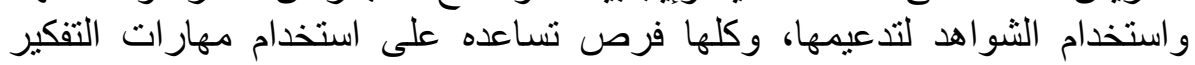

و هذا ما دعا الباحثثين إلى استخدام نموذج الاستقصاء القائم على الجدل؛ لأنه

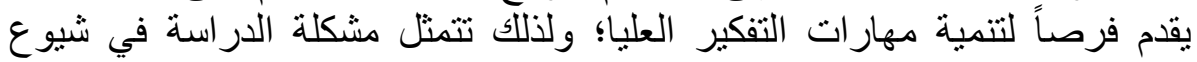

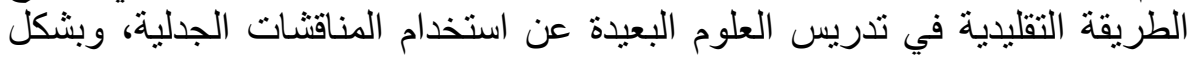
بعيد عن استخدام مهار ات التفكير العليا لدى التيدة التلاميذ.

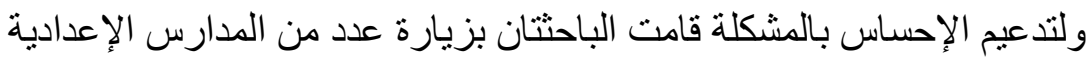

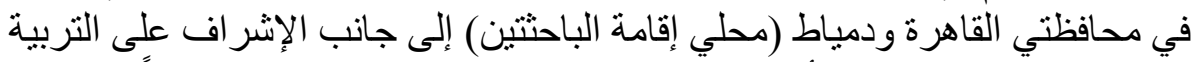

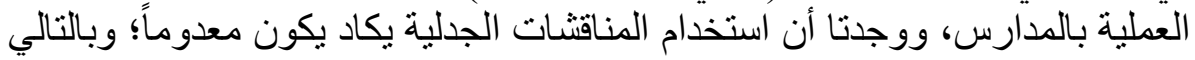
عدم وجود فرص لتنمية مهار ات التفكير العليا. وبالتالي تتمثل مشكلة الدر اسة في السؤال الرئيس التالي:

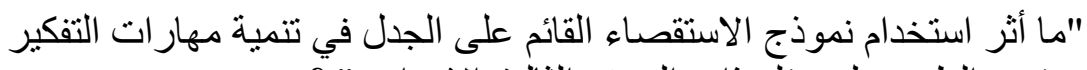
العليا ومستوى الطموح لاى تلميذات الصف الثنالث الإعدادي" ؟ 
ويتفرع عن هذا السؤال الرئيس الأسئلة الفرعية التالية:

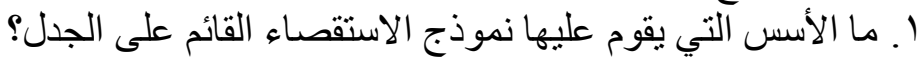

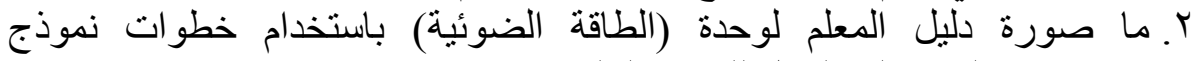

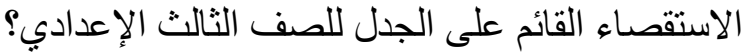
r. ما أثر استخدام نموذج الاستقصاء القائم على الجدل الإلفي في تنمية مهار ات التفكير العليا لاى تلميذات الصف الثالث الثالث الإعدادي؟ ؟. ما أثر استخدام نموذج الاستقصاء القائم على الجدل في تنمية مستوى الطموح لادى تلميذات أمـ الصف الثالث الإعدادي؟

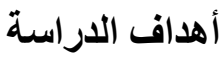

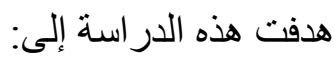

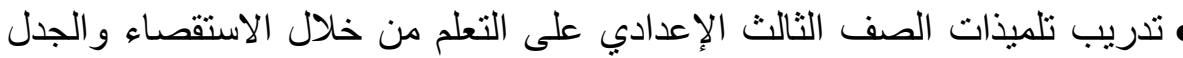

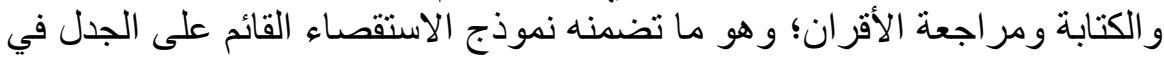
أثناء در استهن لوحدة (الطاقة الضوئية) • تعرف مدى أثر نموذج الاستقصاء القائم على الجدل في اكتساب التلميذات لمهار ات التهات

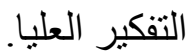
• تعرف مدى أنثر نموذج الاستقصاء القائم على الجدل في تنمية مستوى الطموح لدى الدى التلميذات مجمو عة الدر اسة.

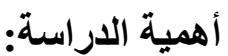

تتبع أهمية الدراسة مما يتوقع أن تسهح به في ميدان تعليم العلوم بالمرحلة

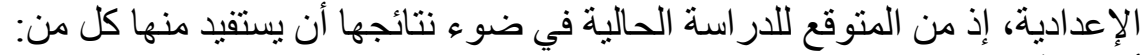

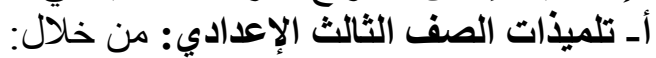

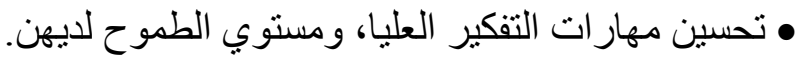

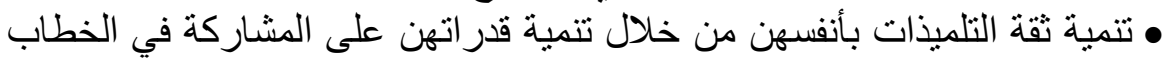
الجدلي. • تنمية التفاعل و التو اصل الاجتماعي بين التلميذات بعضهن البعض.

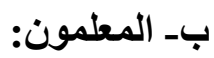
• من خلال تحسين أدائهم التدريسي ومسايرته للاتجاهات الحديثة في التدريس.

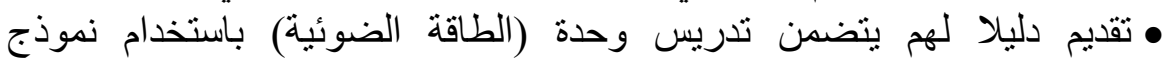
الاستقصاء القائم على الجدل، مما بساعد المتعلمين على تحقيق المعنى وبناء

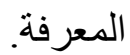
• تتمية التفاعل الاجتماعي بين المعلم وتلاميذه من خلال المناقتشات الجدلية.

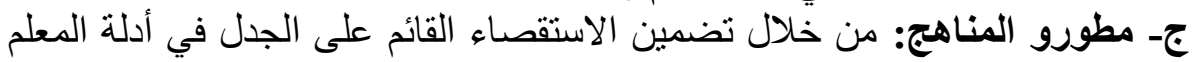
في بعض المواد والمر احل الدر اسية. 
اقتصرت الدراسة الحالية على الحدود التالية:

• مجموعة من تلميذات الصف الثالث الإعدادي بمدرسة (دقهلة الإعدادية بنات) بإدارة (السرو التعليمية) بمحافظة (دمياط).

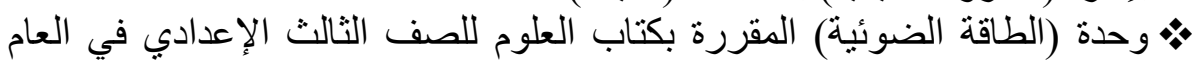

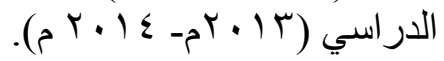

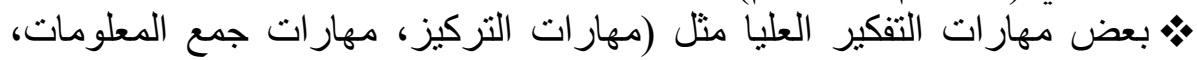

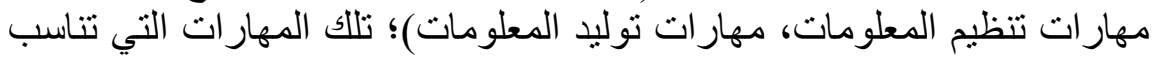

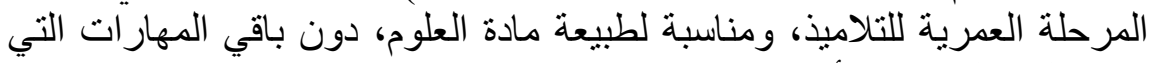
تحتاج لمرحلة عمرية أكبر.

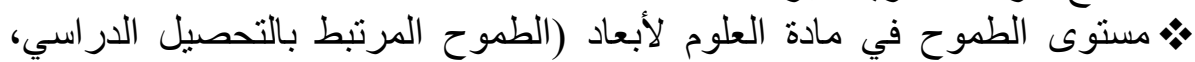

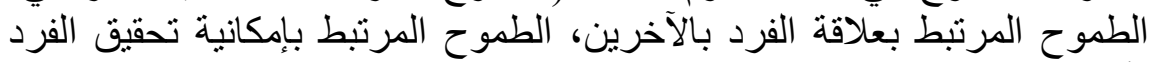
لألهدافه).

\section{فروض الاراسة}

ا ـ يوجد فرق ذو دلالة إحصائية بين متوسطي درجات تلميذات المجمو عة التجريبية

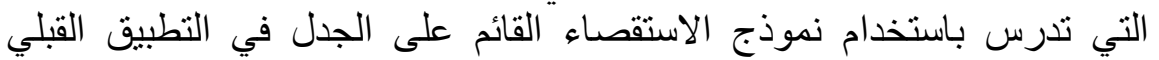
و البعدي لاختبار مهار ات التفكير العليا لصالح التطبيق البعدي.

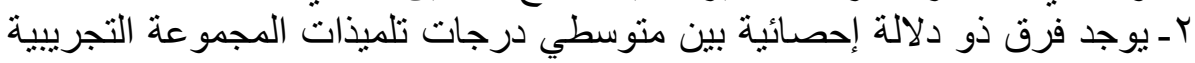
وتلميذات المجموعة الضابطة في التطبيق البعدي لاختبار مهار آتوات التفكير العليا لصالح المجمو عة التجريبية. "- يوجد فرق ذو دلالة إحصائية بين منوسطي درجات تلميذات المجمو عة التجريبية

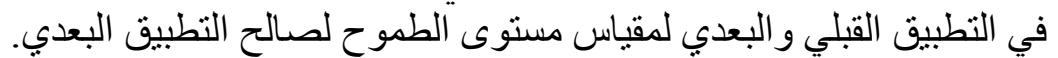

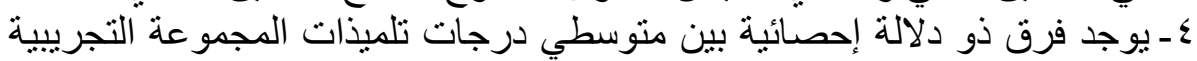
وتلميذات المجمو عة الضـابطة في التطبيق البعدي لمقياس مستوى دوى الطموح لصالح المجمو عة التجريبية.

$$
\text { خطوات الدراسة وإجراعاتها: }
$$

للإجابة عن أسئلة الدر اسة اتبعت الدر اسة الخطو ات التالية: أولا: تحديد أسس استخدام نموذج الاستقصاء القائم على الجدل، وكذلك خطو اته والتي

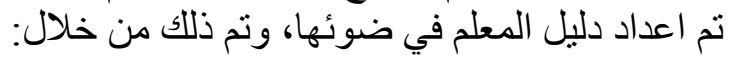

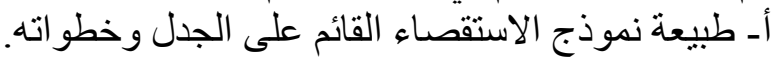

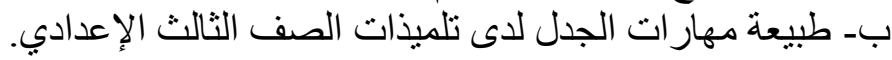

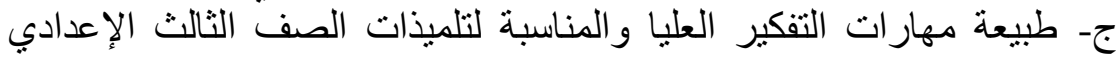
ولخطوات نموذج الاستقصاء القائم على الجدل. د- طبيعة المرحلة العمرية لتلامبذ الصف الثالث الإعدادي، وطبية التيعة مادة العلوم في هذه المرحلة. 
العدد الرابع

ثانيا: تحديد مدى أثز نموذج الاستقصاء القائم على الجدل في تتمية مهار ات التفكير

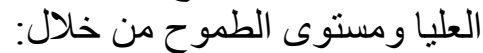

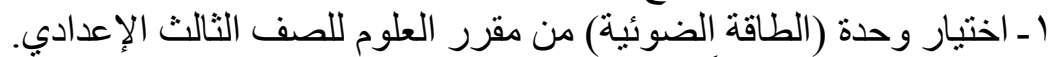

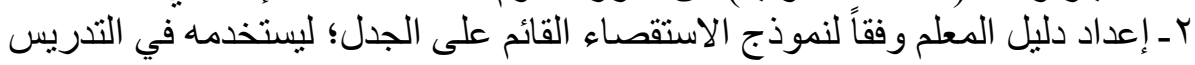
للمجمو عة التجريبية. بـ إعداد كراسة أنشطة للتلميذة يتضمن موضوبة عات الوحدة منظمة تبعا لنموذج

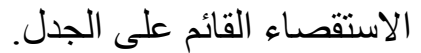

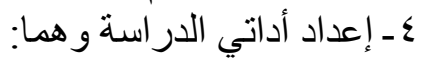

ب- مقياس مستوى الطموح. أـ اختبار مهار ات أتواد التفكير العليا. و التأكد من صدقهما وثباتهما. ـ ـ منهج الدراسة و التصميم التجريبي: تم استخدام المنهجين البحثيين التاليين:

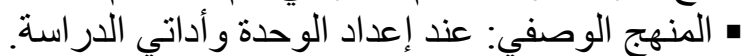

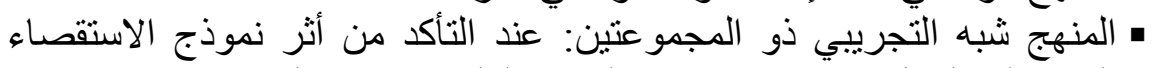
القائم على الجدل في تتمية مهار ات التفكير العليا ومستوى الطموح. وبذلك اشتمل التصميم التجريبي على المتغيرات اتلى التالية: ه المتغير المستقل: الوحدة المقدمة وفقا لنموذج الاستقصاء القائم على الجدل.

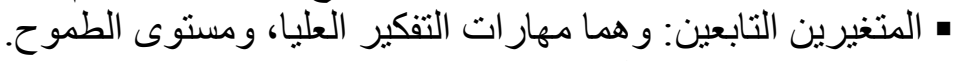

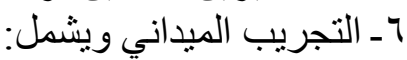

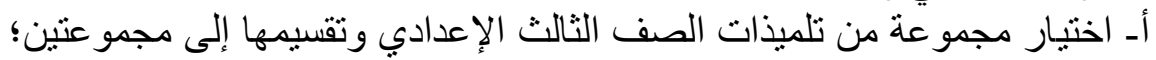

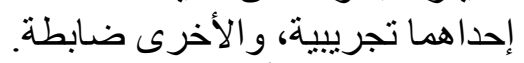
بـ التطبيق القبلي لأداتي الدر اسة للمجمو عتين (التجريبيةــ الضابطة).

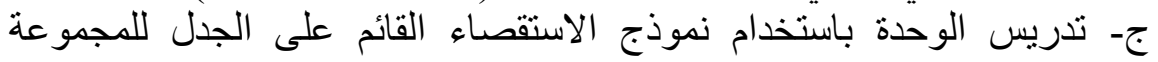

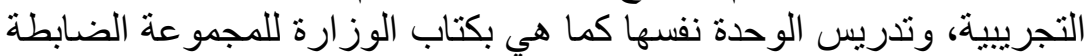
بالطريقة التقليدية. دـ التطبيق البعدي لأداتي الدر اسة للمجمو عتين التجريبية و الضـابطة.

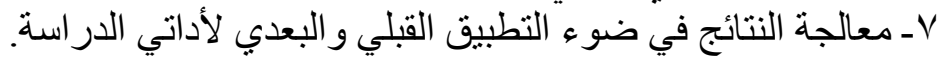

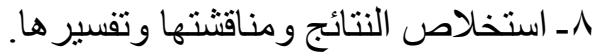

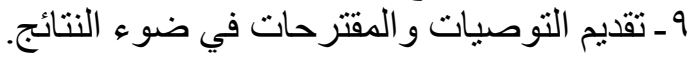
مصطات الدراسة

ه نموذج الاستقصاء القائم على الجدل Argument- Driven Inquiry Model هو نموذج تدريسي يقدم فرصاً للتلاميذ للتعلم بالاستقصاء من خلال اشتر اكهم

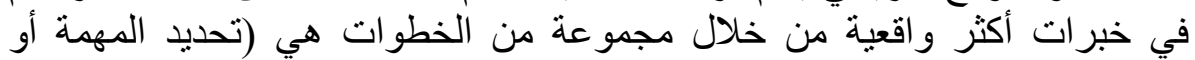

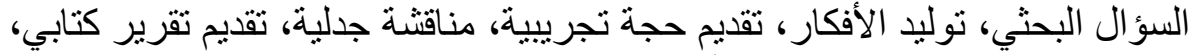
مر اجعة التقرير، مر اجعة ثنائية للأفران). (Sampson, Gleim, 2009, 4) 
العدد الرابع

وسوف تعرفه الباحثنان بأنه: سلسلة من الأنشطة الاستكثافية، نشارك فيها

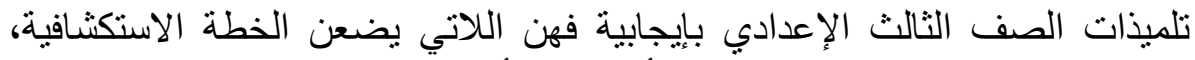

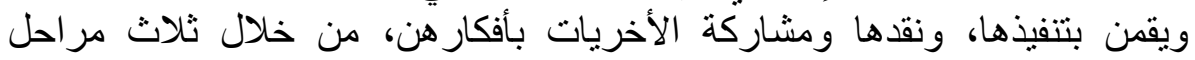

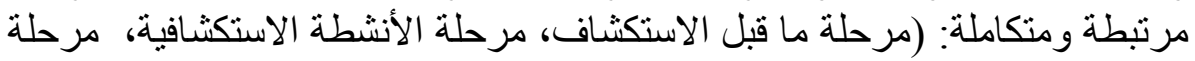

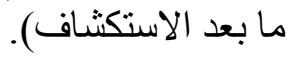

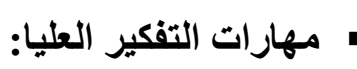

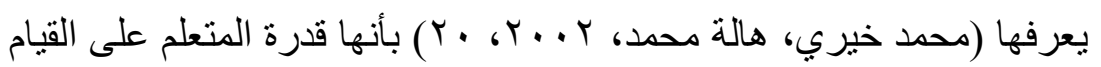

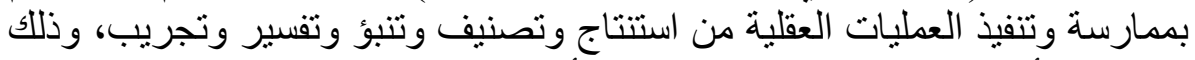
بإتقان تام أثناء العملية التعليمية المباشرة لأنماط التفكير بغرض الته استخدامها في حل المشكلات التي بتعرض لهاء أنثاء لتهياء حياته.

وتعرفها الباحثتان إجرائياً بأنها طرق ذهنية تستخدمها تلميذة الصف التهاء الثالث

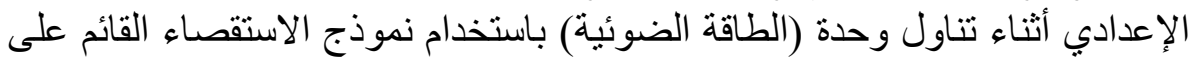

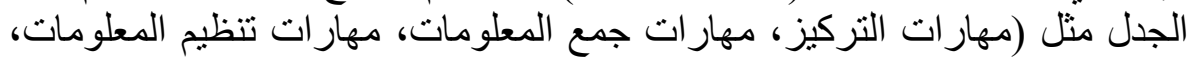

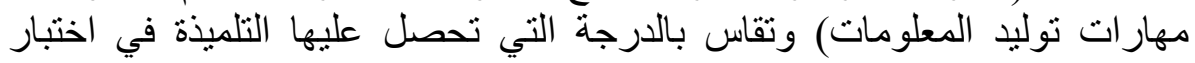
مهار ات التفكير العليا المعد لذلك.

\section{مستوى الطموح: Ambition Level مهار}

يعرفه (شريف مهني، I + . ب) بأنه ما بتطلع الفرد إلى تحقيقه من أهداف ذات مستوى محدد في جوانب حياته المختلفة، ويكون للخبرات التي مر بها في حياته دور

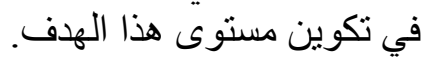

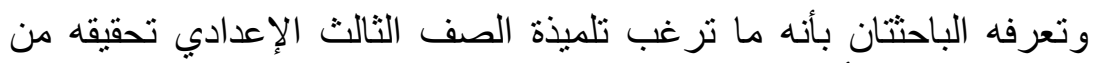

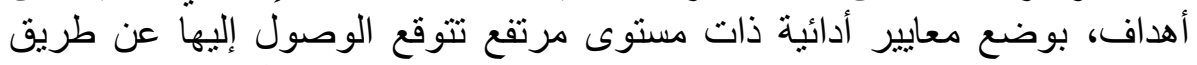

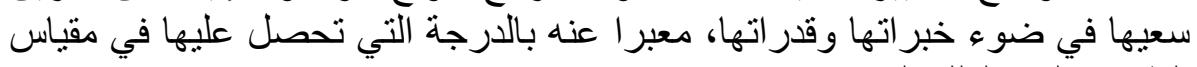

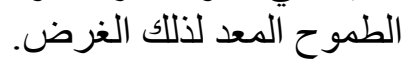

الإطار النظري

تم تناول الإطار النظري من خلال المحاور الآتية: أولا: الجدل وتدريس

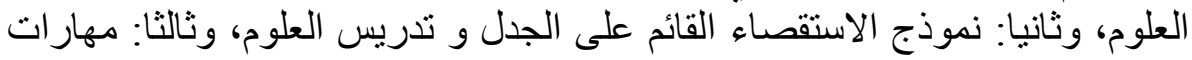

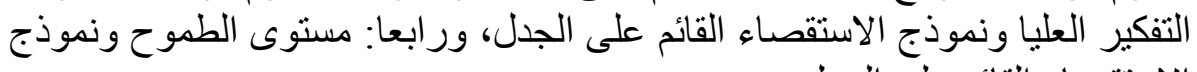

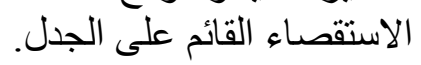

أولاً: الجدل وتدريس العلوم:

الجدل في اللغة يعنى النقاش أو الخصام (جادل الرجل جدلاً خاصمه أثند

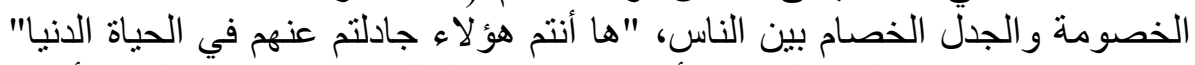

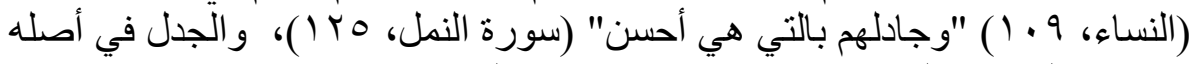

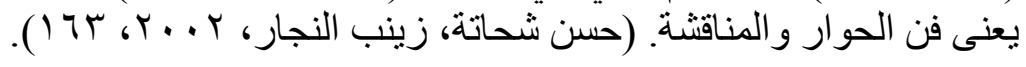


و الجدلي بنظر أفلاطون هو الذي يحسن السؤال والجواب، والغرض التور منه الارتقاء من تصور وقول إلى آخر؛ للوصول إلى إلى أعم التصورات وات وأعلى المبادئ.

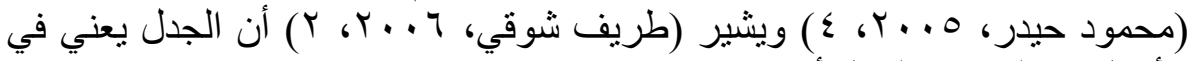
الأصل فن النقاش و والجدل أبي: فن الجدل بطريقة الأسئلة والأجوبة. فن تصنيف المفاهيم وتقسيم الأشياء إلى أجناس و أقو ال.

ويعرفه (Bricker, Bell, 2008, 3) بأنه محور للتدريبات المعرفية،

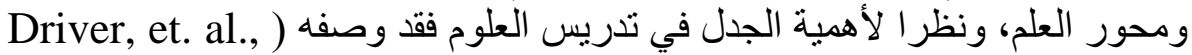
(2000, 9

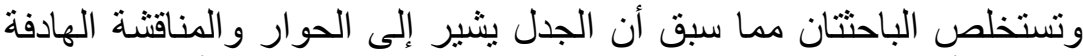

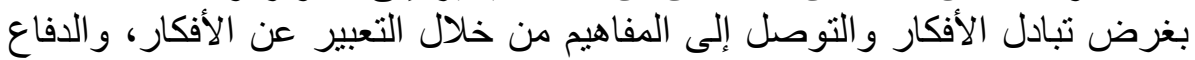

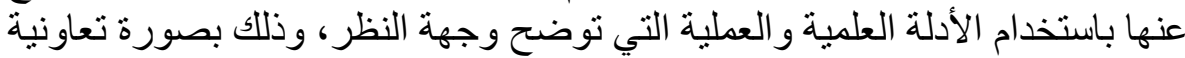

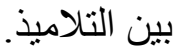

ويعد الجدل عنصراً أساسياً في تدريس العلوم؛ حيث أكدت عليه المعايير العالمية لتدريس العلوم (NRC, 2005)، وكذلك العديد من الباحثين في التربية

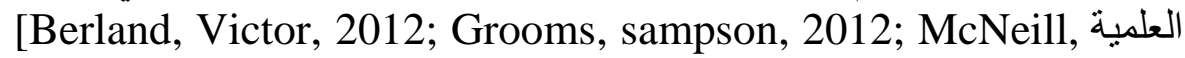

Knight, 2013]

وفى هذا الإطار أكد كل من (Lehrer, schwable, 2009) أن تدريس

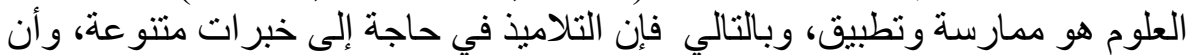

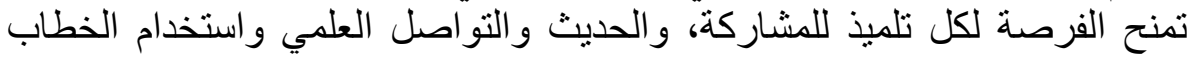

ويشير (Duschl, et. al., 2007) الى أن التدريبات الأساسية في العلوم

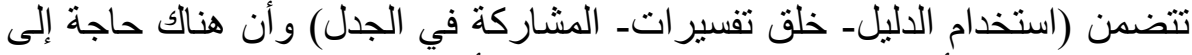

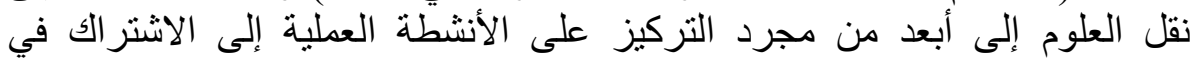

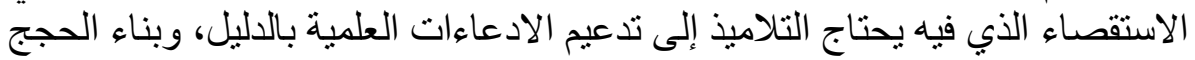
و إعطاء التفسير ات المتعددة. ثانيا: نموذج الاستقصاء القائم على الجدل في تدريس العلوم:

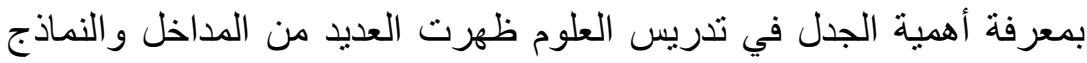

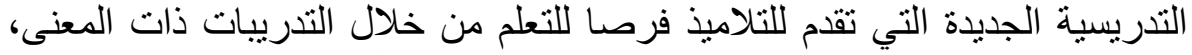

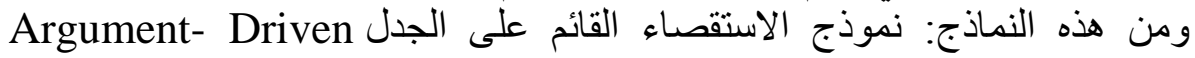
.Inquiry Model

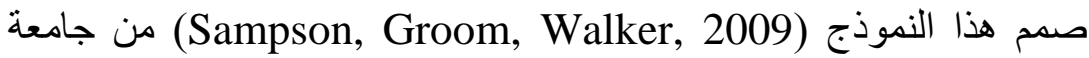
فلوريدا؛ لكي يتيح الفرصة للتلاميذ لبناء استكثافاتهم الخاصة، وتقديم الطرق الفعالة 
العدد الرابع

لمعالجتها، وتنفيذ الاستقصاء وتقييمه، و يؤكد على أهمبة التفكير التأملي والجدل

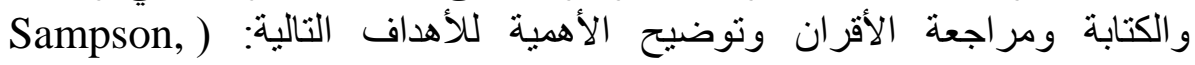

(Grooms, 2009

ه الاهتمام بالخبر ات المعملية؛ لتنمية فهم وتقييم التفسير ات العلمية للظو اهر الطبيعية. ه تشجيع التلامبذ على خلق وابتكار الحجج العلمية التي تبرر التفسيرات المحتملة للأسئلة أو المشكلة المثنارة. • إتاحة وتقديم الفرص للتلاميذ ليتعلموا كيفية اقتر اح، وتدعيم، وتقييم، ومر اجعة أفكار الآخرين من خلال المناقثنة و الكتابة. ه خلق مناخ اجتماعي داخل الفصل يتعلم التلامبذ من خلاله تقدير (الأدلةـ التفكير الناقدـ التشككــ الأفكار الجديدة- طن درق التفكير المختلفة).

خطوات النموذج: خSampson, Grooms, 2008, 4; Sampson, Gleim, 2009, 7]

$$
\text { يتكون هذا النموذج من سبع خطو ات: }
$$

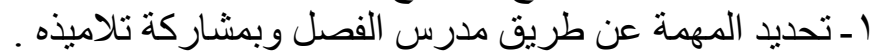

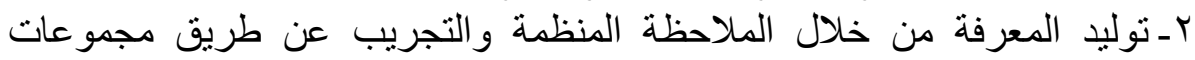

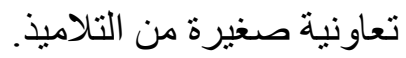

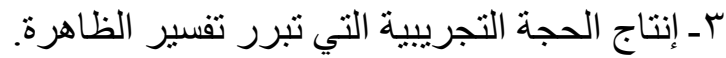

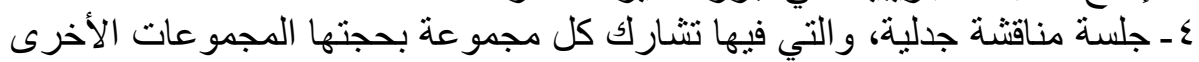
للمناقتة ونقد الدعاوي المقدمة من كل مجموعة، ولتحديد أي التفسيرات هو فو الأكثر قبول للصحة. ه ـ كتابة تقرير فردي بقوم بـه كل تلميذ لما تم القيام به.

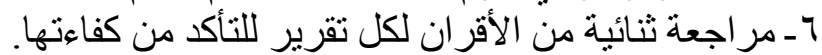

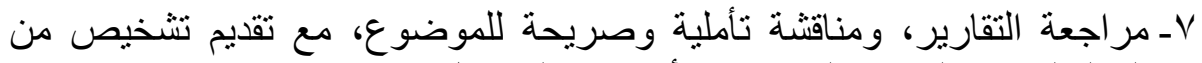
المعلم لتوجيه التلاميذ إلى خبرات منة أكثر في المستقبل. وفى العرض التالي سوف تقوم الباحثتان بعرض كل خطوة بالتفصبل لتوضيح دور كل من المعلم والتلميذ في هذا النموذج، وربط كل خطوة بأهميتها في تدريس العلوم.

Identification of the Task الخطوة الأولى: تحديد المهمة في هذه الخطوة يقوم معلم الفصل بتحديد المهمة في صورة مشكلة تتحدى

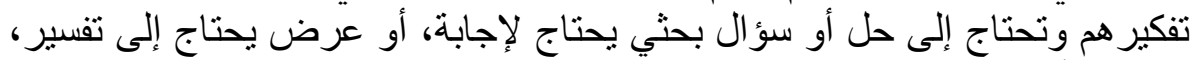

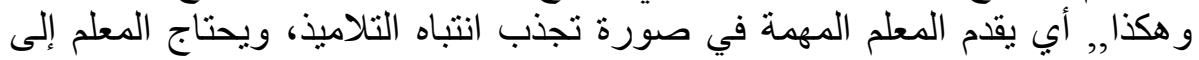

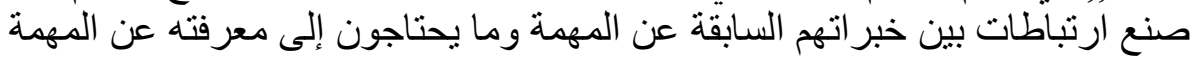
لحلها. 
و التلميذ في هذه المرحلة سيحاول أن يجمع كل خبراته السابقة المرتبطة

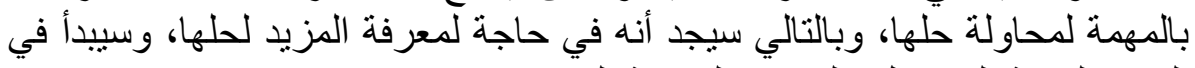
التفكير لكيفية الحصول على هذه المعرفة الجديدة.

\section{Generation of data الخطوة الثانية: توليد الأفكار}

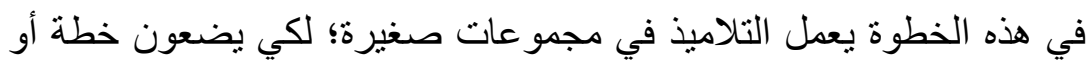

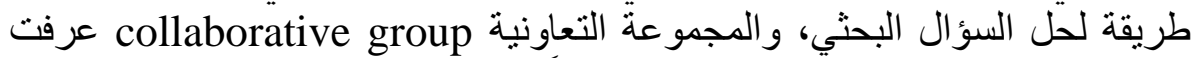

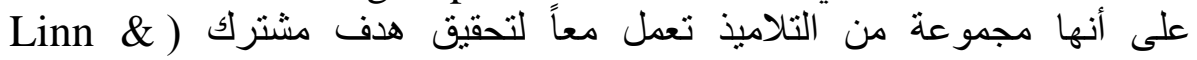
.(Burbules, 1993

والتلاميذ في هذه المرحلة يحتاجون إلى تعلم كيفية تصميم الاستكثافات،

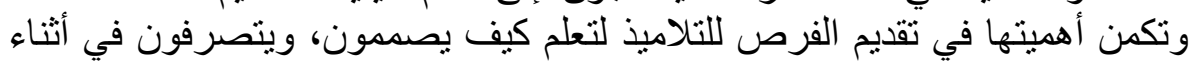

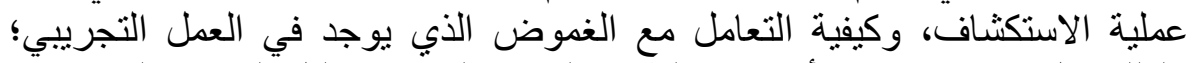

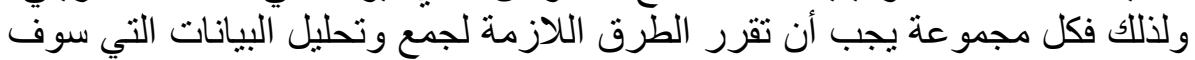
تحتاجها لتبرير الإجابة للسؤال البحثي. (Bell, Smetana, Binns, 2005)

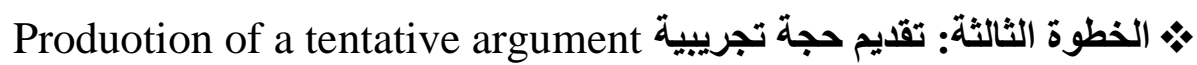
يقوم التلاميذ في هذه الخطوة بتقديم الحجة التي سوف تنكون من الادهاء Claim, والادعاء هو استتناج أو تفسير أو إجابة للسؤ ال البحثي.

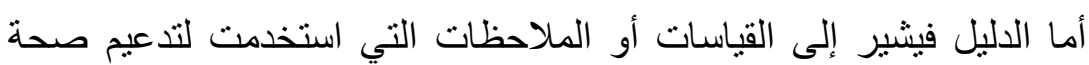

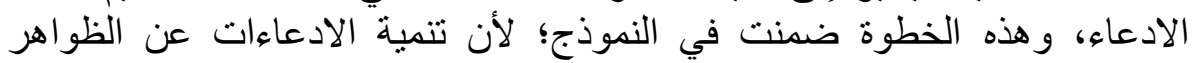

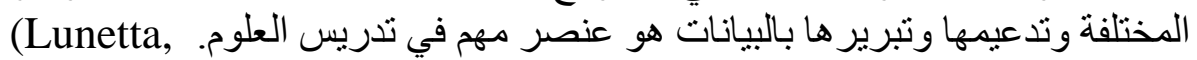

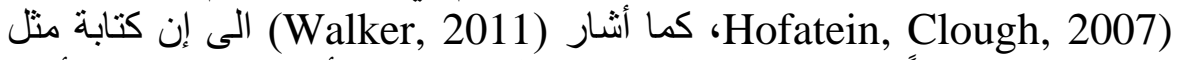

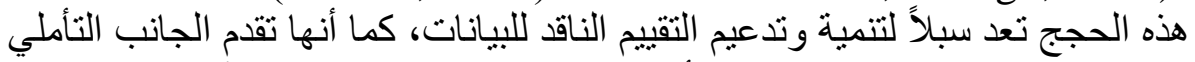

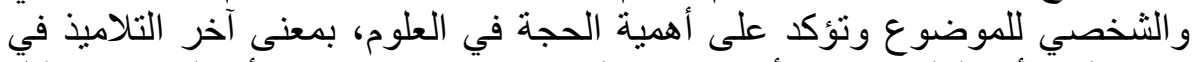

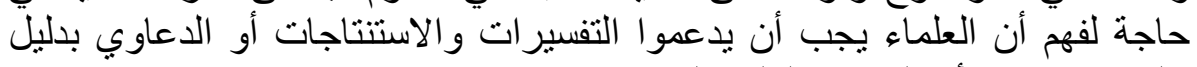
علمي مناسب؛ لأن المعرفة العلمية ليست غاء فامضة

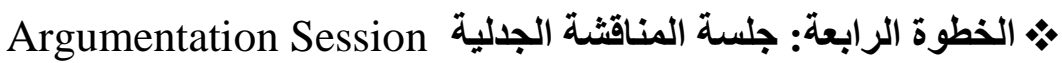

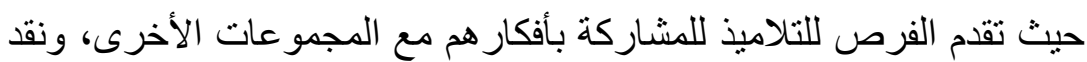

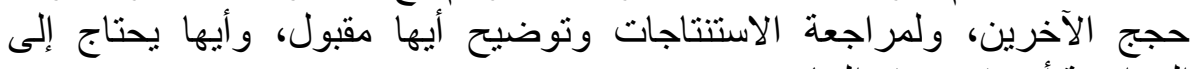
المراجعة أبي تقييم ونقد النتائج.

وترى الباحثنان أن التلاميذ يتعلمون أفضل عندئ عندما يتواجهون مع أفكار

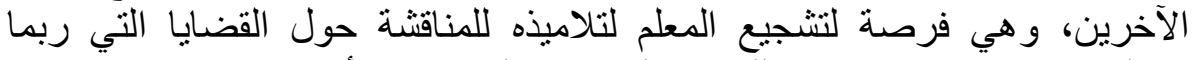

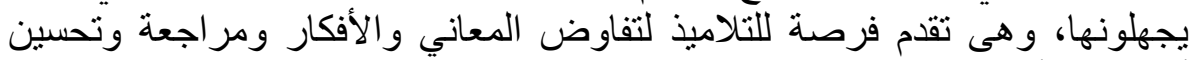

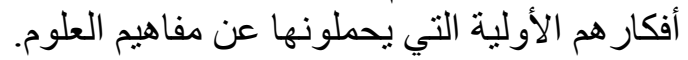




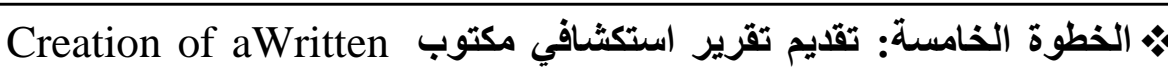
investigation report

ويكون ذللك لكل مجمو عة على حده، و الكتابة هي جزء و ومكون مهم في تدريس

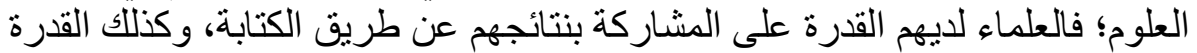

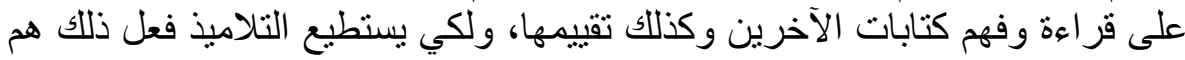
في حاجة لتعلم كيفية الكتابة بطريقة تعكس معايير للمجتمع العلمي.

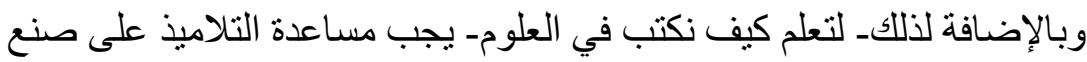

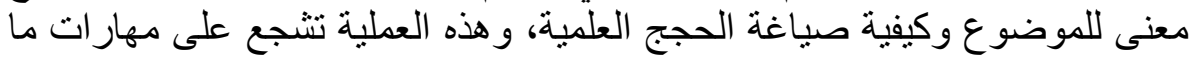

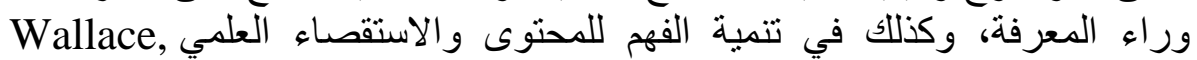
(Hand, Prain, 2004) يمكن أن نساعدهم على الكتابة من خلال الإجابة عن الأسئلة التالية:

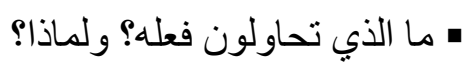

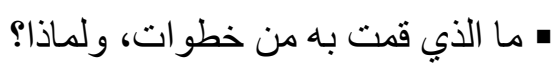

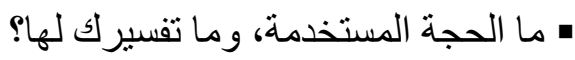

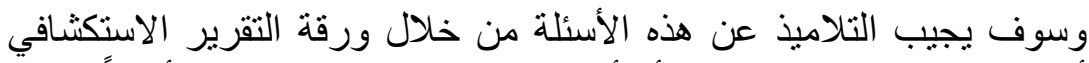

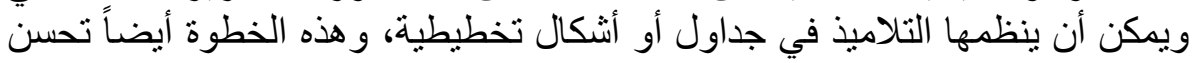

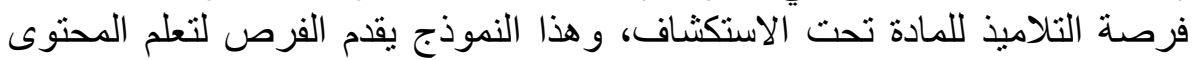

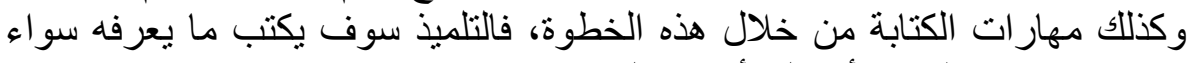

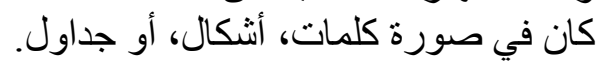

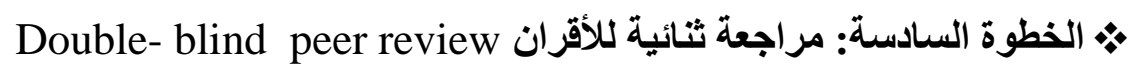

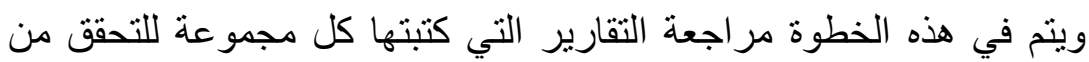

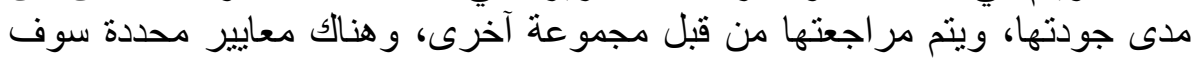

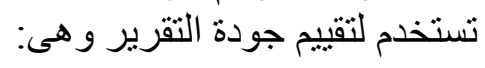
ـ هل السؤال البحثي و الأهداف من الاستقصاء و واضحة هن:

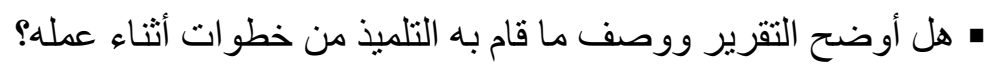

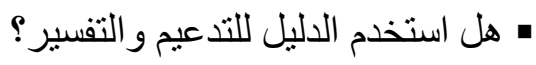

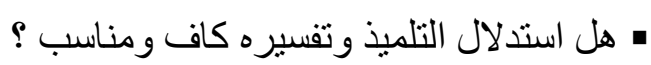

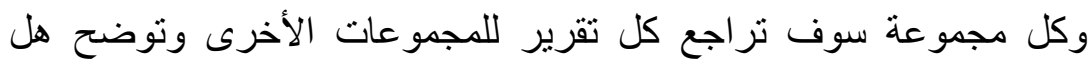

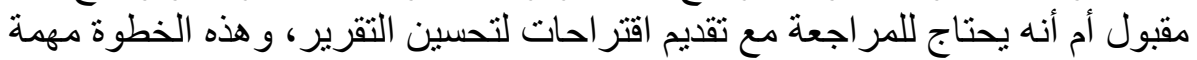

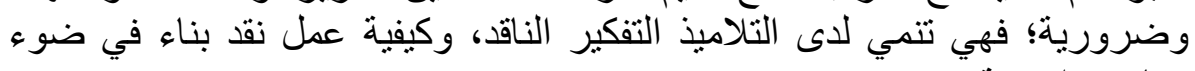
معايير و اضحة ومحدةدة. 
Revision of the Rreport الخطوة السابعة: مراجعة التقارير

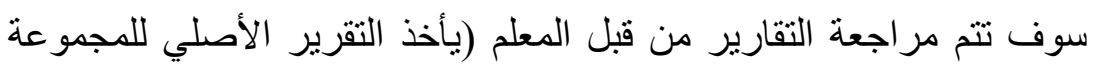

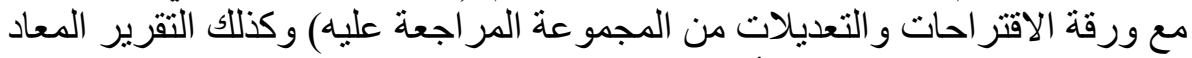

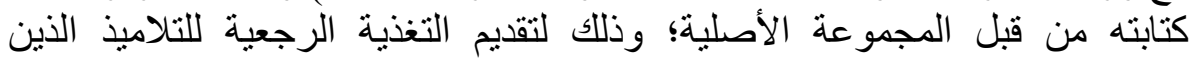

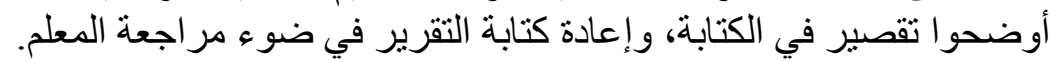

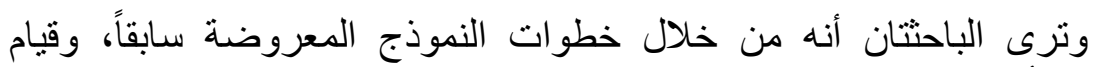

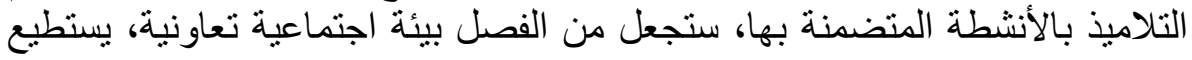

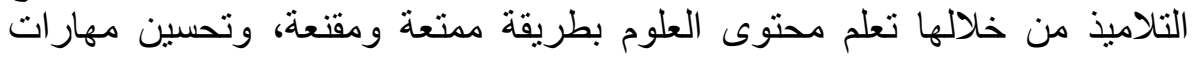

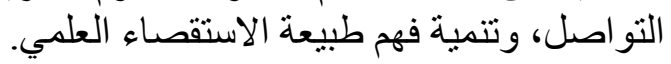
وسوف تقوم الباحثتان باستخدام خطو ات نموذح الاستقصاء القائم على الجدل متضمنة في المر احل الثثلاثة التالية: المرحلة الأولى: مرحلة ما قبل الاستكشاف (الاستقصاء): وسوف تتضمن هذه المرحلة الإجر اءات التالية: ـ تقديم السؤال البحثي أو المشكلة من قبل المعلم.

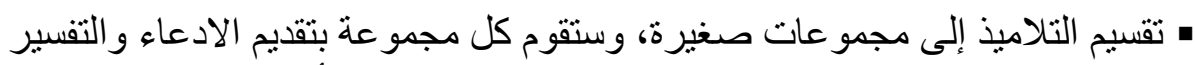
لحل المشكلة، ووضع الخطة الاستكثافية التي سيتبعونها في أثناء الاستقصاء.

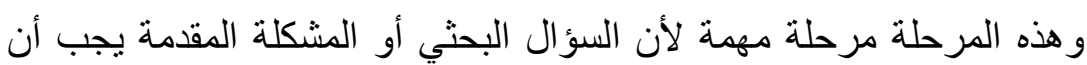

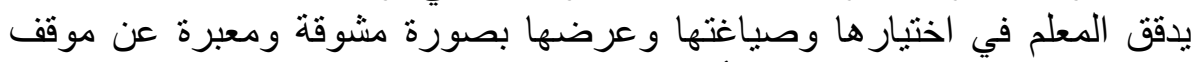

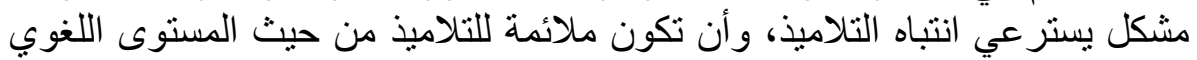

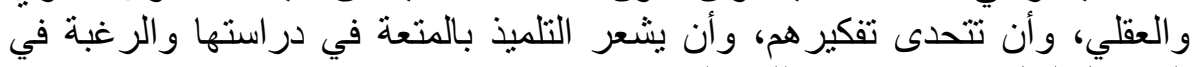
الوصولّ لحل جديد ومناسب للمشيكلة.

\section{المرحلة الثانية: مرحلة الأنشطة الاستكثافية:}

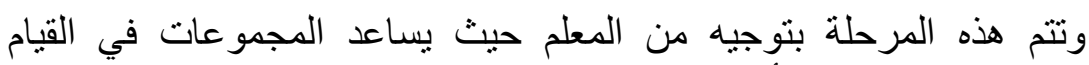

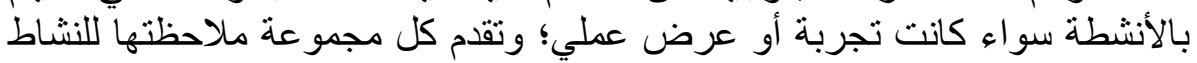

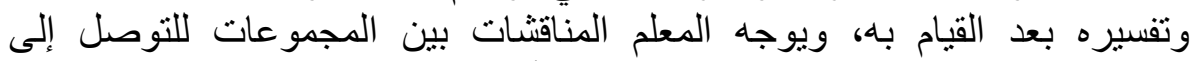

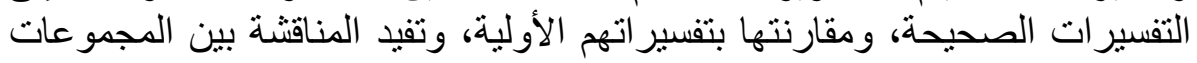

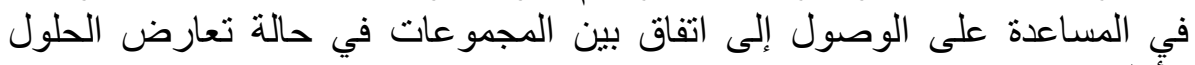
الأولية.

\section{المرحلة الثالثة: مرحلة ما بعد الاستكشاف:}

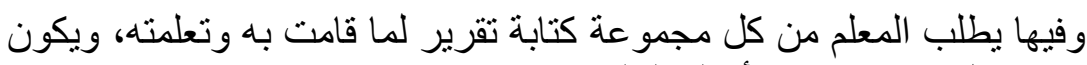

التقرير من خلال الإجابة عن الأسئلة التالية:

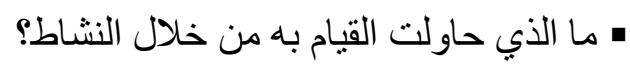




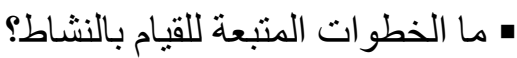

• ما هو تفسير للنتائج؟ وهل اختلفت عن التفسير قبل القيام بالنشاط؟

• ما الأفكار الجديدة المكتسبة؟ وكيف نستفيد منها في حياتتا اليومية؟

وتراجع هذه التقارير في حصص النشاط، حيث تراجع كل مجموعة تقرير المجموعة الأخرى، وتقدمه للمعلم للمر اجعة النهائية لتقديم التغذية الرجعية، وتئية وتقديم مشكلات وقضايا أخرى مرتبطة بالنشاط.

\section{الأساس الفلسفي للاستقصاء القائم على الجدل}

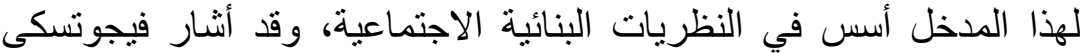
(Odgen, 2000, 213)

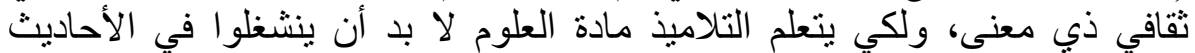
العلمية، فالحديث أداة مهمة لتوطيد الاتصال بين المعلم و المتعلم، وله دور مهم في في لإني تكوين العمليات العقلية وإعادة ترتيبها.

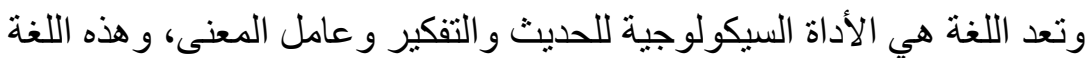

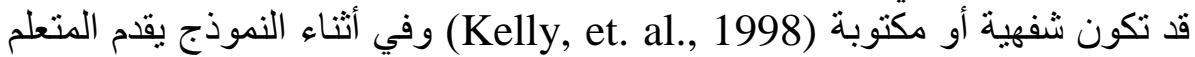

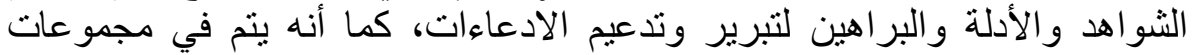
صغيرة وكلها صور للبنائية الاجتماعية.

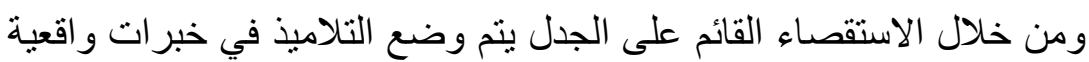

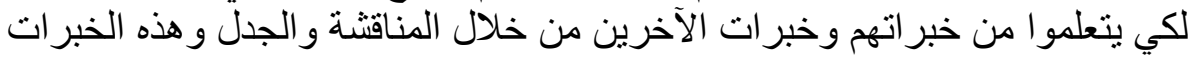

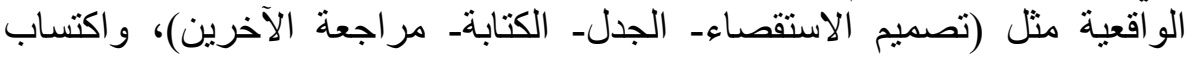
المهارات الجدلية التى سوف تساعدهم على التعامل مع المواقف الجديدة-Garcla

[Ford, 2008; mila, et. al., 2013]

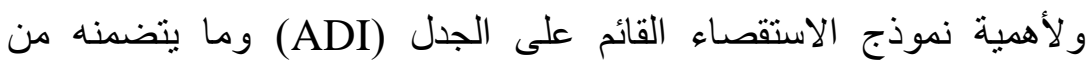

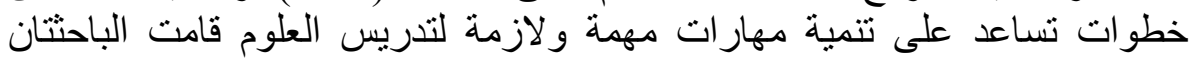

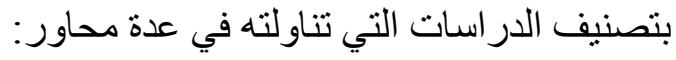

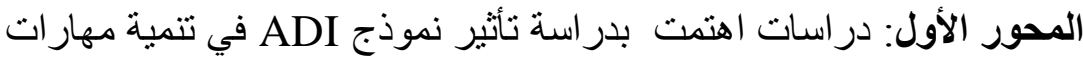

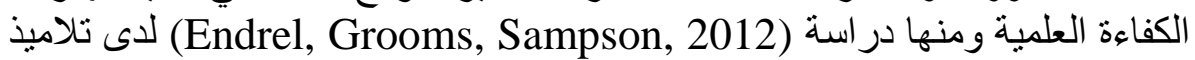

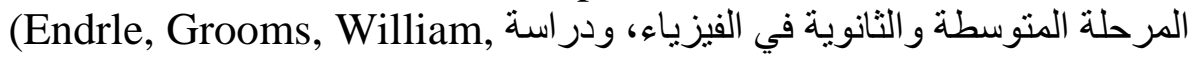
Sampson, Hester, 2012) (Endrle, 2012) (Bekiroglu, Aydeni, 2013)

المحور الثاني: در اسات اهتمت بتأثير نموذج ADI في تنمية مهار ات الكتابة العلمية مثل دراسة (Sampson, Walker, 2012) لدى طلبة الجامعة في الكيمياء، ودراسة (Enderle, Sampson, Campbell, 2012)، لدى تلاميذ المرحلة الكية 


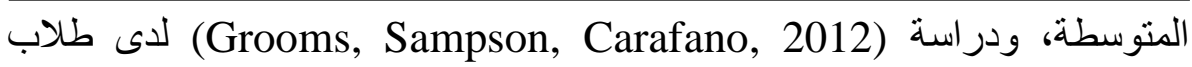
المدرسة الثانوية، ودراسة (sampson, et. al., 2013) لدى تلاميذ المرحلة المتوسطة و الثانوية.

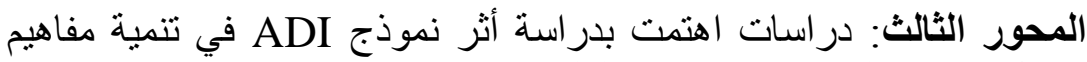

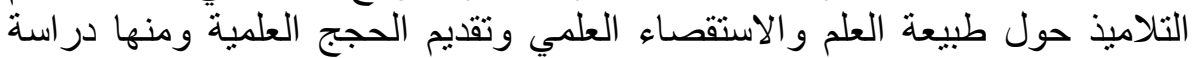

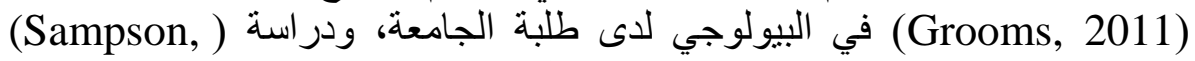

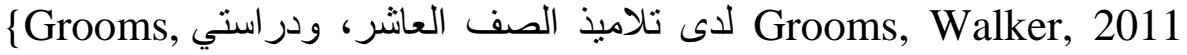
ودر لدى طلاب المرحلة الثانوية، ودر اسة (walker, sampson, 2013) لدى الطالب المعلم في الكيمياء. ثالثا: مهارات التفكير العليا: ا ـ ماهية مهارات التفكير العليا:

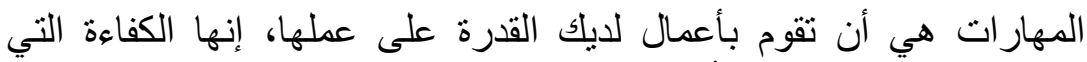

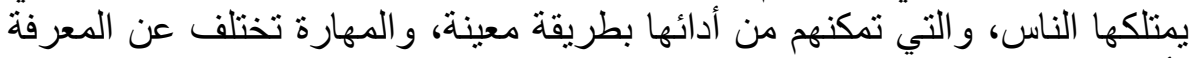

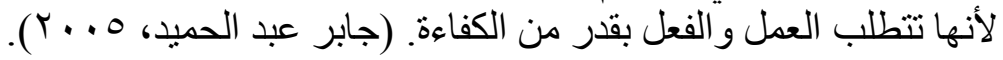

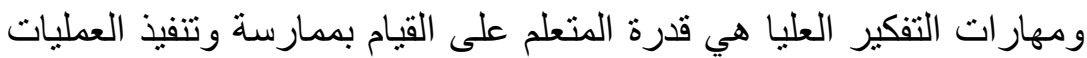

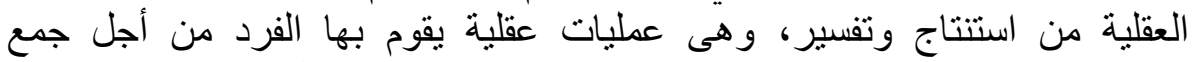

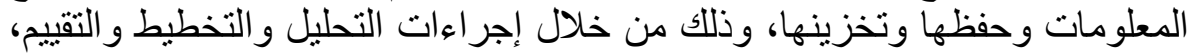

و الوصول إلى استنتاجات وصنع القرار وات. (Muijs, Reyholds, 2011, 78).

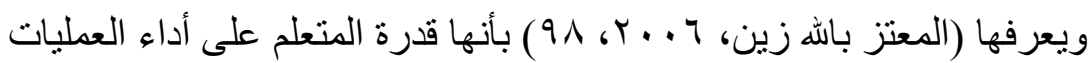

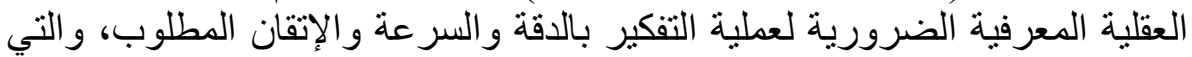

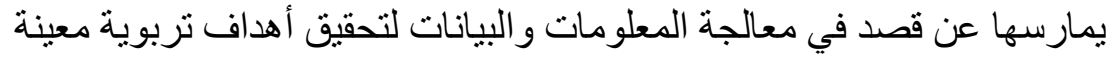

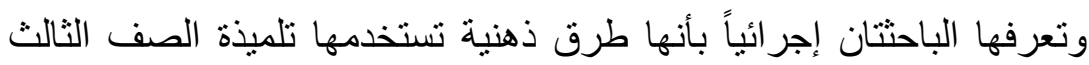

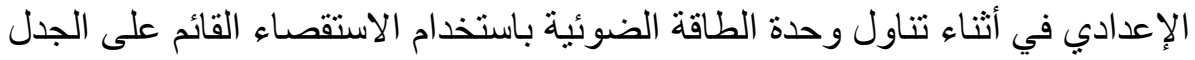

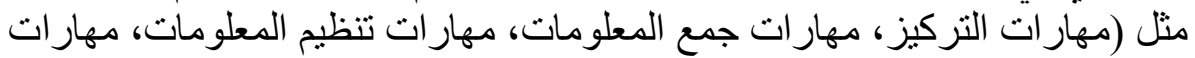

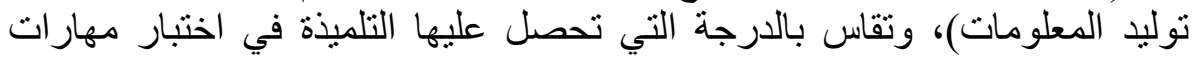
التفكير العليا المعد لذلك. ولتك.

\section{r - أهمية تنمية مهارات التفكير العليا:}

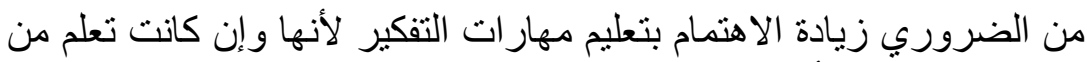

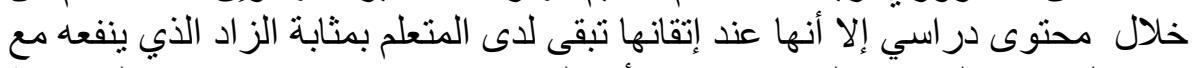

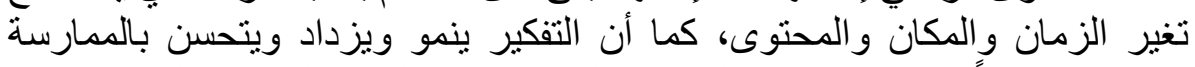

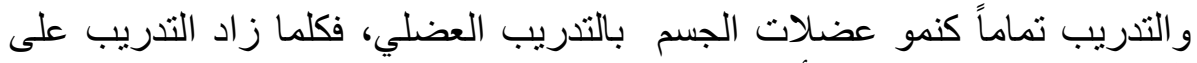

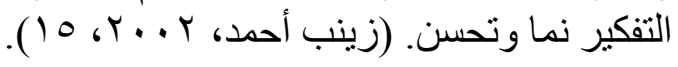




العدد الرابع

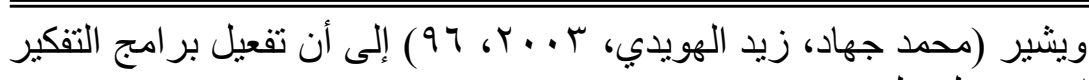

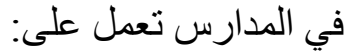

ـ تنشيط التحدي في المو اقف غئ غير المتوقعة.

- ت توفير مناخ للتفكير الناقد.

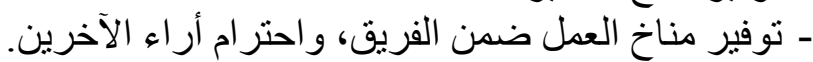

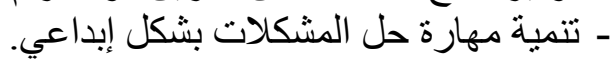

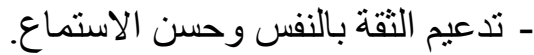

ـ تعلم مهار ات حياتية أخرى أهمها التو اصنل المنظم إلى إنى جانب مهار ات التفكير.

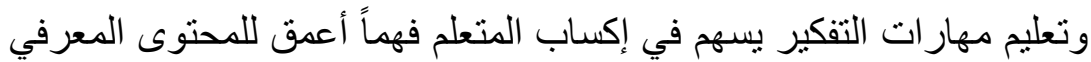

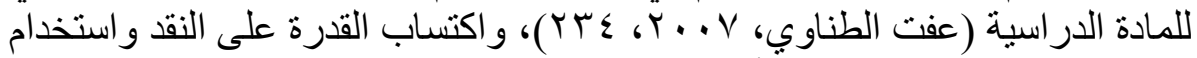

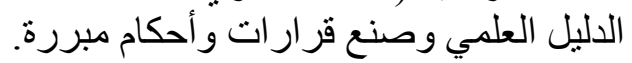

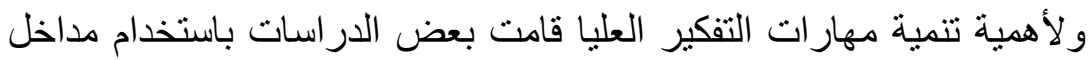

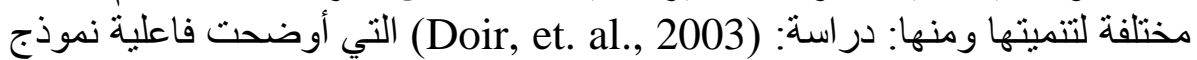

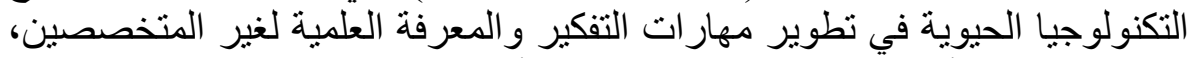

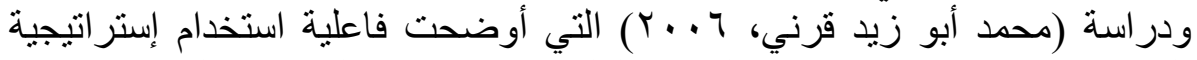

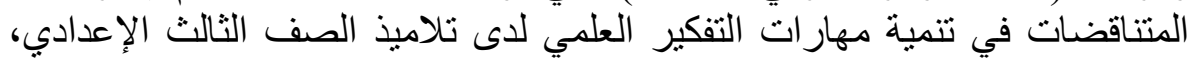

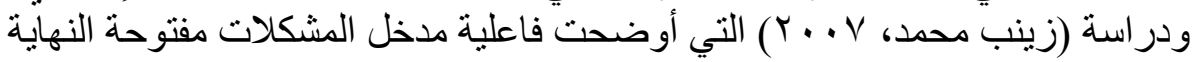

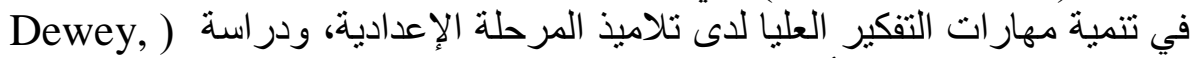

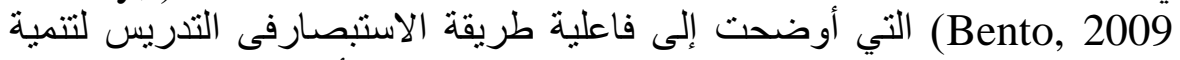

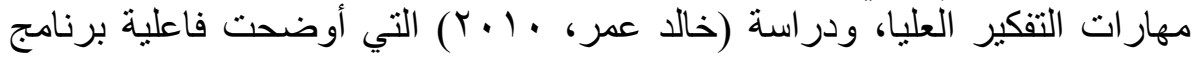
معد وفق فنية دي بونو لقبعات التفكير الست في تتمية مهارات التفكير العليا لدى التى تلاميذ الصف الثالث الإعدادي.

\section{r- تصنيف مهارات التفكير:}

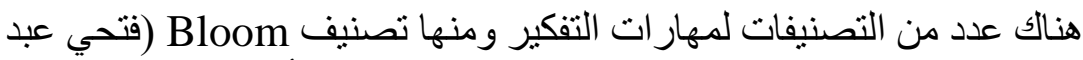

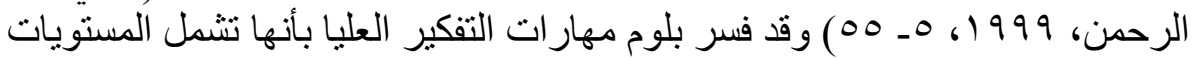

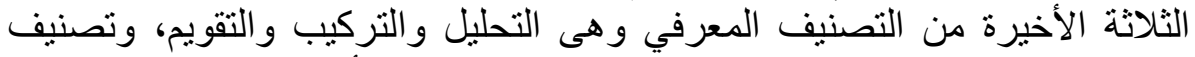

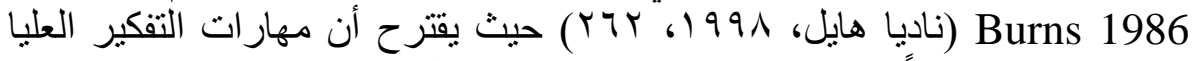

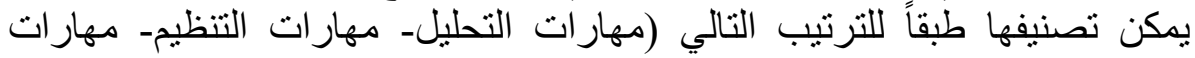

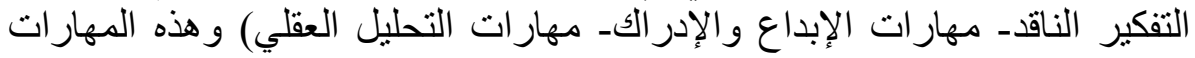

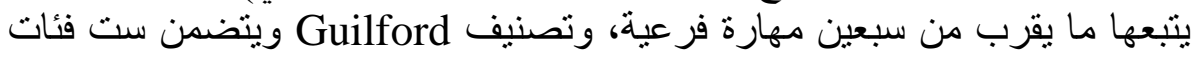

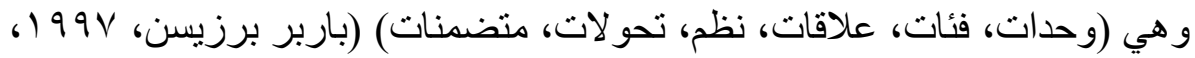

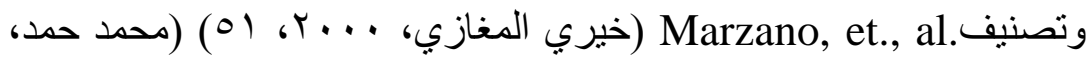

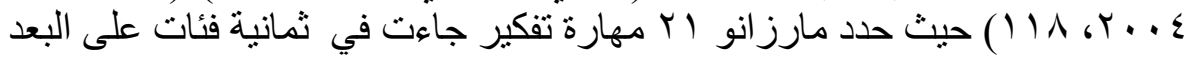




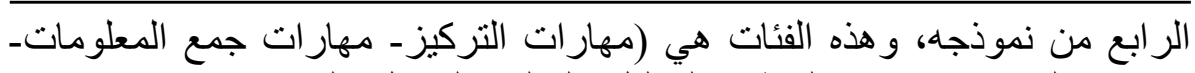

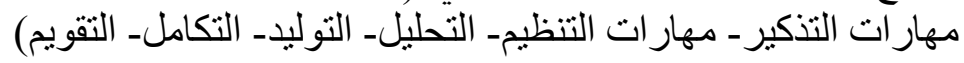

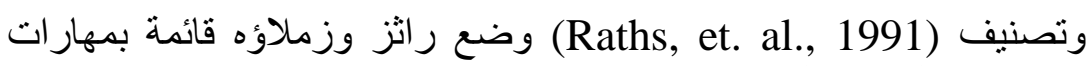

التفكير العليا على النحو التالي: (محمد شاهين، 999 (1) (Y)

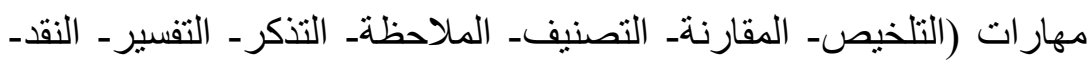

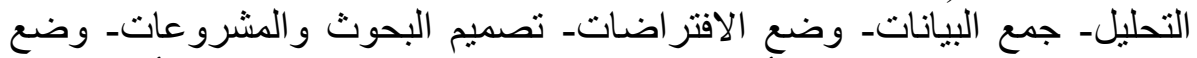

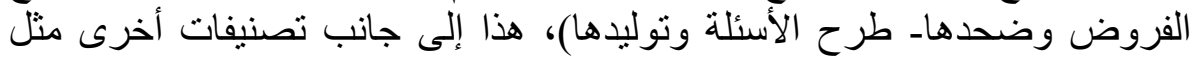

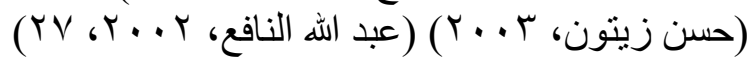

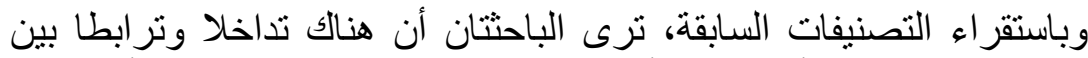

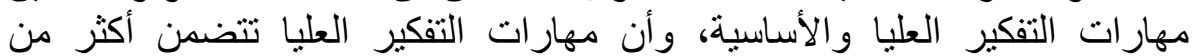

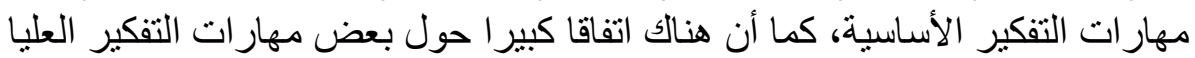
و إن اختلفوا في مسمياتها.

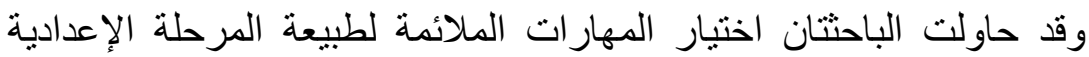

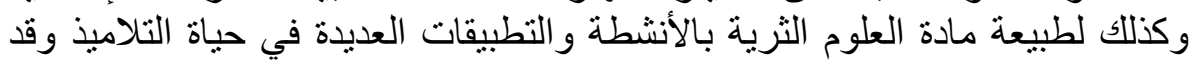
تبنت الدر اسة الحالية بعض مهار العات التفكير العليا الآتية:

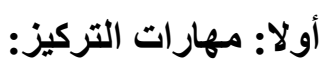

ا ـ تحديد المشكلات.

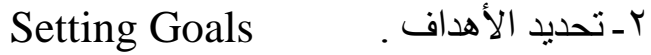
ثانيا: مهارات جمع المعلومات: Observation المطات Formulating Questions بـ المياغة الأسئلة

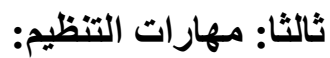
ا ـ المقارنة. Comparing

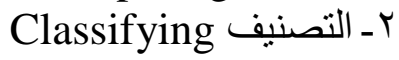
رابعا: مهارات توليد المعلومات:

ا- التنبؤ مان

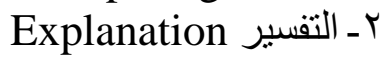
r- ب- الفع الفرضيات Putting Hypotheses

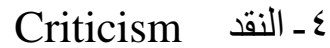

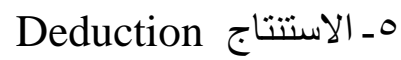
Tـ التوسيع Elaboration 


$$
\begin{aligned}
& \text { وفيما يلي توضيح لكل مهارة من المهار ات السابقة: }
\end{aligned}
$$

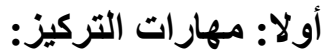

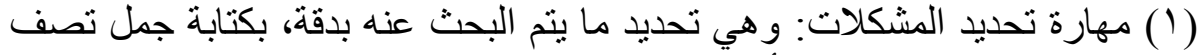

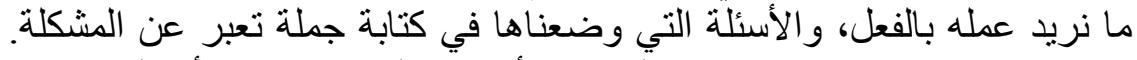

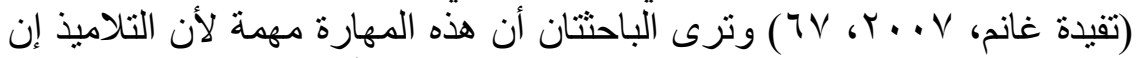

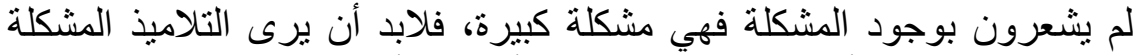

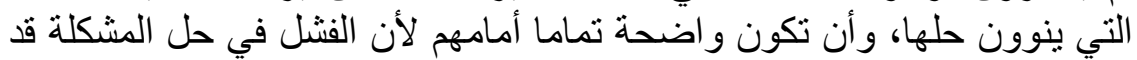

$$
\text { يرجع إلى عدم الثُعور بها أو غموضنها. }
$$

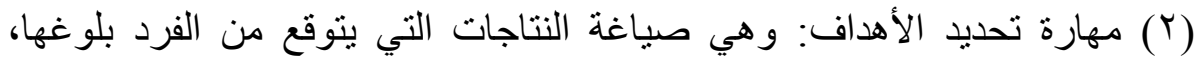
وتحديدها من البداية يوفر وينظم الوقت والئ والجهد.

ثانيا: مهارات جمع المعلومات:

(1) مهارة الملاحظة: ويقصد بها اكتشاف أو تفسير الظواهر أو الفو الأحداث، باستخدام

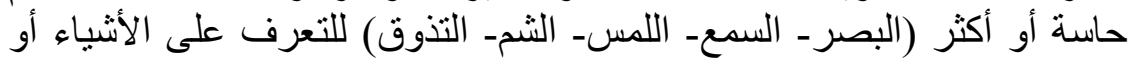

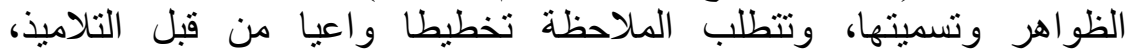

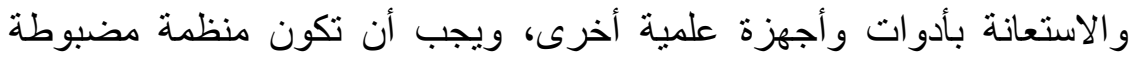

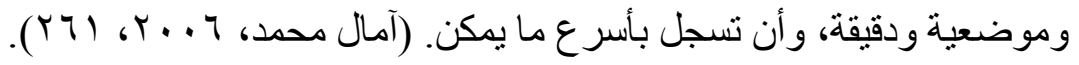

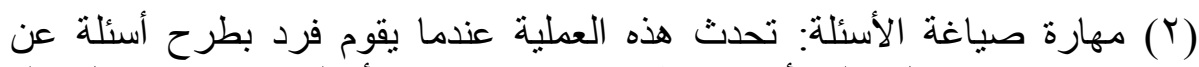

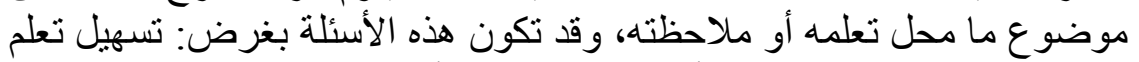

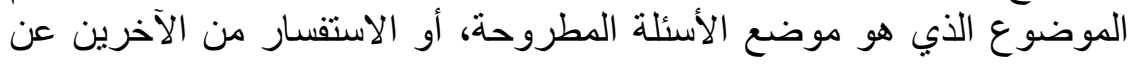

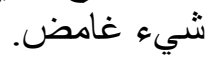

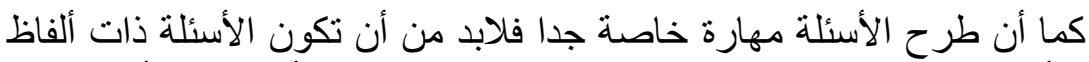

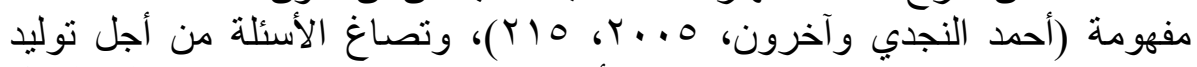

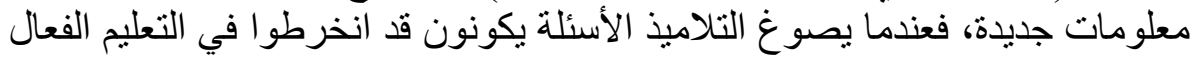

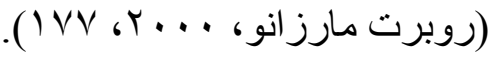

$$
\begin{aligned}
& \text { ثالثا: مهارات تنظيم المعلومات: }
\end{aligned}
$$

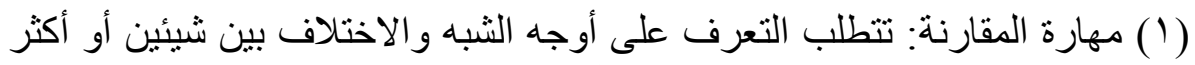

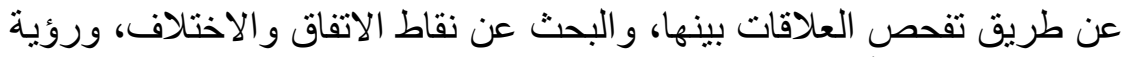
ما هو موجود في أحدهما ومفقود في الآخر.

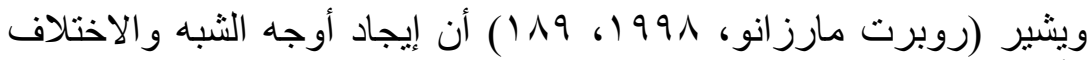

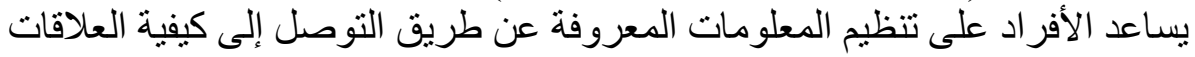

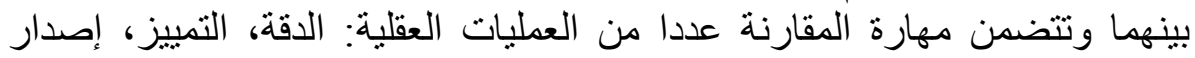
الأحكام، وأوجه الثبة و الاختلاف الثقاف 


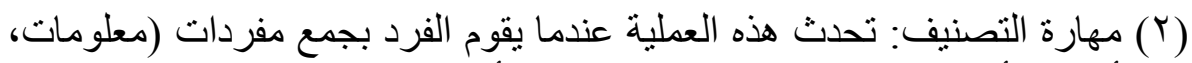

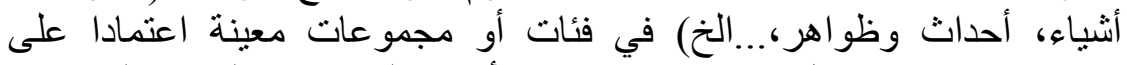

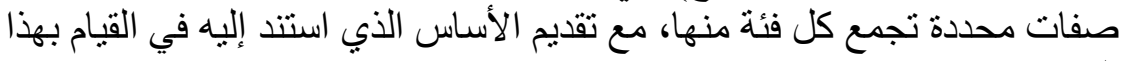

\section{رابعا: مهارات توليذ المعلومات:}

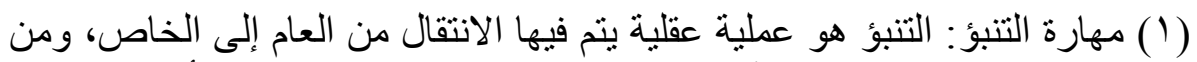

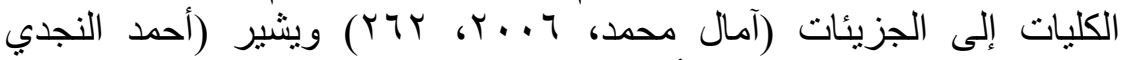

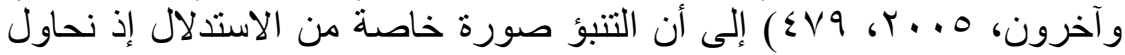

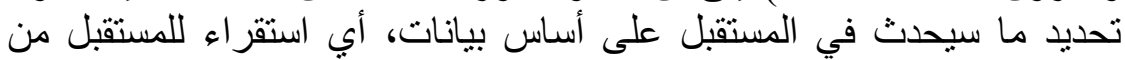

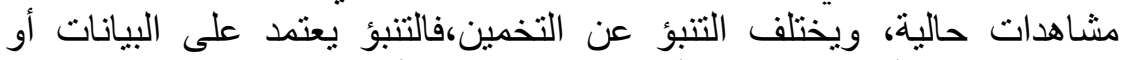
الخبرة السابقة، أما التخمين فلا أساس له من من بيانات أو خبرة سابقة.

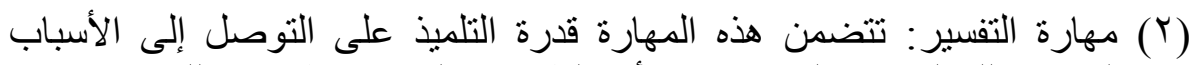

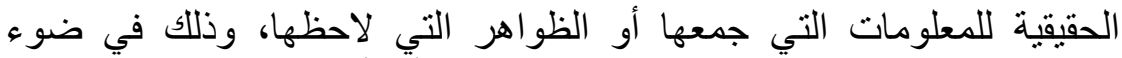

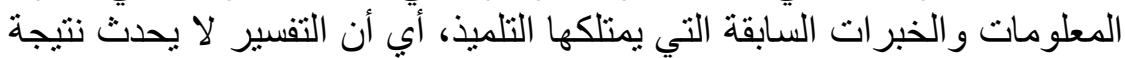
المشاهدة ولا نتيجة جمع المعلومات لكن يتطلب استخدام التحليل أو ربط النتائج التي حصل عليها بما يعرفه من معلومات. (Parkinson, 2004, 169). (T) مهارة فرض الفروض: هي القدرة على تحديد الفروض التي تصلح كحل

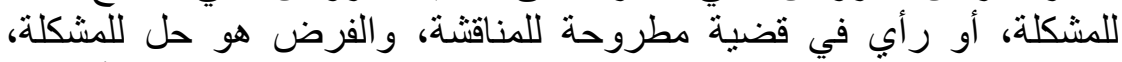

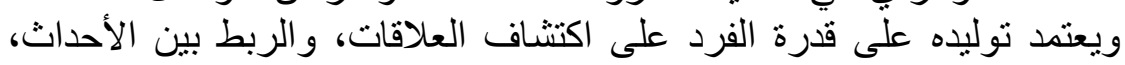
وتعتمد قيمة الفرض على مدى قابليته للاختبار، و وعلى ما بحدى ليحده من توقعات حول نتائج معينة.

( ) مهارة النقد: هي عملية فكرية تتضمن القيام بفحص دقيق لموضوع بهدف تحديد

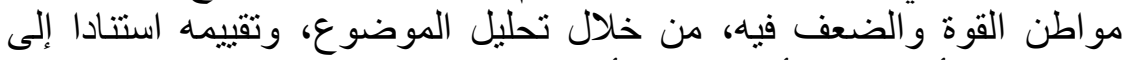

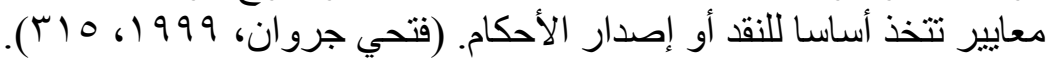

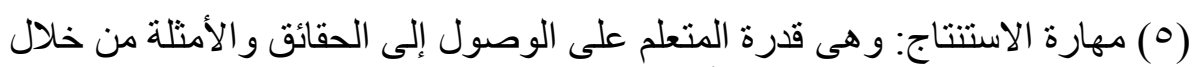

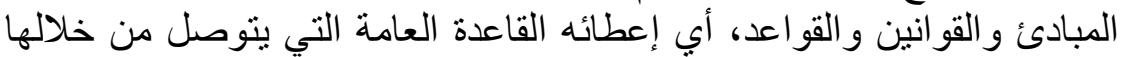

إلى تفسير للمو اقف المفردة التي يتم ملاحظتها (Mayer, 2003).

مهارة التوسيع: وتعني القدرة على إضافة تفاصبل جديدة متتوعة لفكرة ما والتوسع فيها، ويقاس التوسيع بعدد الأفكار أو المعاني التي تضاف التهاف إلى الفكرة

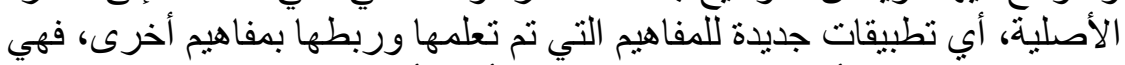

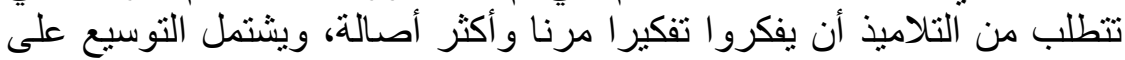

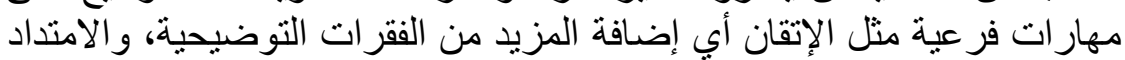
أي ربط فكرنين فريدنين، و التدعيم أي الوصف إعن بمزيد من المعلومات مثل الزمان

و المكان. (Haliday, Martin, 1993). 
ع ـ دور المعلم والتلميذ في تعلم مهارات التفكير:

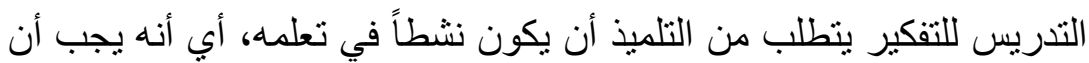

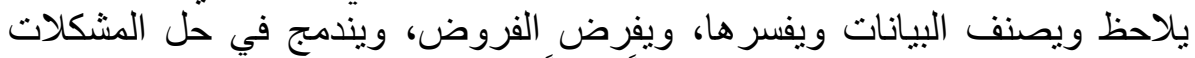

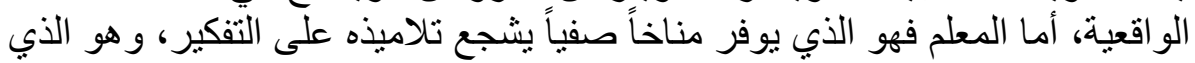
يستخدم الاستر اتيجيات التعليمية التي تفعل دور التلميذ وتستثير تفكيره. (نعيمة حسن

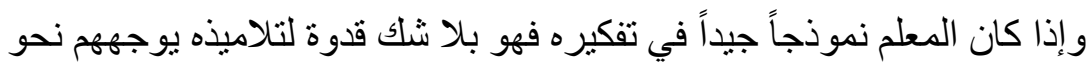

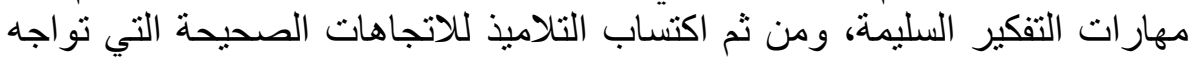

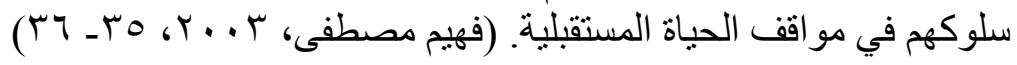

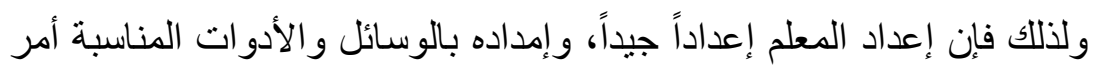

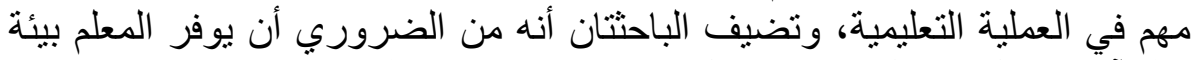

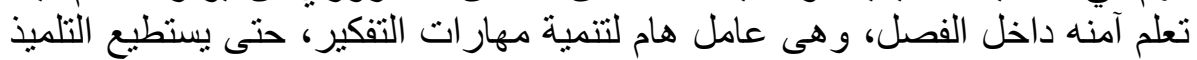

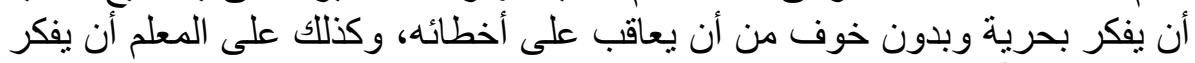
بصوت عال أمام التلاميذ ليدربهم على كيفية التفكير في المو اقف الف المختلفئ.

\section{•موذج الاستقصاء القائم على الجدل ومهارات التفكير العليا:}

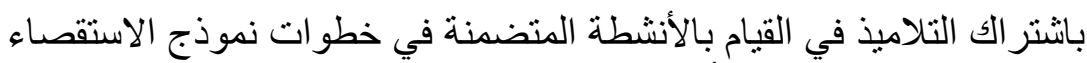

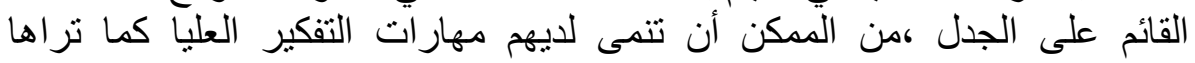

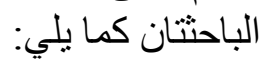

باثتر اك التلاميذ في المرحلة الأولى فهم يحتاجون إلى تحديد المشكلة تحديدا

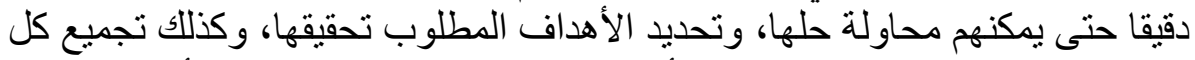

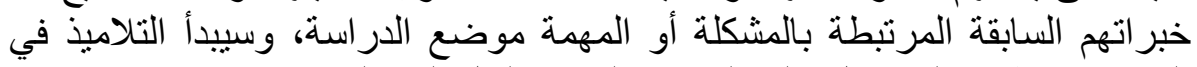
التفكير في طرق الحصول على المعرفة اللازمة لحة لحل المشكلة.

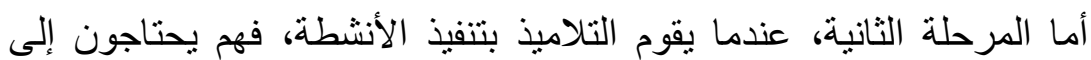

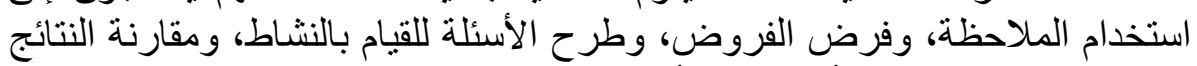

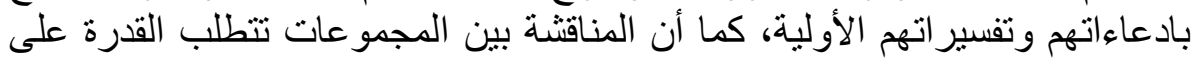
تقديم التفسير ات بصورة علفية صحية صحية.

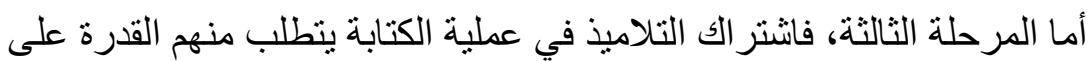

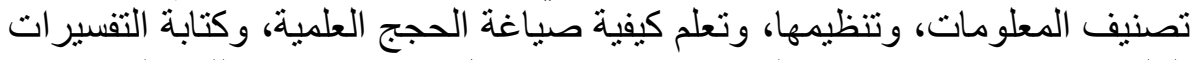

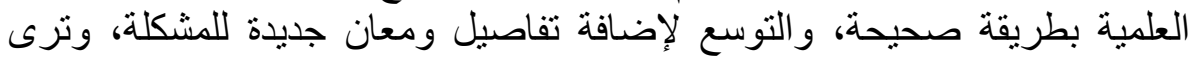

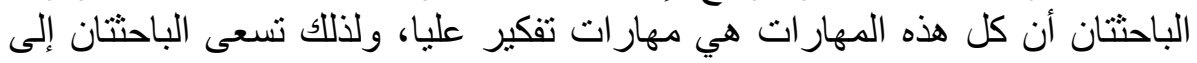
تنميتها من خلال نموذج الاستقصاء القائم على الجدل. 


\section{رابعا: مستوى الطموح Ambition /Aspiration Level}

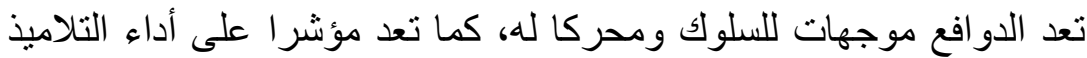

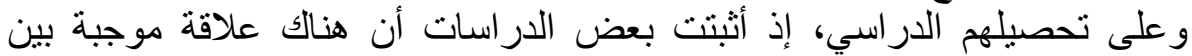

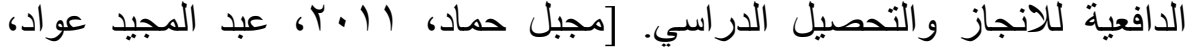

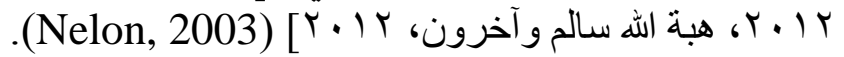

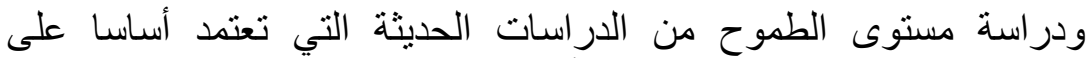

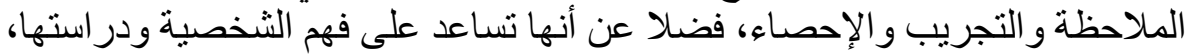

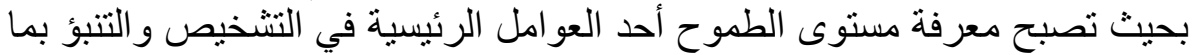

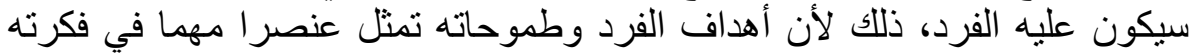

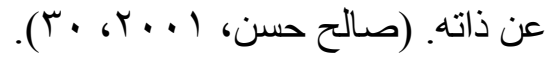

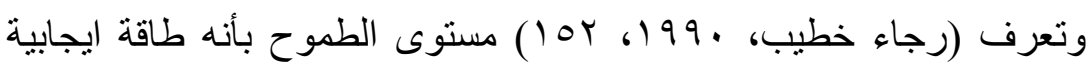

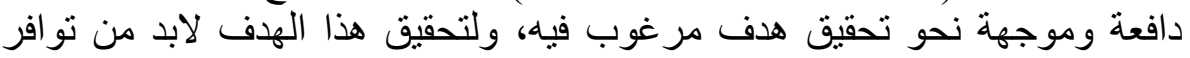

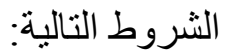

( ) أن يكون طموح الفرد مو ازيا لقدر اته و استعداداته، حتى لا يصاب بالإحباط إذ لم يتحقق هذا الطموح.

(Y) أن يتمتع الفرد بظروف اجتماعية، و اقتصادية، ور عاية صحية ونفسية.

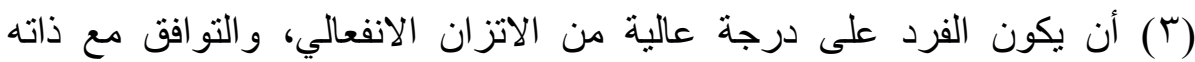

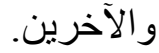

(§) أن يكون الفرد و اثقا بذاته وقدر اته، ويتمتع باهتمام وتقدير الآخرين.

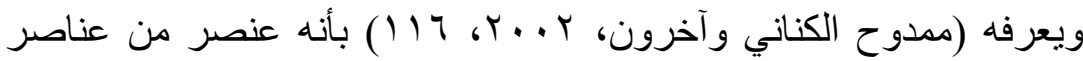

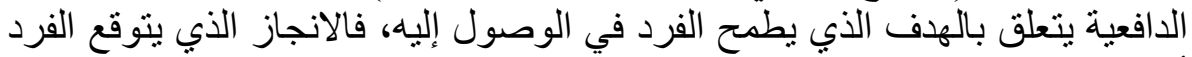

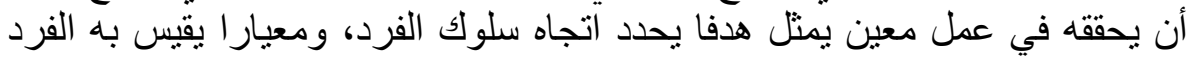

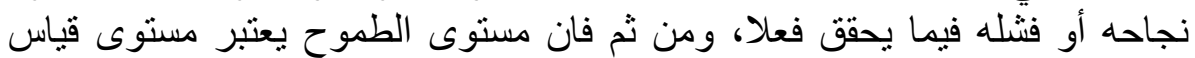
يفرضه الفرد على نفسه ويطمح إلى الوصول إليه، ويقيس إنجاز اته بالنسبة إليه.

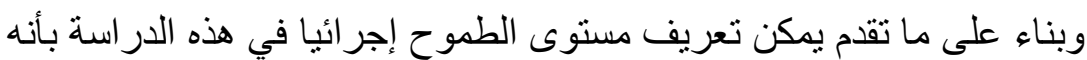

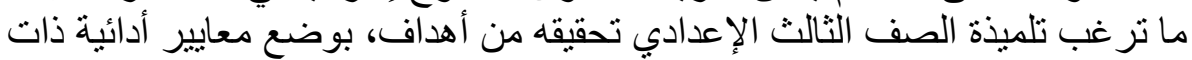

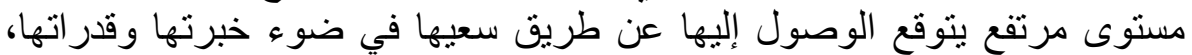

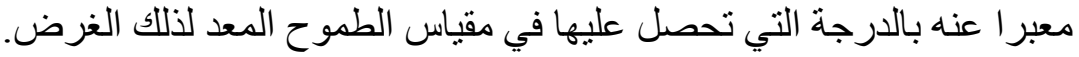

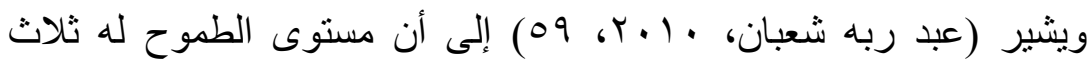

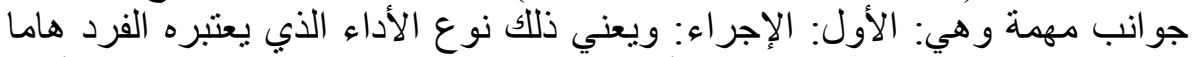

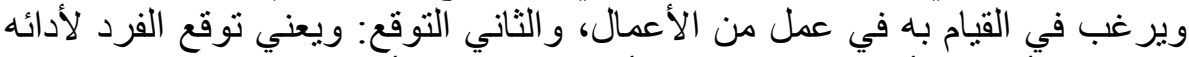
لهذا العمل أو ذاك، أما آلتالث: و هو إلى أي حد يعد هذا الأداء هاما بالنسبة للفرد. 


\section{أبعاد مستوى الطموح}

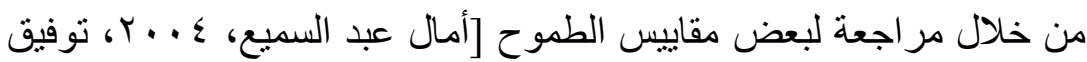

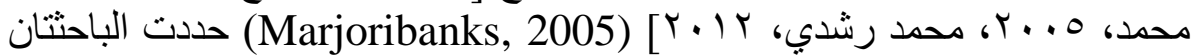
ثلاث أبعاد لمستوى الطموح المرتبط بـ بـ بـ (التحصيل الدراسي، علاقة الفرد بالآخرين، إمكانية تحقيق الفرد لأهدافه).

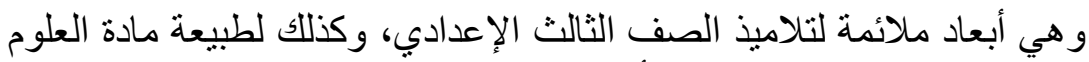

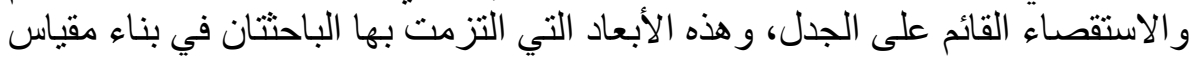
الطموح و هي كما يلي: الأني • الطموح المرتبط بالتحصيل الدراسي: يقصد به إديا إدراك الفرد للعوامل التي تدفعه لتحقيق الانجاز الأكاديمي.

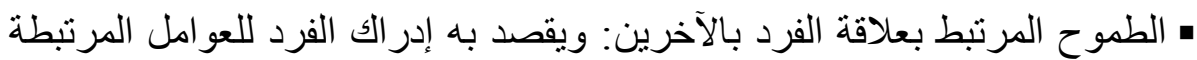

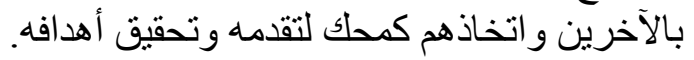

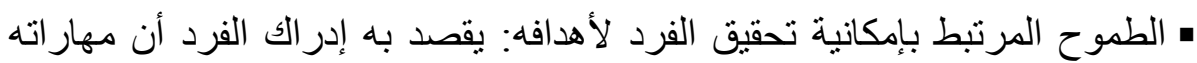
وقدر اته تؤ هله لتحقيق الأهداف التي حددها لنفسا.

أهمية دراسة مستوى الطموح

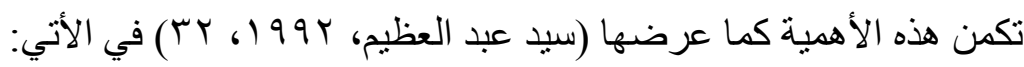

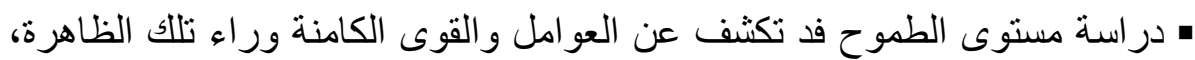

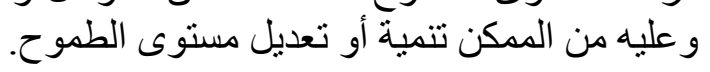

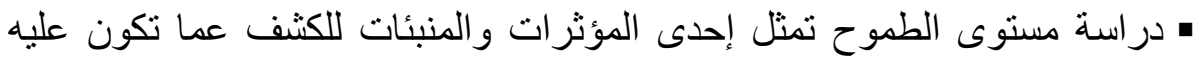

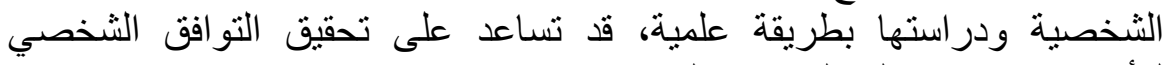
للأفر اد، مما يعود على المجتمع بالفائدة وزيادة الإنتاج.

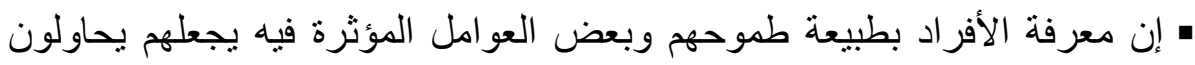

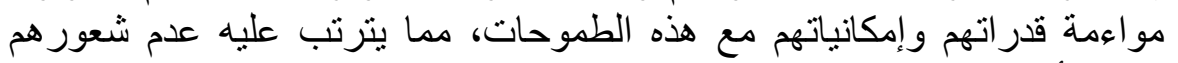

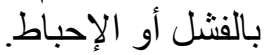

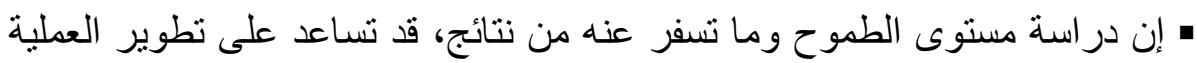

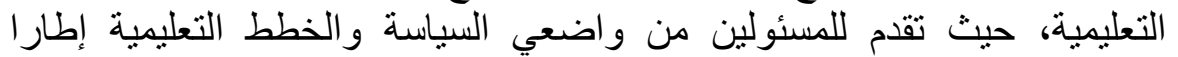

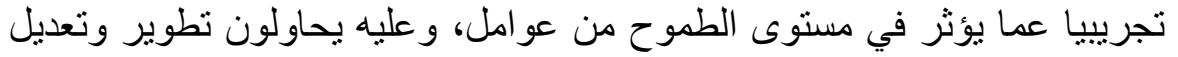
المناهج وطرق التدريس بما يتمشى مع مع تللك النتائج.

\section{الاستقصاء القائم على الجلل ومستوى الطموح:}

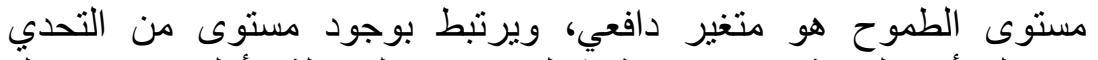

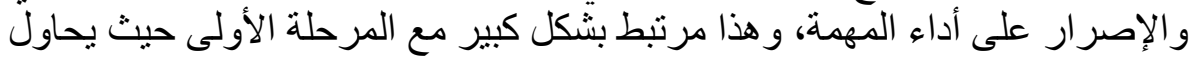

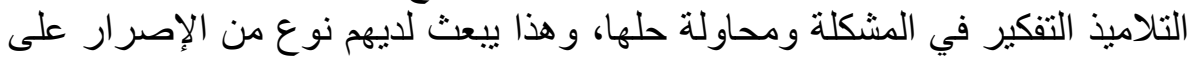


العدد الرابع

حل المشكلة، كما يعبر عن المستوى أو الهدف الذي يضعه التلمبذ لنفسه متمثلا في محاولته إلى الوصول إلى الحل بمثابرة معتمدا على قدر اته وخبر اته السابقة.

أما العمل في المجمو عات الصغيرة أثناء تتفيذ الأنشطة كما في المرحلة الثانية

فهو يحدد نشاط المتعلم من خلال البيئة الاجنماعية و علاقته بالآخرين.

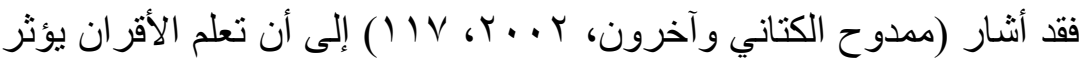
على مستوى الطموح، فالتلميذ عادة يضع لنفسه مستوى طموح بيلائم معايير الجماعة، و هذا مرتبط بدرجة كبيرة بالبعد الثاني وهو هو الطموح المرتبط بعلافة الفرد بالآخرين. ويظهر هذا البعد أيضا من خلال المناقنة الجدلية بين المجمو عات، فالمناقشة بين التلاميذ تجعل التلميذ يفكر فيما هو عليه، وهل يحتاج إلى أهداف أخرى لتح لتحقيقها أم لا، و أي مستوى هو عليه، و هل يتطلع إلي تحقيق مستويات أعلى أم لا.

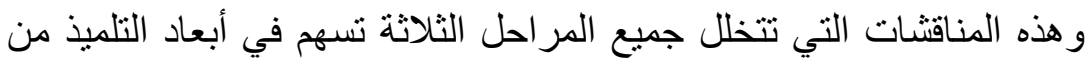
التمركز حول ذاته وتحوله للتمركز حول الآخرين وتقبل أفكار هم و احتر امها. أما البعد الثالث وهو الطموح المرتبط بإمكانية تحقيق الفرد لأهدافه فهو مرتبط

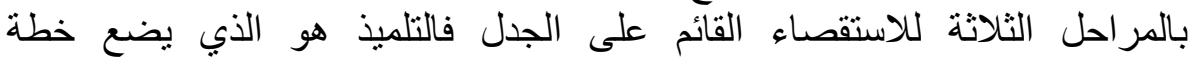
الاستكثاف ويكتب الأهداف ويحاول تحقيقها، ثم تتم عملية النقاش الجدلي ثم مر اجعة الأقران حتى يتوصل التلاميذ الى التحقق من أهدافهم، ومر اجعتها وتنقيحها. إجراءات الاراسة للإجابة عن أسئلة الاراسة والتحقق من صحة فروضها اتبعت الباحثتان الإجراعات التالية: أولاً: اختيار المحتوى العلمي وإعداد كراسة أنشطة للتلميذة:

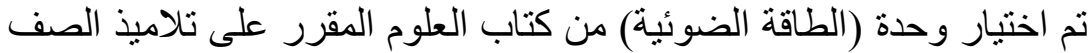

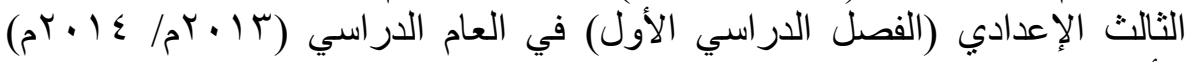

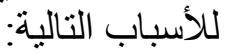
ـ تتناول هذه الوحدة عديد من الموضوعات التي تثير تساؤلات لدى التلميذات،

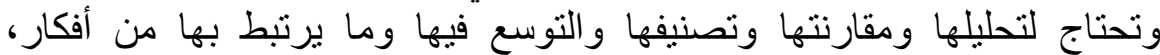
وتطبيقات بالحياة مما ينمى لديهن مهار ات التفكير العليا.

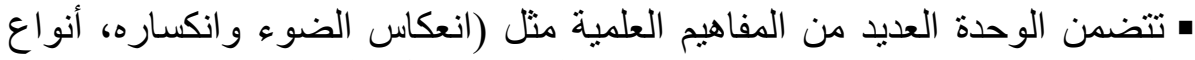

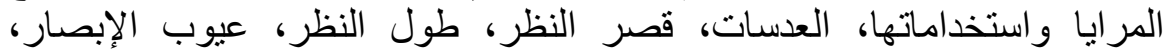

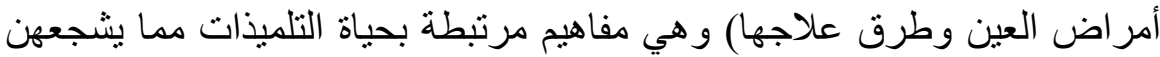

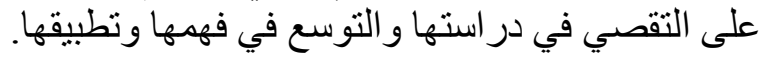
وقد تم تحليل الوحدة لتحديد أوجه التعلم المتضمنة بها للاستفادة منها في بناء دليل المعلم، وكر اسة نشاط التلميذة، وإعداد اختبار مهار ات التفكير العليا. 


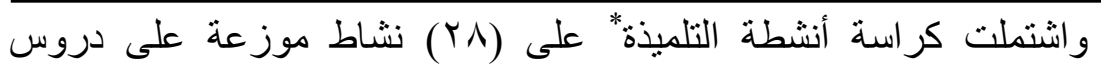

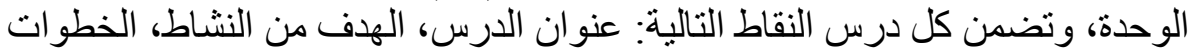

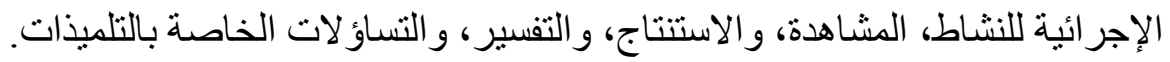

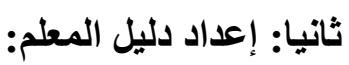

قامت الباحثنان بإعداد دليل المعلم** للاسترشاد به في تدريس وحدة (الطاقة

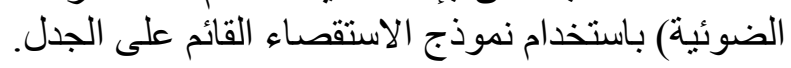

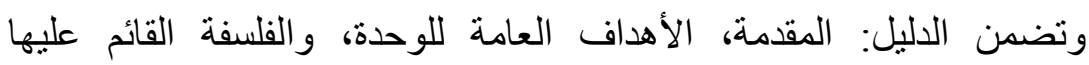

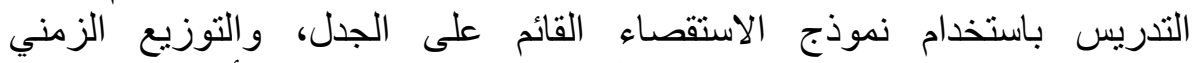

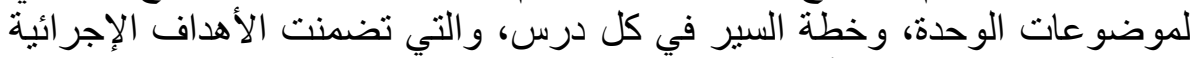

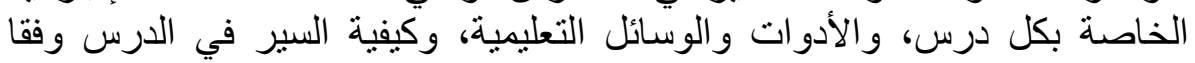

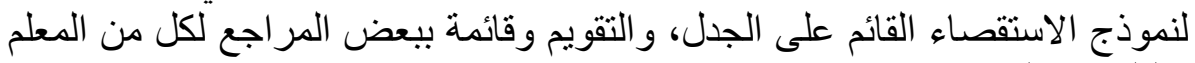
و التلميذة و التي يمكن الاستفادة منها. ثالثا: إعداد أداتي الدراسة:

في ضوء أهداف الدراسة أعدت الباحثتان الأداتين التاليتين: (1) (ختبار مهارات التفكير العليا:

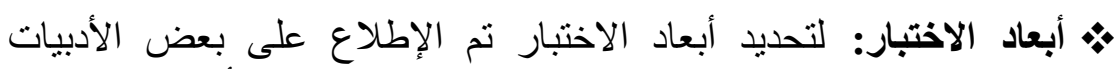
و البحوث و الدر اسات التي تناولت مهار ات التعاد التفكير العليا وتم تحديد الأبعاد التالية: • البعد الأول: مهارات التركيز (تحديد المشكلات، تحديد الأهداف). • البعد الثاني: مهار ات جمع المعلومات (الملاحظةـ صياغة الأسئلة) • البعد الثالث: مهار ات تنظيم المعلومات (المقارنة_ التصنيف).

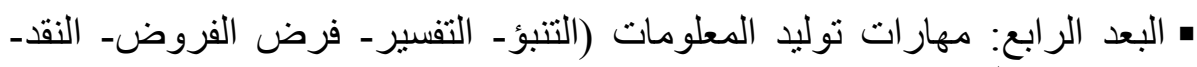

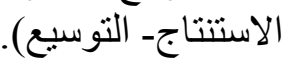

\section{• خ تحديد نوع مفردات الاختبار:}

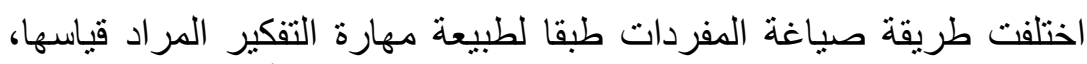

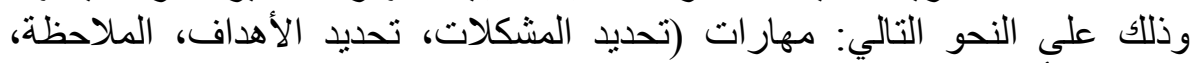

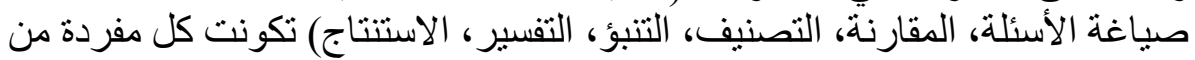

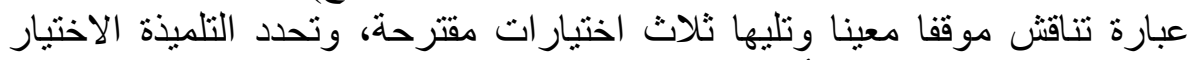
الصحيح بوضع علامة (/) أمام الاختيار الصحيح.

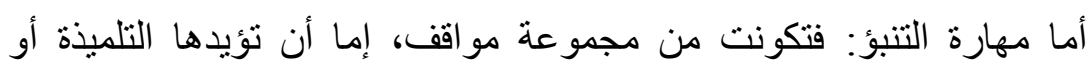

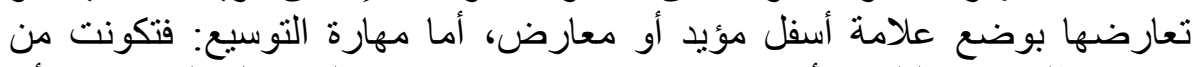

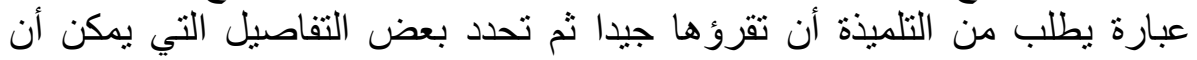

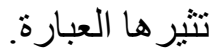




\section{هد صدق الاختبار:}

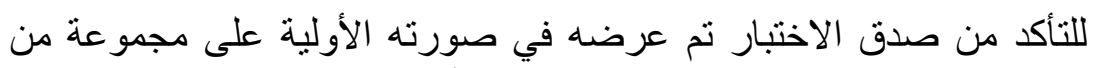

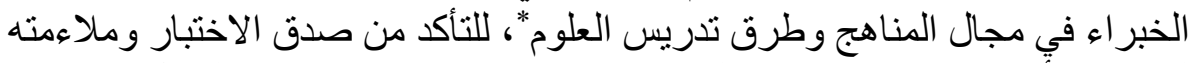

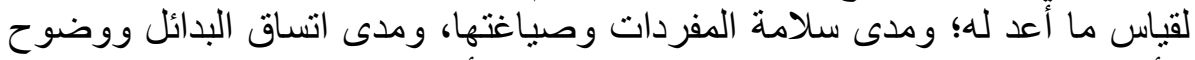

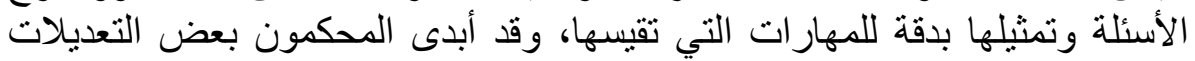
التي أخذتها الباحثنان في الاعتبار عند إعداد الصورة النهار النهائية للاختبار.

\section{• بـ التجربة الاستطلاعية للاختبار:}

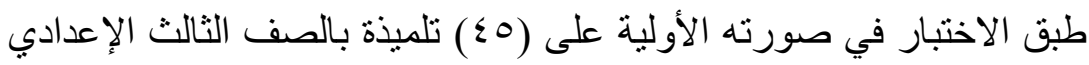
بهذف:

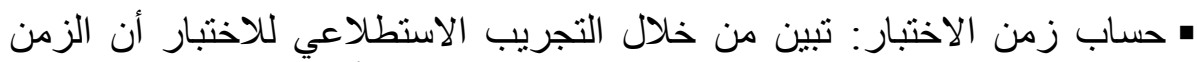

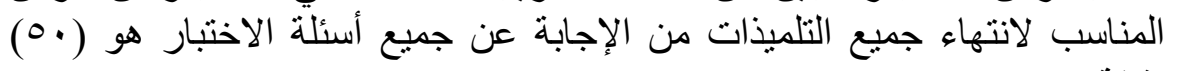

دقيقة.

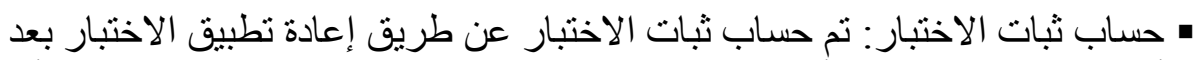

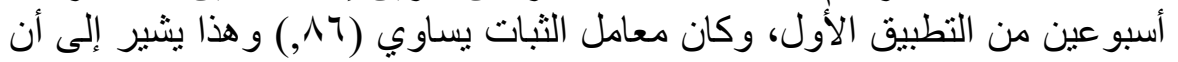
الاختبار يتمتع بدرجة عالية من الثبات التبات

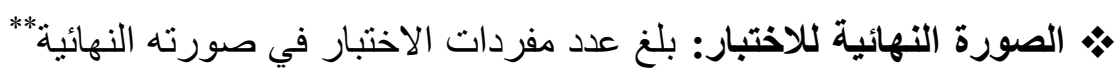

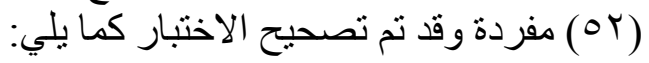

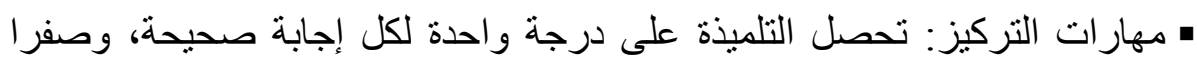

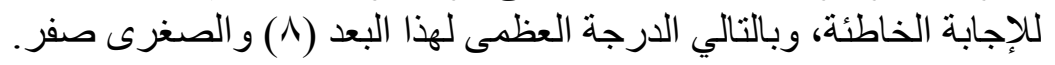

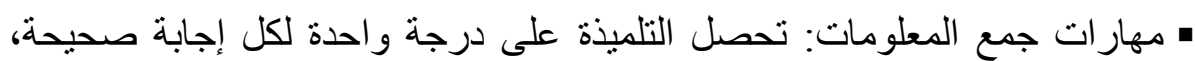

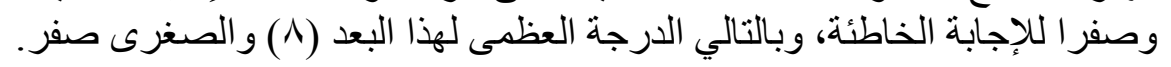

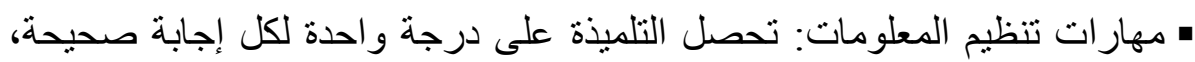

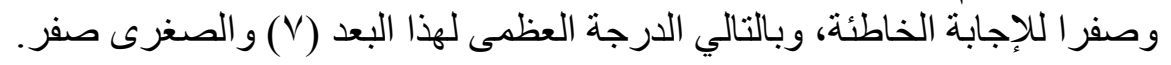

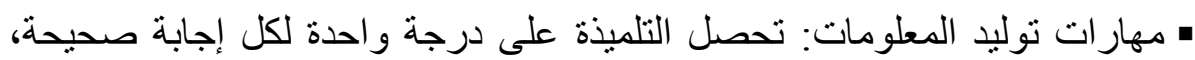

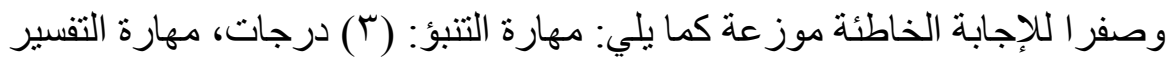

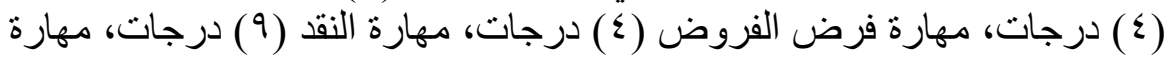

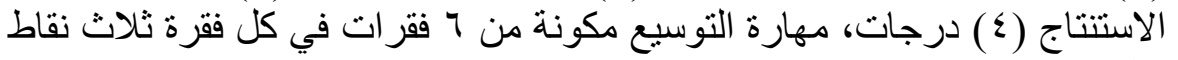

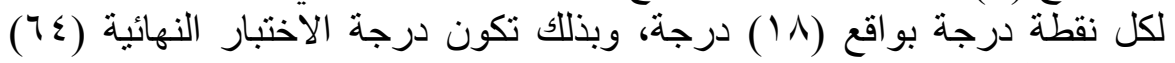

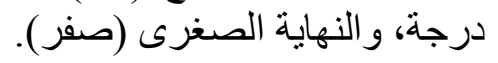




\begin{tabular}{|c|c|c|}
\hline 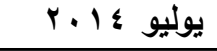 & المجلد السابع عشر & العدد الرابع \\
\hline \multicolumn{3}{|c|}{ جدول (1) } \\
\hline الارجة الكلية & أرقام الأسئلة: & أبعاد الاختبار \\
\hline & & 1 - مهار ات التركيز \\
\hline$\varepsilon$ & Y,r, & أـ تحديد المشكلة \\
\hline$\varepsilon$ & 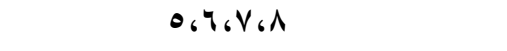 & بـ تحديد الأهداف \\
\hline & & ץ ـ مـهار ات جمع المعلومات \\
\hline$\varepsilon$ & $961.61161 \%$ & أـ الملاحظة \\
\hline$\varepsilon$ & $10617,1761 \leq$ & ب- طرح الأسئلة \\
\hline & & بـ ــ مهارات تنظيم المعلومات \\
\hline$\varepsilon$ & $1 V_{6} 1 \Lambda_{6} 196 \%$. & أـ المقارنة \\
\hline$r$ & MI, Y r, r & بـ التصنيف \\
\hline & & ع ـ مهارات توليد المعلومات \\
\hline$r$ & $r \leqslant 6 r \theta_{6} r T$ & أ- التنبؤ \\
\hline$\varepsilon$ & $r V_{6} r \Lambda_{6} r q_{6} r$. & بـ التفسير \\
\hline$\varepsilon$ & 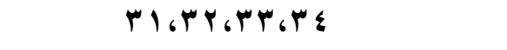 & ج- فرض الفروض الفر \\
\hline$\wedge$ & $r 0_{6} r q_{6} r V_{6} r \Lambda_{6} r q_{6} \varepsilon, 6 \leqslant 16 \leqslant r$ & دـ النقد \\
\hline$\varepsilon$ & $\varepsilon r_{6} \leqslant \varepsilon ، \leqslant 0 ، \varepsilon q$ & هـ الاستنتاج \\
\hline 7 & $\leqslant V_{6} \leqslant \Lambda_{6} \leqslant 960.001,0 Y$ & و- التوسيع \\
\hline
\end{tabular}

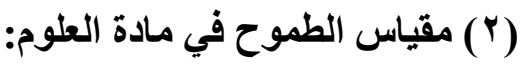

• الهُف من المقياس:

يهدف إلى قياس مقدار النمو في مستوى الطموح لاءى تلميذات الصف الصف الثالث

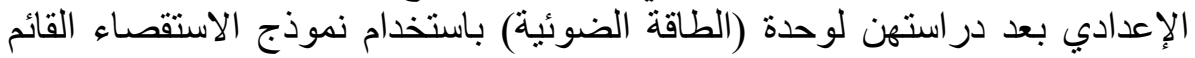
على الجدل.

\section{• تحديد أبعاد المقياس:}

تحددت أبعاد مقياس الطموح فيما يلي:

ا - مستوى الطموح المرتبط بالتحصيل الدراسي.

r- مستوى الطموح المرتبط بعلاقة الفرد بالآخرين. r- مستوى الطموح المرتبط بإمكانية تحقيق الفرد لأهدافه.

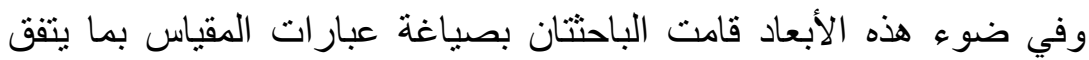

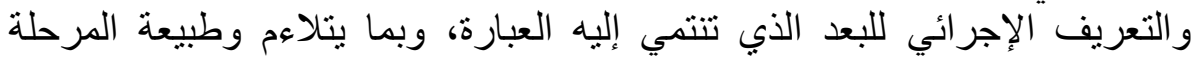

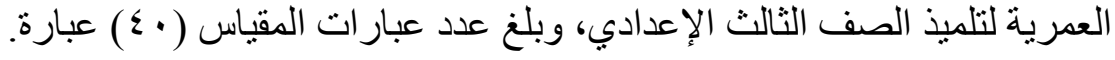

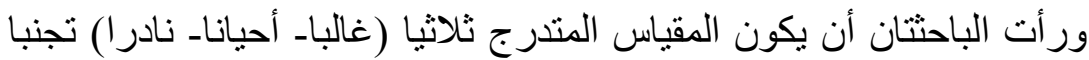

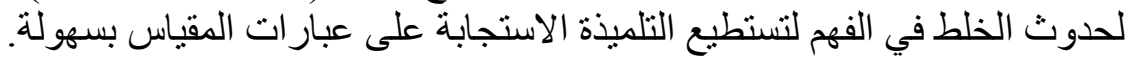




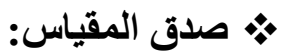

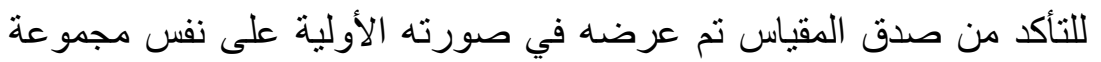

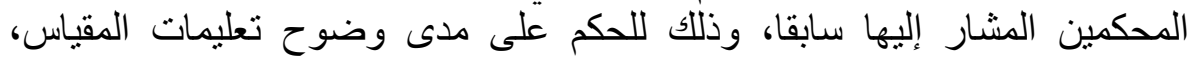

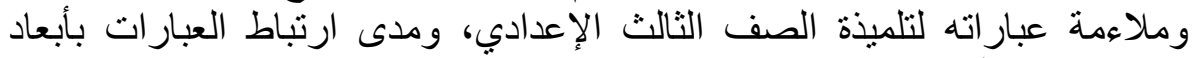

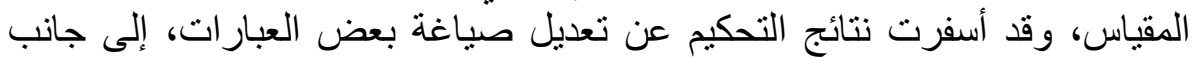
حذف لبعض العبار ات لعدم ملاءمتها للبعد الذي تنتئمي إليها.

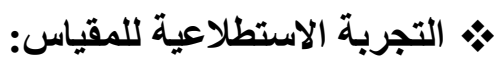

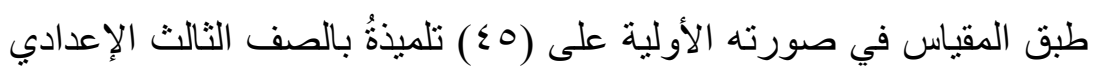

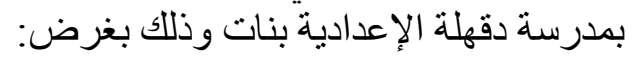

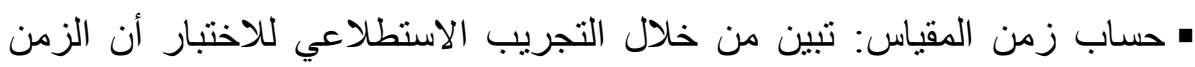

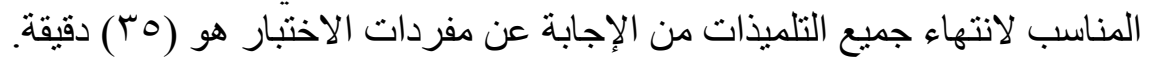

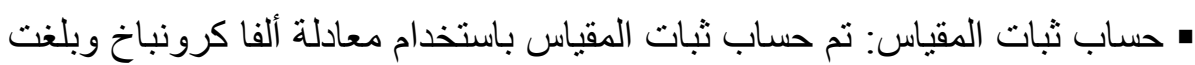

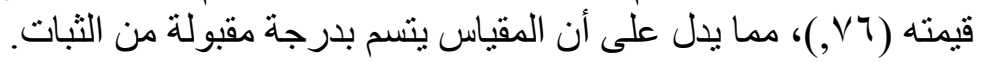

\section{• الصورة النهائية للمقياس:}

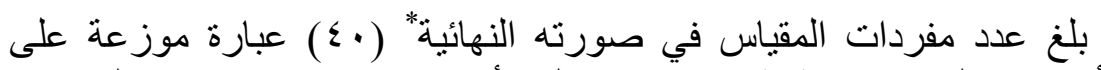

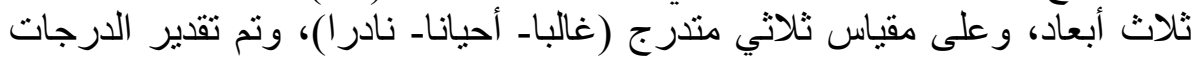

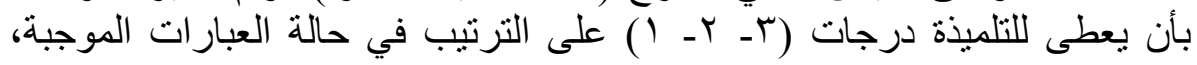

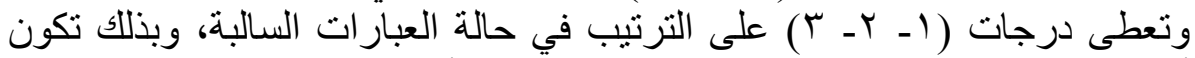

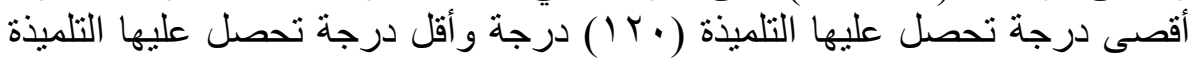

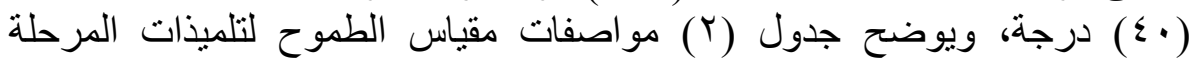
الإعدادية.

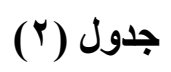

مواصفات مقياس الطموح

\begin{tabular}{|c|c|c|c|c|}
\hline$\%$ & مج & العبار ات السالبة & العبارات الموجبة & أبعاد المقياس \\
\hline$r$. & Ir & $\left.\varepsilon_{6} q_{6}\right) \varepsilon_{6} r r_{6} r r$ & 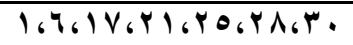 & التحصيل الدراسي \\
\hline ro & 1. & r,V, & $1.61 r_{6} 1 q_{6} Y \varepsilon_{6} r V_{6} r V$ & علاقة القرد بالآخرين \\
\hline \multirow[t]{2}{*}{$\leq 0$} & 11 & 0,10,rr, rT,r & $\left.\left.r_{6} \Lambda_{6} \mid r_{6}\right) Y_{6} r_{0}, r_{1}\right)_{6} \varepsilon_{6}$ & إمكاتية تحقيق الفرد \\
\hline & & $r_{6} r q_{6} r q_{6} r q q$ & $\varepsilon \cdot \sigma \mid \Lambda_{6} \mathrm{r}^{\prime}$ & لأهدافه \\
\hline $1 \ldots$ & $\varepsilon$. & IV & $\overline{r r}$ & المج \\
\hline
\end{tabular}

خامساً: التصميم التجريبي وإجراءات التجربة:

اتبعت الدر اسة الحالية المنهج شبه التجريبي وكانت الخطوات اتجريه: المنبعة كالتالي:

* ملحق(0) : الصورة النهائية لمقياس مستوى الطموح .

مجلة التربية العلمية 
العدد الرابع

• متغير ات الدراسة: المتغير المستقل: المعالجة التدريسية (نموذج الاستقصاء القائم

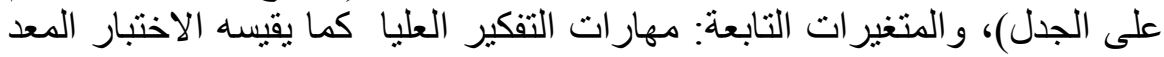
لذللك، ومستوى الطموح كما يقيسه المقياس المعد لذلكئ.

ه اختيار مجموعة الدراسة: تم تطبيق الدراسة بمدرسة دقهلة الإعدادية بنات بإدارة

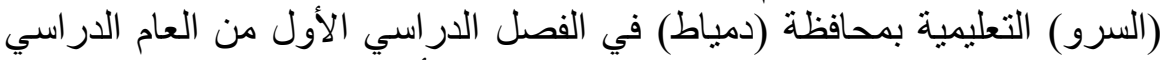

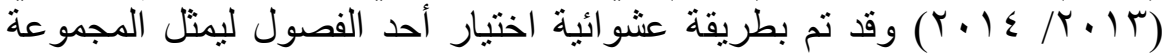
التجريبية وهو فصل (T/1) وفصل آخر بمدرسة السرو الإعدادية بنات ليمثل المجموعة الضابطة و هو فصل (T// (1)، وكان العدد التجريبي للمجمو عة التجريبية

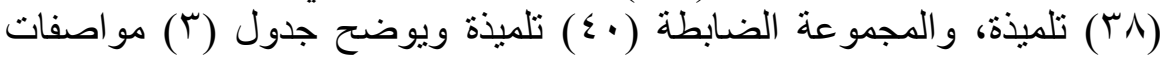
مجمو عة الدر اسة.

$$
\text { جدول (r) }
$$

مواصفات مجموعة الدراسة

\begin{tabular}{|c|c|c|c|}
\hline المجموعة & الفصل & العدد التجريبي & المدرسة \\
\hline التجريبية & $1 / \mu$ & $\Gamma \wedge$ & دقهلة الإعدادية بنات \\
\hline الضابطة & $1 / \mu$ & $\varepsilon$. & السرو الإعدادية بنات \\
\hline
\end{tabular}

\section{(1) (التطبيق القبلي لأداتي الاراسة}

تم تطبيق أداتي الدراسة (اختبار مهار ات التفكير العليا، ومقياس مستوى

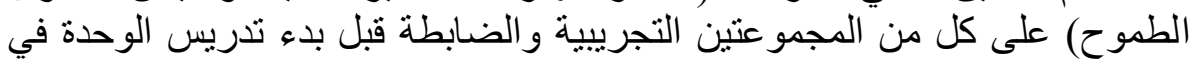

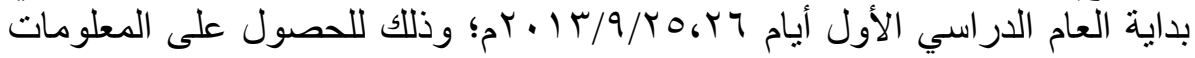

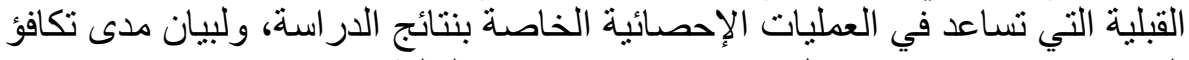

المجمو عتين، ويوضتح جدول (ع) نتائج الاختبار ات القبلية.

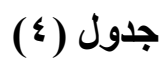

\begin{tabular}{|c|c|c|c|c|c|c|}
\hline \multirow{3}{*}{ الدلالة } & \multirow{3}{*}{ قيمة (ت) } & \multicolumn{2}{|c|}{ المجموعة الضـابطة } & \multicolumn{2}{|c|}{ المجمو عة التجريبية } & \multirow{3}{*}{ الاختبار } \\
\hline & & \multicolumn{2}{|c|}{$\varepsilon \cdot=r_{\dot{U}}$} & \multicolumn{2}{|c|}{ } & \\
\hline & & $r_{\varepsilon}$ & $\bar{t}^{5}$ & $\overline{l \varepsilon}$ & 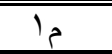 & \\
\hline غير دالة & $.7 \mathrm{~V}$ & V.7. & (r.AI & 1.90 & TO.YA & مهار ات التفكير العليا \\
\hline غير دالة &. .19 & سזr & 71.10 & $\Lambda . \leqslant r$ & Tr.0. & مستوى الطموح \\
\hline
\end{tabular}

\section{نتائج التطبيق القبلي}

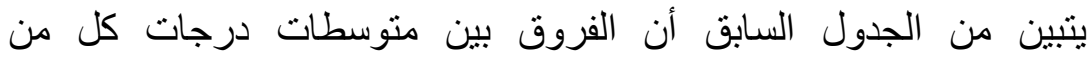
المجمو عتين التجريبية والضابطة على اختبار مهار ات التفكير العليا، ومقياس مستوى مئن الطموح غير دالة، مما يعني أنه لا توجد فروق ذات دلالة إحتئ إحسائية بين المجمو عتين التجر بيية و الضنابطة قبليا. 
رابعا: تدريس الوحدة: - ملرد

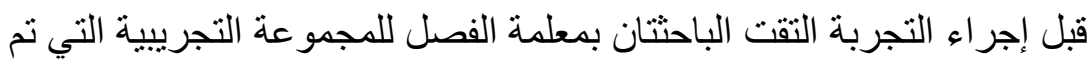

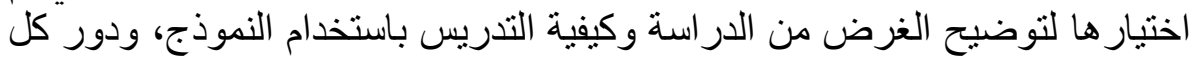

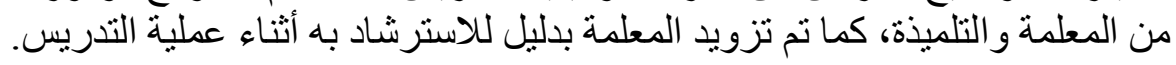

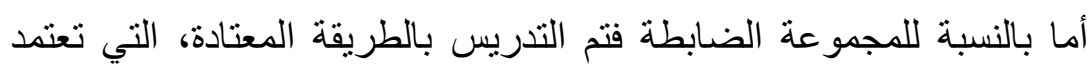

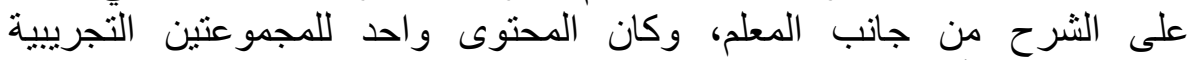

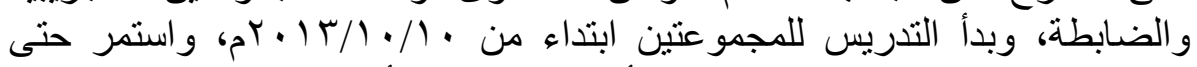

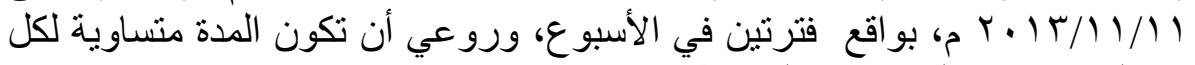
من المجمو عتين التجريبية و الضابطة فئرة

انطباعات التلميذات "مجموعة الاراسة" عن التجربة التجاتة ودراسة الوحدة بنموذج الاستقصاء القائم على الجدل:

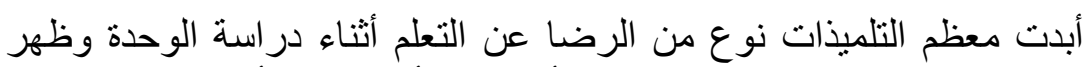

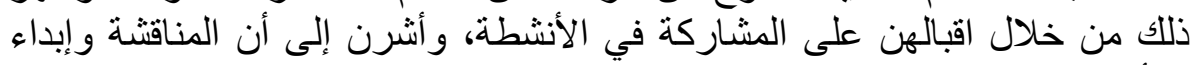

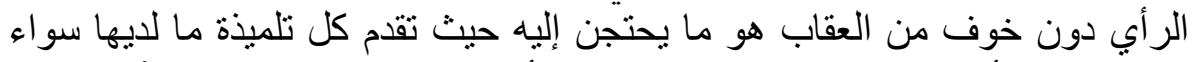

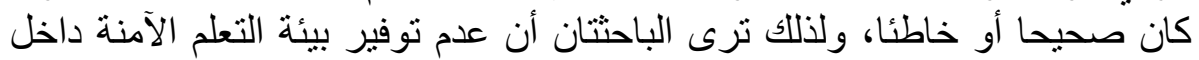
الفصل من أهم أسباب عزوف التناب ولميذات عن المشاركة والبات المناقثنة أثناء التندريس.

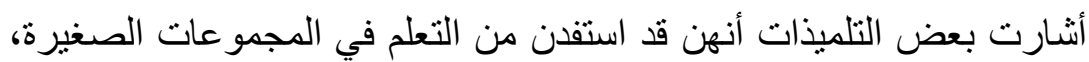

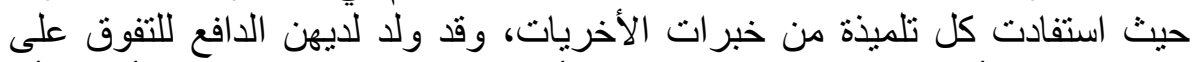

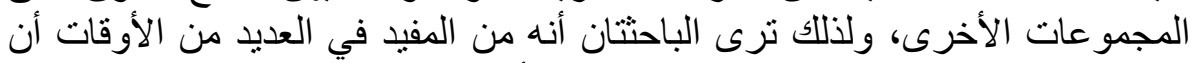

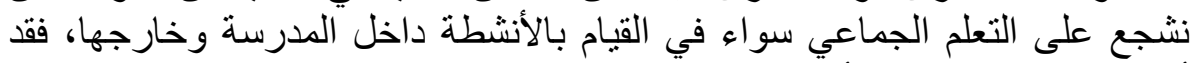

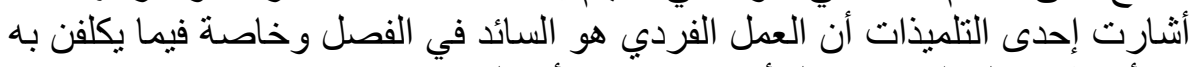

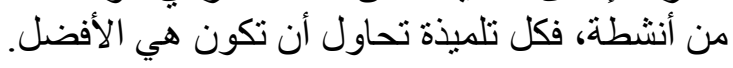

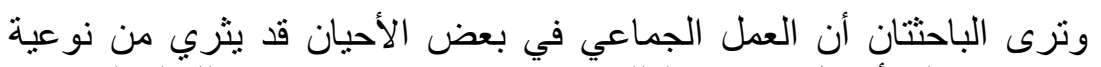

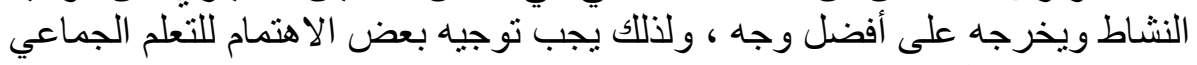

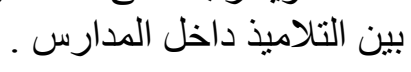

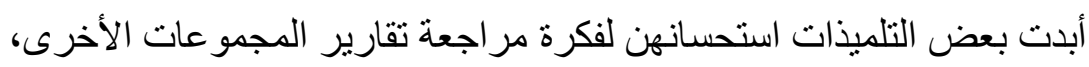

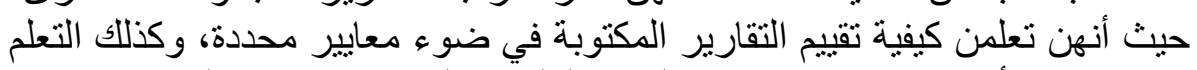

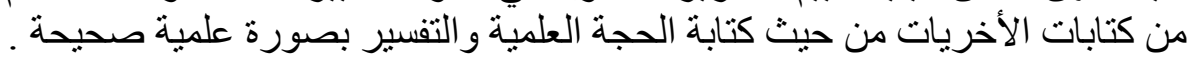
خامسا: التطبيق البعدي لأداتي الدراسة:

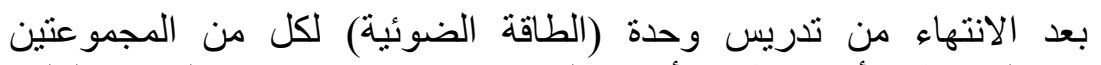

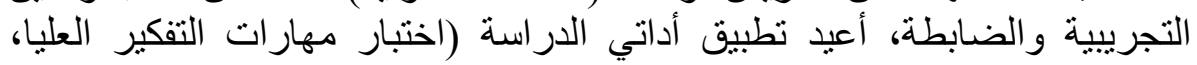

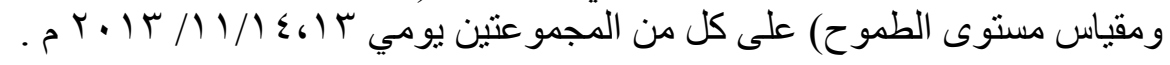




\section{عرض النتائج ومناقشتيها}

تناولت الباحثتان عرض النتائج التي تم التوصل إلتينها واليها من خلال تجربة

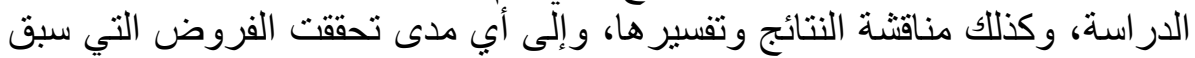

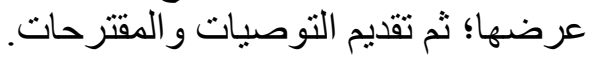
أولاً: نتائج تطبيق اختبار مهارات التفكير العليا:

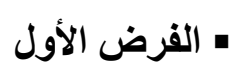

نص الفرض الأول للاراسة على أنه: يوجد فرق ذو دلالة إحصائية بين

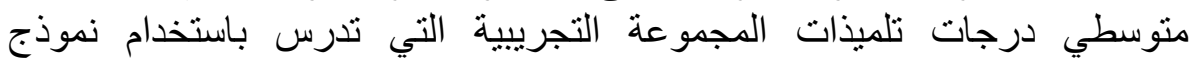

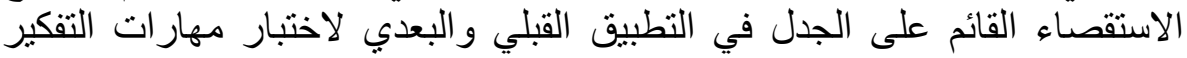
العليا لصالح التطبيق البعدي.

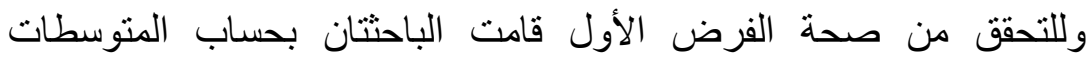

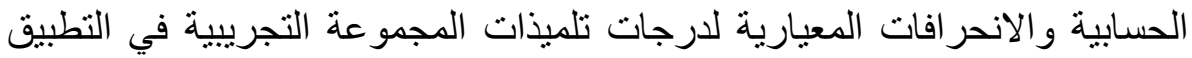

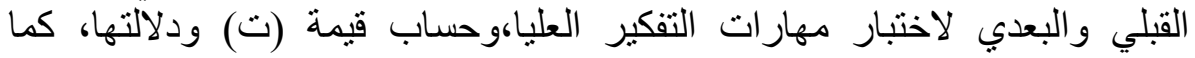

\section{جدول (0)}

يوضحها جدول (0).

المتوسطات الحسابية والانحرافات المعيارية، وقيم (ت) ودئ ودلالتها؛ لنتائج التطبيق

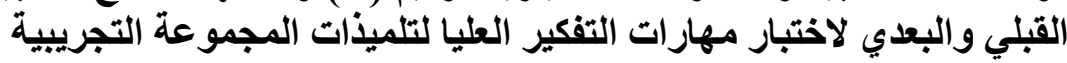

$$
(r \wedge=\dot{0})
$$

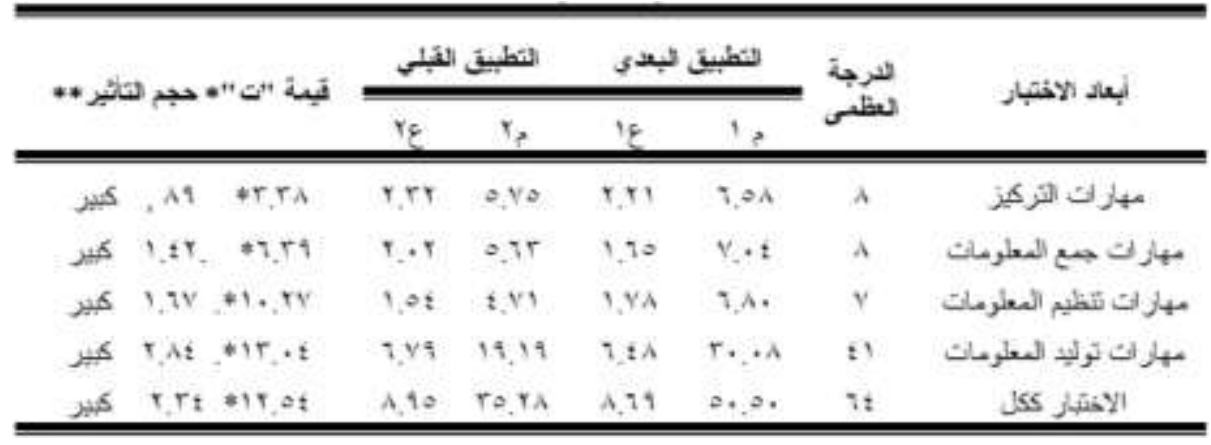

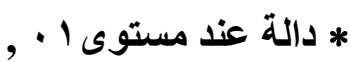

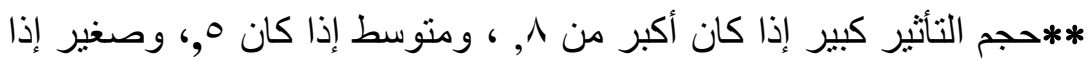
كان أقل من ب , (رشدي فام ،

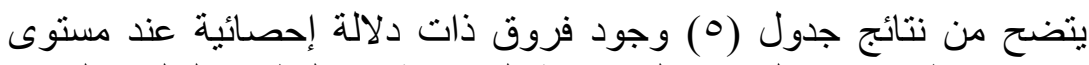

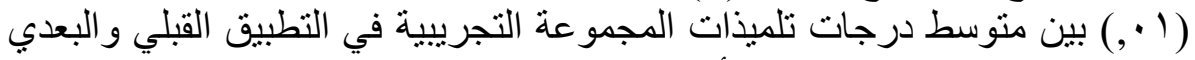

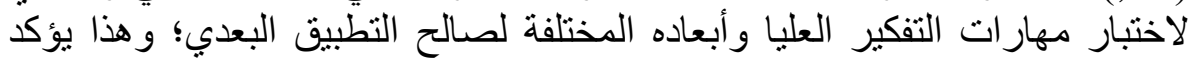


العدد الرابع

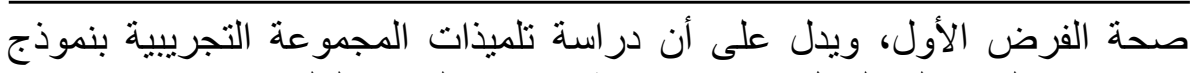
الاستقصاء القائم على الجدل ساهم في تنمية مهار ات التفئ درل التهير العليا.

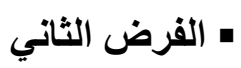

نص الفرض الثاني على أنه: يوجد فرق ذو دلالة إحصائية بين متوسطي درجات تلميذات المجموعة التجريبية وتلميذات المجموعة الضابطة في التطبيق دوني البعدي لاختبار مهار ات التفكير العليا لصالح المجمو عة التجريبية.

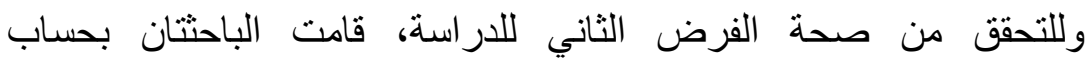
المتوسطات الحسابية والانحر افات المعيارية لدرجات تلميذات المجموعة التجريبية وتلميذات المجموعة الضابطة، في التطبيق البعدي لاختبار مهارات التفكير العليا،

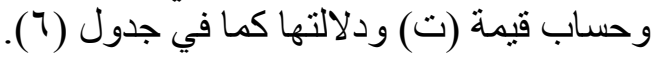

جدول (')

المتوسطات الحسابية، والانحر افات المعيارية، وقيم (ت) لتتائج التطبيق البعدي

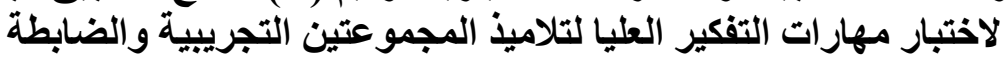

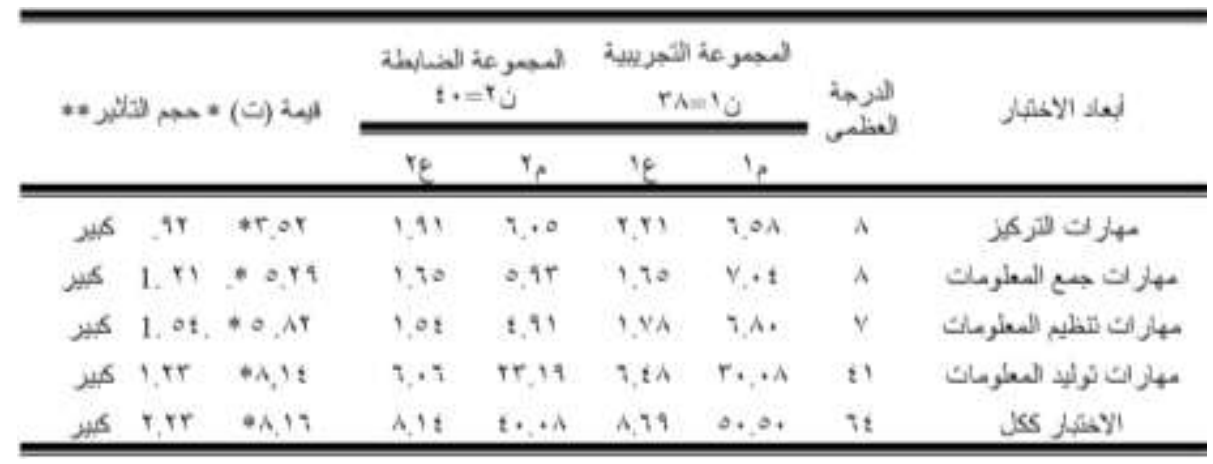

يتضح من جدول (7) وجود فروق ذات دلالة إحصائية عند مستوى (1 (,..) بين متوسط درجات تلميذات المجموعتين التجريبية و الضابطة في التطبيق البعدي دوني لاختبار مهار ات التفكير العليا و أبعاده المختلفة لصالح تلميذات المجمو عة التجريبية؛

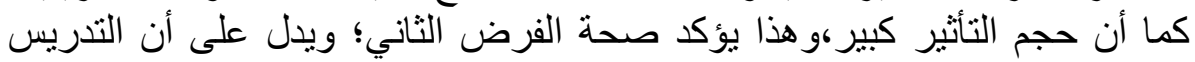

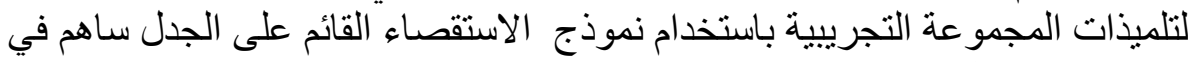
تنمية مهار ات التفكير العليا.

تفسير التتائج الخاصة بأثر التدريس باستخدام نموذج الاستقصاء القائم على

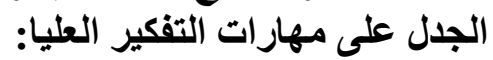

أوضحت نتائج اختبار الفرضين الأول والثاني اكتساب القدرة على مهارات

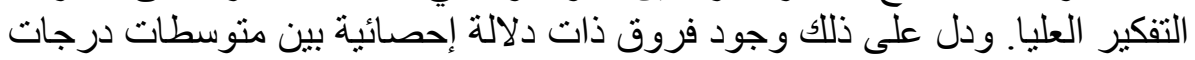
تلميذات المجموعة التجريبية في التطبيق القبلي والبعدي على اختبار مهار ات التفكير

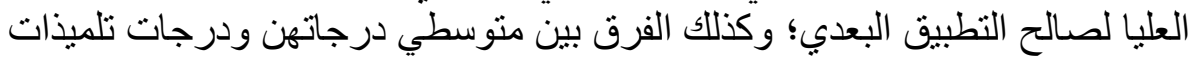


العدد الرابع

المجموعة الضابطة في التطبيق البعدي لاختبار مهارات التفكير العليا لصالح

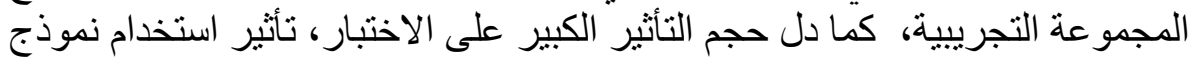
الاستقصاء القائم على الجدل في تنمية مهار ات التفكير العليا.

وترى الباحثتان أن أثز استخدام نموذج الاستقصاء القائم على الجدل في تنمية مهارات التفكير العليا قد يرجع إنى ألى الثئ ه اشتر الك التلميذات في المرحلة الأولى ساهم في تدريبهن على بعض مهار ات التفكير إتهات

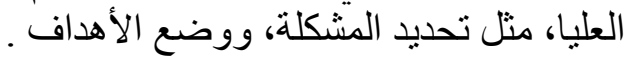

• اشترالك التلميذات في مجموعات للقيام بأنشطة المرحلة الثانية، ساهم في تنمية قدر اتهن على الملاحظة الدقيقة، والتوصل للتفسيرات العلمية الصحيحة، ومناقشتها

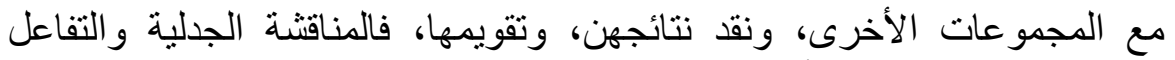

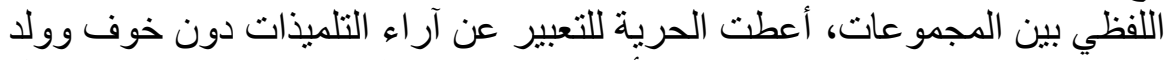
لديهن الدافع للتفكير، والاستماع للأخريات ساعد على تنى تلهية مهارات التحليل و التفسير و النقد و التقويم. لأعني.

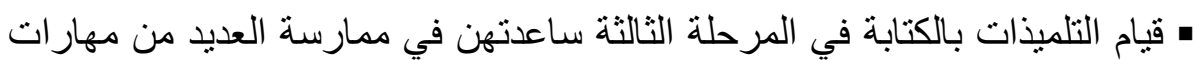

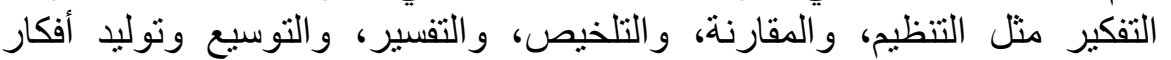

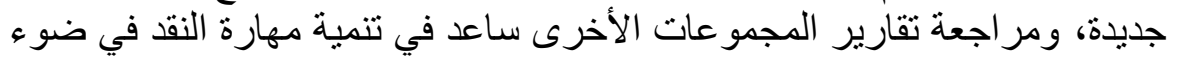
معايير محددة .

وبهذا تتفق نتائج اختبار هذين الفرضين مع ما توصلت إليه الدر اسات التالية:

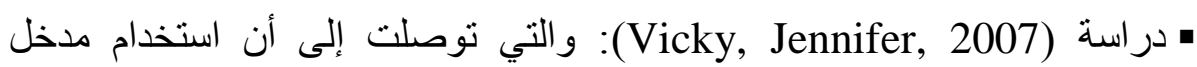
الاستقصاء الموجه بالعملية القائم على المشاركة النشطة في تدريس الكيمياء ساعد على تنمية مهار ات التفكير الناقد ه دراسة (حياة رمضان، 1 . . ب)): و التي أوضحت فاعلية إستر اتيجية (كون- شاركاستمع- ابتكر) في تنمية مهار ات التفكير العليا لدى تلاميذ الصف الصف الخامس الابتدائي.

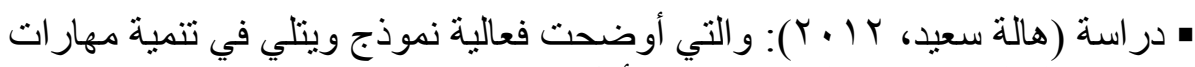

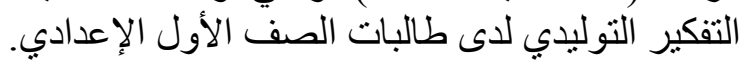

ثانياً: نتائج تطبيق مقياس مستوى الطموح: ه الفرض الثالث

نص الفرض الثالث على أنه: "يوجد فرق ذو دلالة إحصائية بين متوسطي درجات تلميذات المجموعة التجريبية في التطبيق القبلي والبعدي لمقياس مستوى دئ دئ التئي الطموح لصالح التطبيق البعدي. وجدول (V) يوضح نتائج التطبيق البعدي لمقياس مستوى الطموح للمجمو عتين التجريبية و الضابطة. 


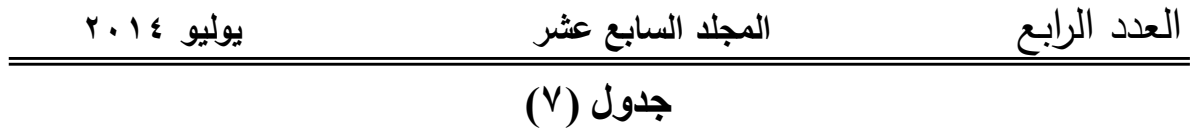

المتوسطات الحسابية والانحرافات المعيارية، وقيم (ت)، ودلالتها لنتائج التطبيق

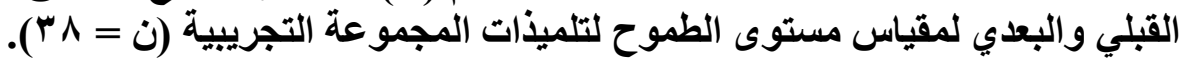

\begin{tabular}{|c|c|c|c|c|c|c|}
\hline \multirow{2}{*}{\multicolumn{2}{|c|}{ قيدة "ت "" حجم الثاثثر "*" }} & \multicolumn{2}{|c|}{ التطبيق القباب } & \multicolumn{2}{|c|}{ التطبيق البثى } & \multirow{2}{*}{ أبعاد المقياس } \\
\hline & & $r_{\varepsilon}$ & te & $1 \varepsilon$ & 10 & \\
\hline 1,1, كيبز & $n, 1, r$ & r.or & 11,11 & $r . \wedge$. & $\times 9,79$ & التحصبل الثر اسب \\
\hline 1. Vv & $+1+.19$ & r.ra & $11, r$ & $r, t A$ & $r:, 20$ & عالمة للفرد بالآخرين \\
\hline 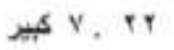 & $n * v, v r$ & $2,3 \mathrm{~A}$ & $r 0, r q$ & $r, 19$ & 24,3 & 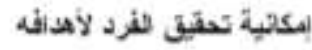 \\
\hline S S S & $=Y+, A$ & $A_{t} t_{+}$ & $i+0$. & vor & $1 \ldots+r+$ & للدرجة الكلية \\
\hline
\end{tabular}

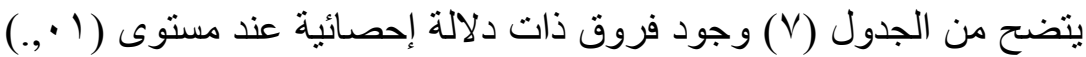

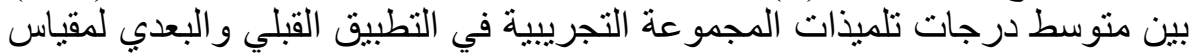

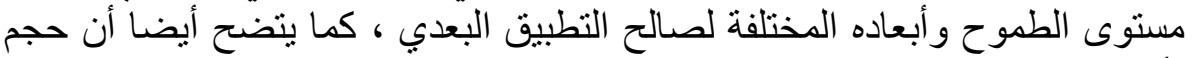

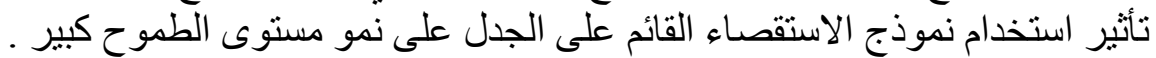

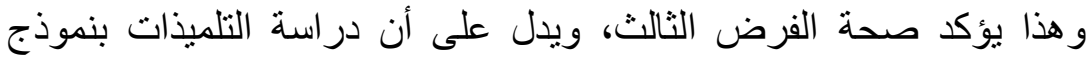
الاستقصاء القائم على الجدل ساعد في نمو مستوى الطموح.

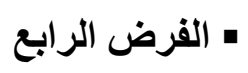

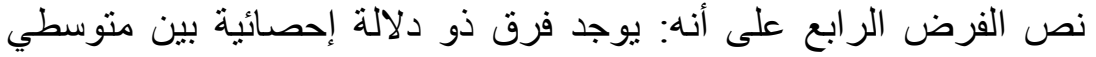
درجات تلميذات المجموعة التجريبية وتلميذات المجيه المبوعة الضابطة في في التطبيق

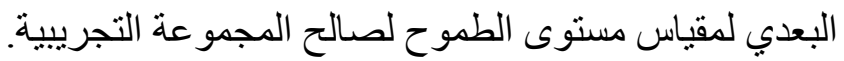
وجدول (^) يوضح نتائج التطبيق البعدي لمقياس مستوى الطموح للمجمو عتين التجريبية و الضابطة.

$$
\text { (^) جدول (^) }
$$

المتوسطات الحسابية والاتحرافات المعيارية وقيم (ت) لنتائج التطبيق البعدي

\begin{tabular}{|c|c|c|c|c|c|}
\hline \multirow{2}{*}{ 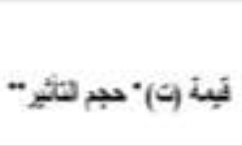 } & \multicolumn{2}{|c|}{ 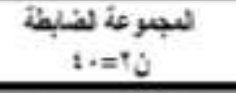 } & \multicolumn{2}{|c|}{ البسو عi لتجريس } & \multirow{2}{*}{ بعلد الإتبر } \\
\hline & ' & $T^{2}$ & ig & 12 & \\
\hline 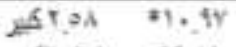 & $T: t:$ & $17, y$ & $T . A$. & $T 1 T i$ & تحصيل لبز سي \\
\hline 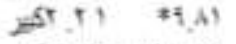 & $5.4 \mathrm{~A}$ & 10,00 & $T: A$ & $T: 12$ & عالة لفزدبالأفرغ \\
\hline 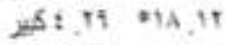 & $r, 75$ & $\pi,+1$ & 7.49 & $21, x$ & كوبة نمئي لفزد لودنه \\
\hline 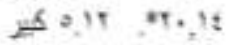 & 3,14 & 3,9 & $r, 2 r$ & $1 . . \mathrm{TT}$ & 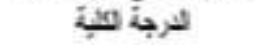 \\
\hline
\end{tabular}

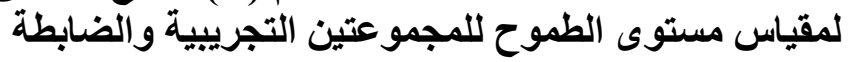


يتضح من جدول (^) وجود فروق ذات دلالة إحصائية عند مستوى ( ' (,.)

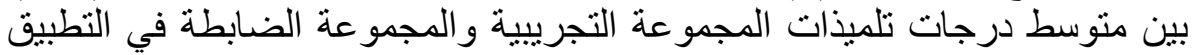

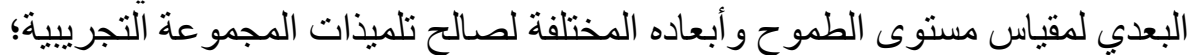

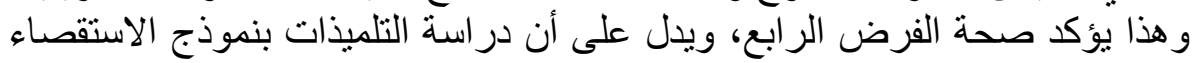
القائم على الجدل ساهم في نمو مستوى الطموح لائرن.

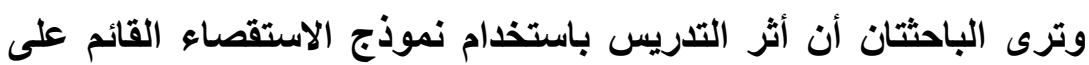

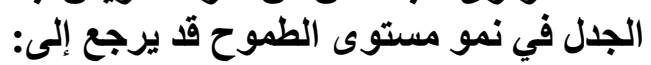

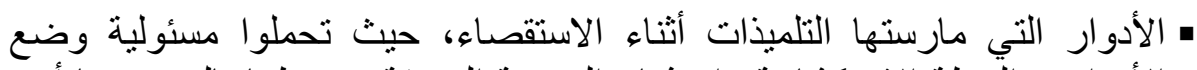

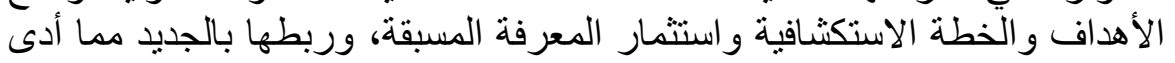

$$
\text { إلى نمو مستوى الطموح المرتبط بالتحصيل. }
$$

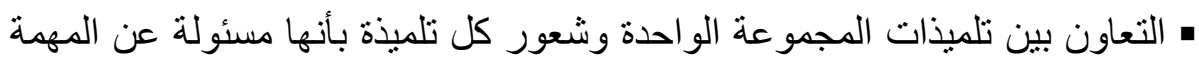

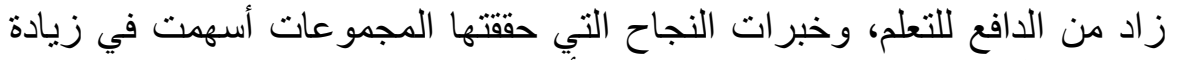

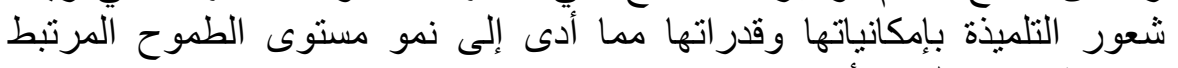
بإمكانية تحقيق الفرد لأهدافه.

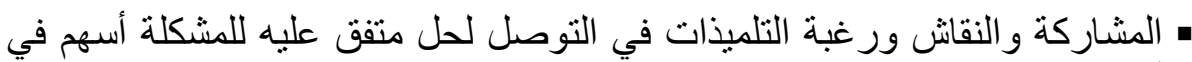

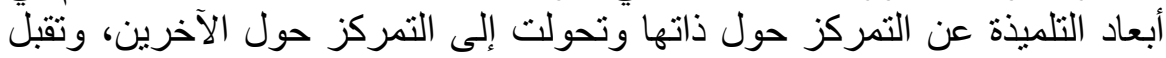

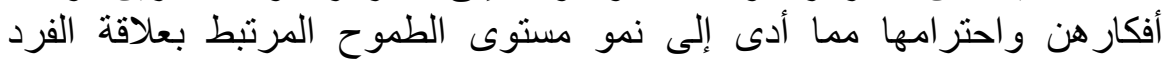

$$
\text { بالآخرين }
$$

• ممارسة التلميذة للأنشطة بحرية ومرور ها بخبر ات النجاح في حل المشكلة زادت بهات

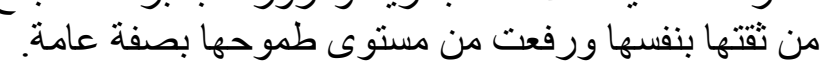

وبهذا تتفق نتائج اختبار هذين الفرضين مع ما توصلت إليه الدراسات التالية:

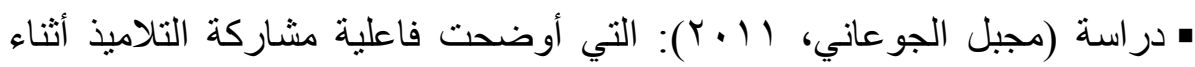
التدريس في زيادة مستوى الطموح.

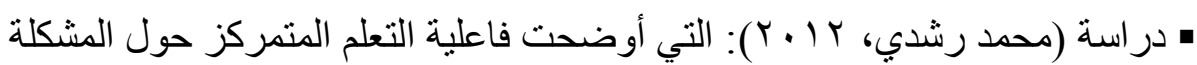

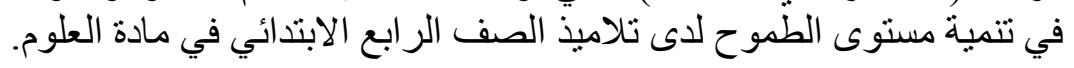

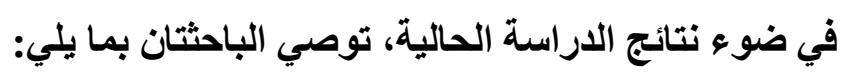

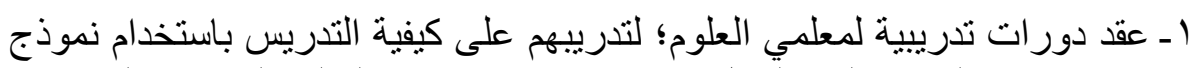

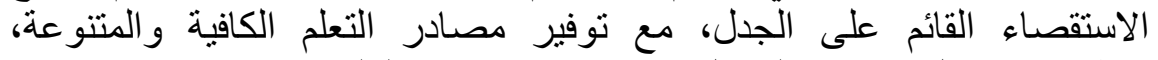
و إطلاعهم بشكل مستمر على كل جديد في مستحدثات فئل العلم.

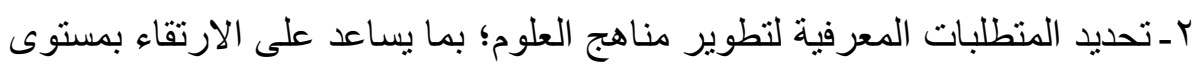
تعليمها وتعلمها في ضو المعات النماذج التدريسية الجديدة. 
العدد الرابع

بـ إعادة النظر في أهداف المقررات التربوية والأكاديمية المتضمنة في بر امج إعداد المعلم بحيث تتسجم مع الأهداف العالمية للتربية العدية التمية.

ع ـ تدريب معلمي العلوم على إتاحة الفرصة للتلاميذ على إحراز النجاحات التي تزبد

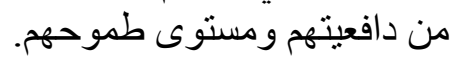

ـ تضمين بر امج إعداد المعلم في كليات التربية النماذج التدريسية الحديثة التي تؤكد على استخدام الجدل في تدريس العلوم.

خامساً: البحوث المقترحة: تقترح الباحثتان عددا من البحوث المستقبلية استكمالا واستمر ار اللدر اسة الحالية وذلك كما يلي:

ه فاعلية استخدام الاستقصاء القائم على الجدل في تصحيح التصور ات العلمية الخاطئة وطبيعة العلم لدى تلاميذ المرحلة الابتدائية.

ه برنامج مقترح في ضوء الاستقصاء القائم على الجدل في تتمية المفاهيم العلمية و الرضنا عن التعلم لدى تلاميذ المرحلة الإعدادية.

ه دراسة تشخيصية لأهم أسباب انخفاض مستوى الطموح لدى تلاميذ المرحلة الابتدائية.

• برنامج مقترح لتنمية مهارات الجدل العلمية و التفكير الاستدلالي لطلاب المرحلة

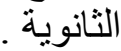

ـ فاعلية استخدام نموذج الاستقصاء القائم على الجدل في تتمية الفهم العميق والدافعية

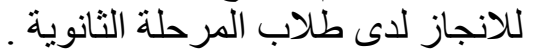

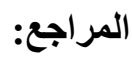

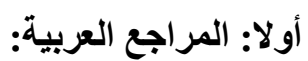

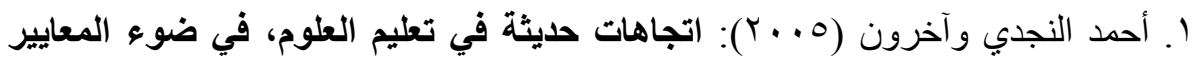
العالمية وتنمية التفكير والنظرية (البرية البنائية، القاهرة، دار الفئة في الفكر العربي.

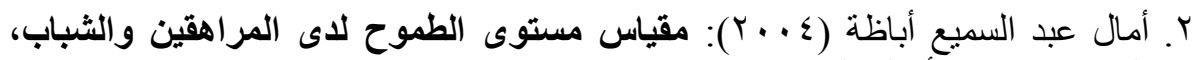

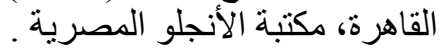

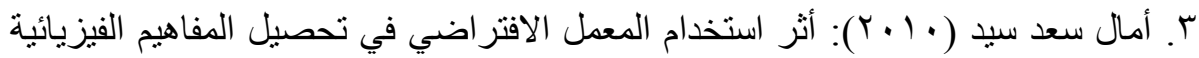

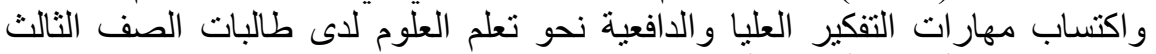
الاعدادي، مجلة التربية العلمية، المجلد الثالث عشر ، العدد التهابة السادس.

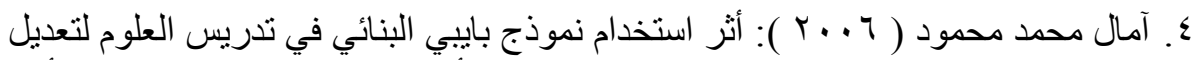

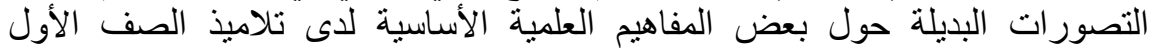

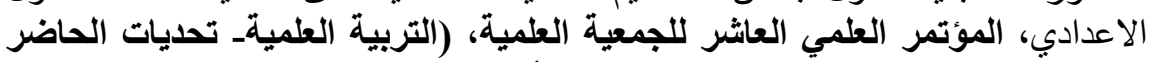

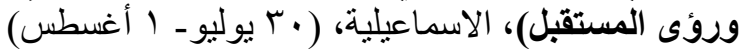
๑. باربر برزيسن (99V ( )): قراعات في مهارات التفكير وتعليم التفكير الناقد والتفكير

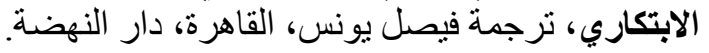


العدد الرابع

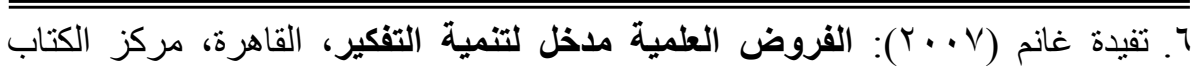
للنشر.

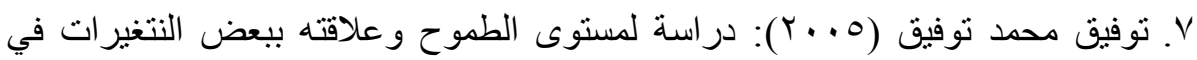

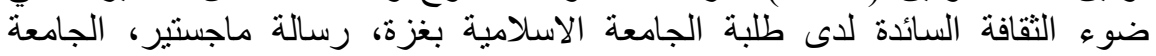

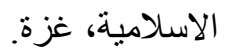

^. جابر عبد الحميد جابر (0 . . ץ): التدريس والتعلم: الأسس النظرية، القاهرة، دار الفكر العربي.

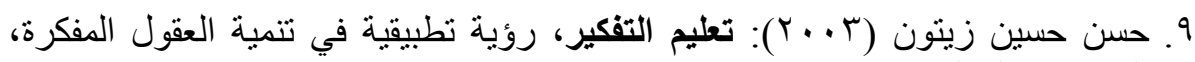
القاهرة، عالم الكتب جنب

• . . حسن شحاتة، زينب النجار (r . . (Y): معجم المصطلحات التربوية والنفسية، الدار المصرية اللبنانية.

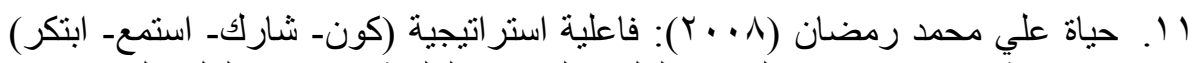

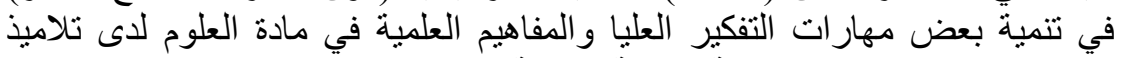

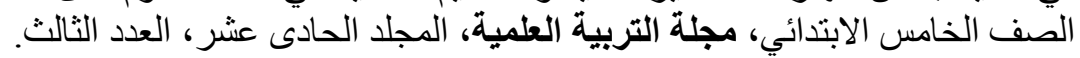

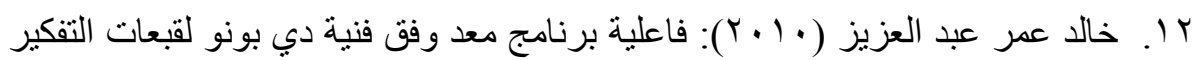

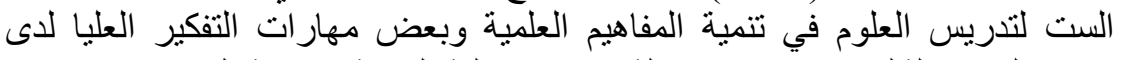
تلاميذ الصف الثالث الاعدادي، رسالة دكتور اةت، كلية التربية، جامعة المنية التيا.

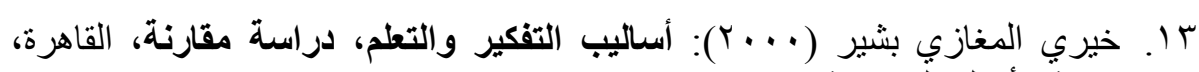
مكتبة الأنجلو المصرية بـيزية

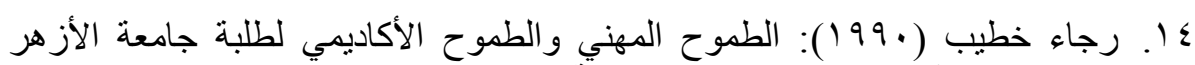

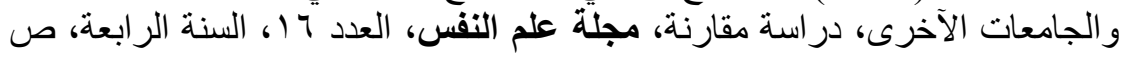

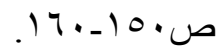

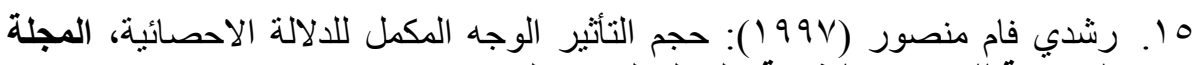

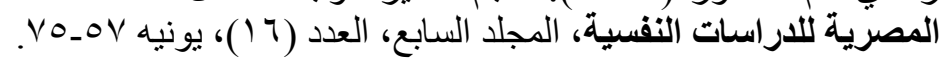

7 ا . روبرت مارزانو (991 (1)): أبعاد التفكير، ترجمة يعقوب نشوان ومحمد صالح، دار غزة للطباعة و النشر.

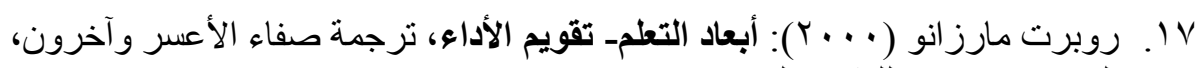

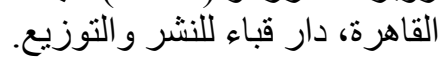

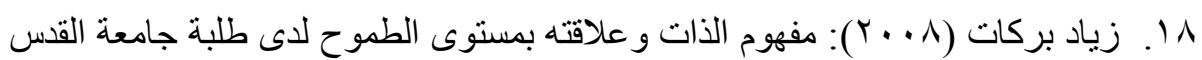

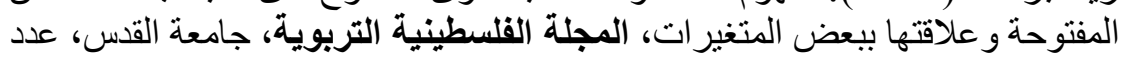

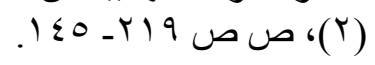

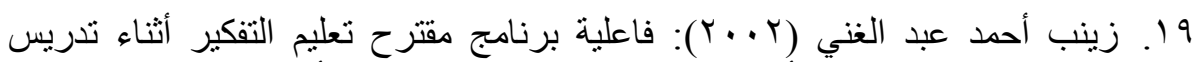

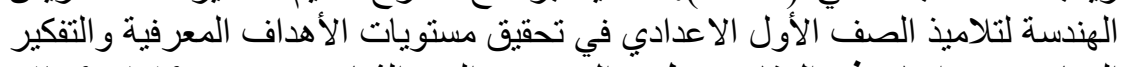

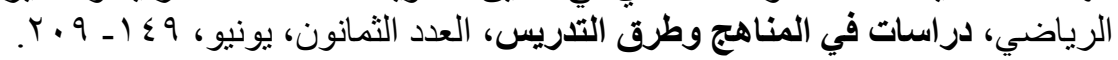


العدد الرابع

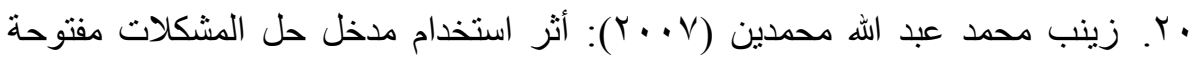
النهاية في تدريس العلوم لتنمية مهار ات التفكير العليا لدى تلاميذ المرحلة الاعدادية رسالة ماجستير، كلية البنات، جامعة عين شمس.

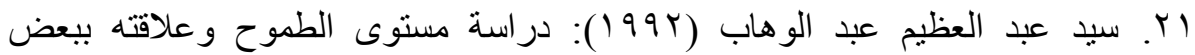

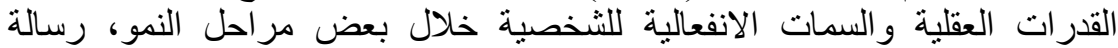
ماجستير، كلية التربية جامعة المنيا.

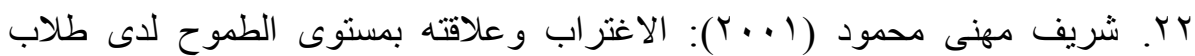

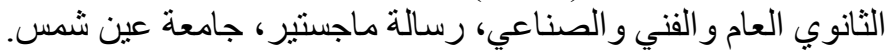

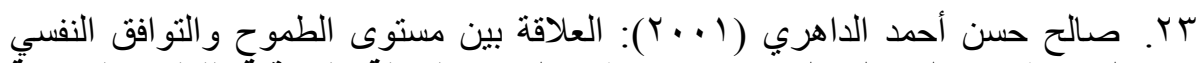

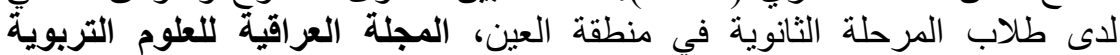

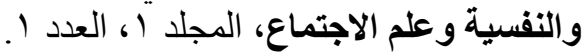

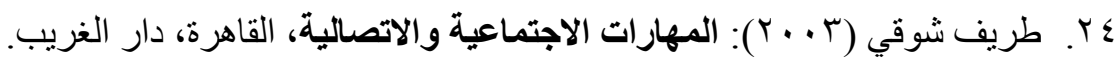

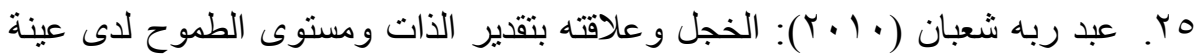
من المعاقين بصريا، رسالة ماجستير ، الجامعة الاسلامية بغزة عاته فلسطين.

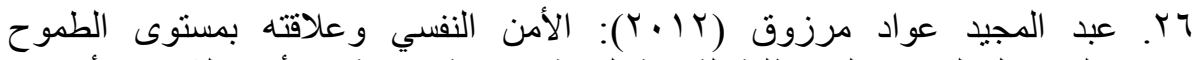

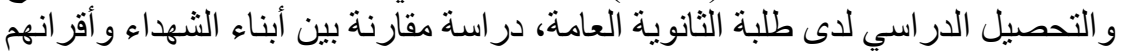

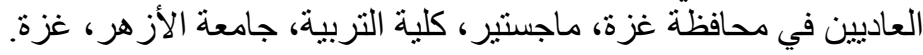
rV

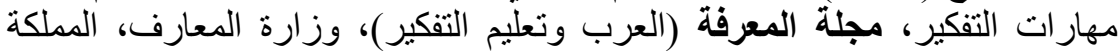

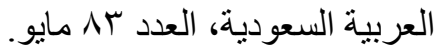

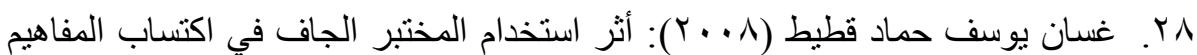

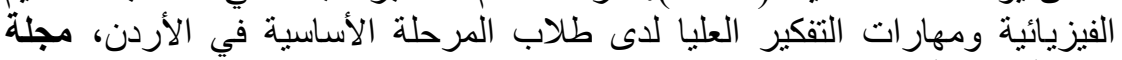

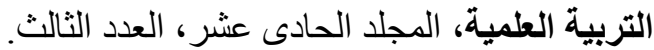

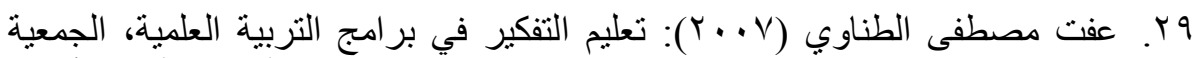

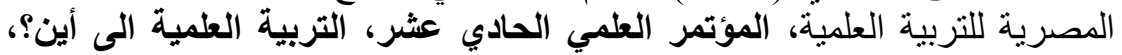

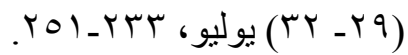

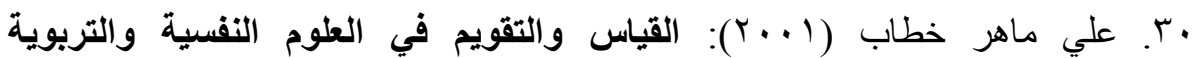
والاجتماعية، القاهرة، مكتبة الأنجلو المصرية. اسب. فتحي عبد الرحمن جروان (9999): تعليم التفكير مفاهيم وتطبيقات، عمان، دار الكتاب العربي.

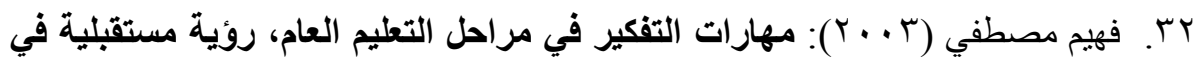
الوطن العربي، القاهرة، دار الفكر العربي. ماري.

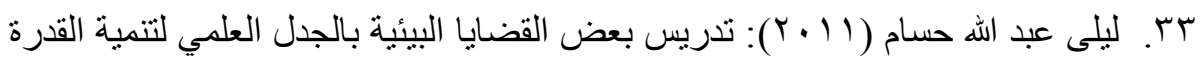

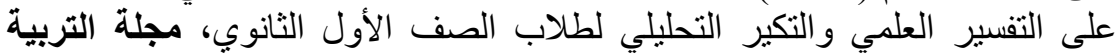
العلمية، العدد الر ابع، المجلد الر ابع عشر. 


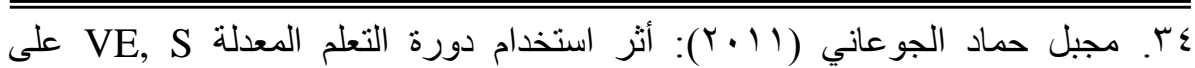

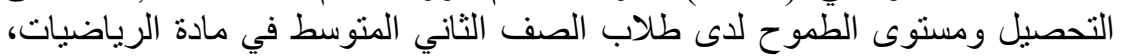

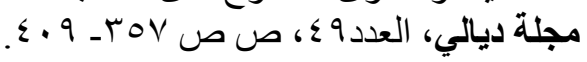

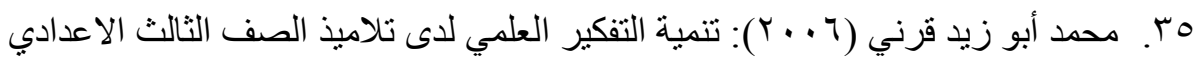

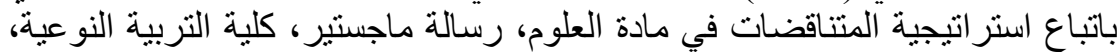
جامعة عين شمس.

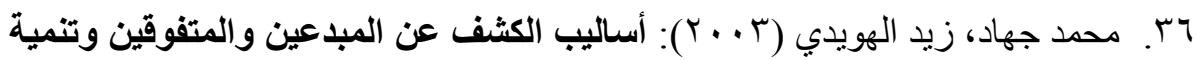

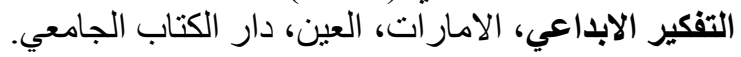

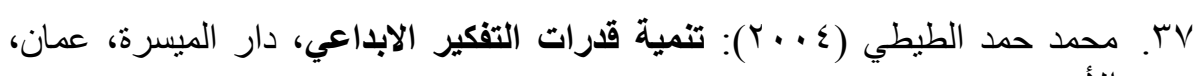
الأردن.

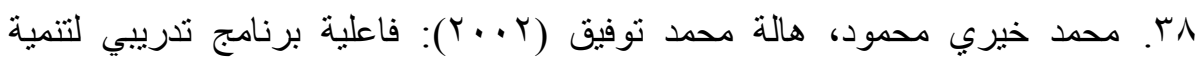

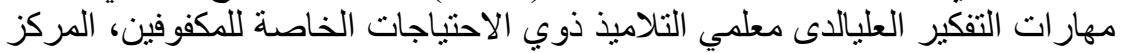
القومي للبحوث و التنمية، شعبة بحوث التئي تطوير المناهج.

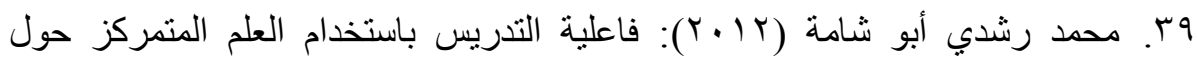

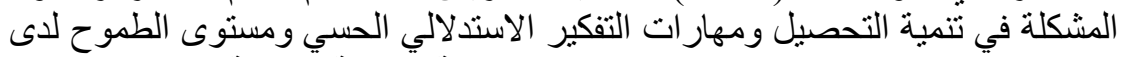

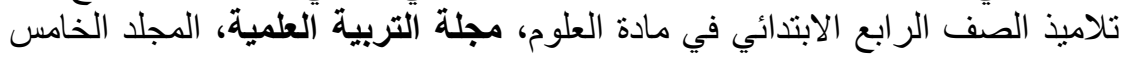
عشر، العدد الثالث.

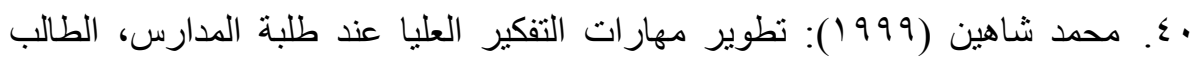

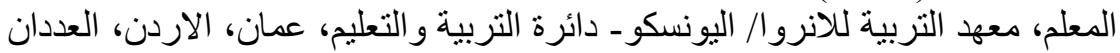

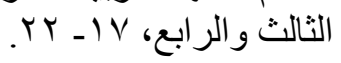

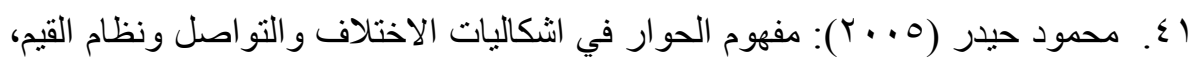

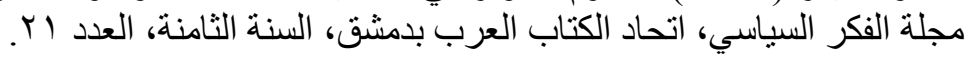

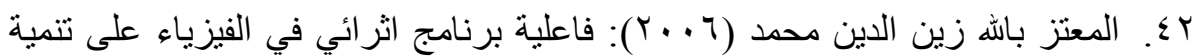

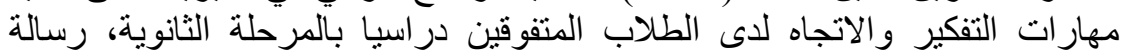
دكتور اه، كلية التربية، جامعة عين شين شمس.

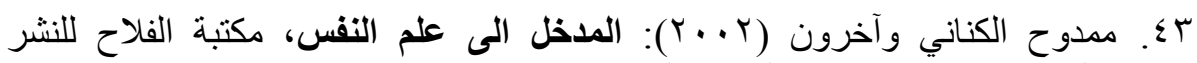
و التوزيع، طب، الامار ات العربية المتحدة.

ع . ناديا هايل السرور (991 ()): تربية المتميزين والموهوبين، القاهرة، دار الفكر العربي.

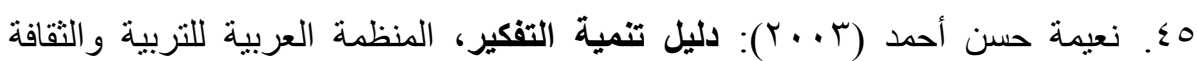

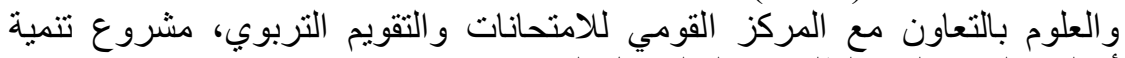

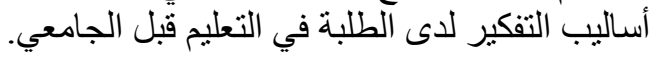

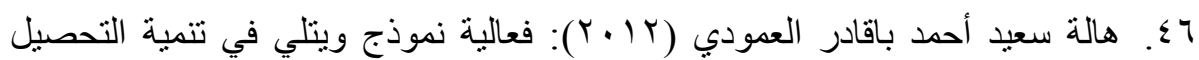

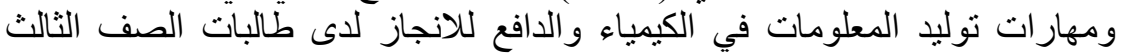

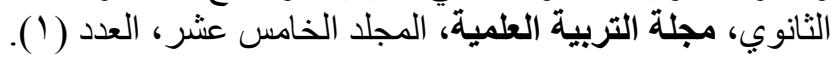


العدد الرابع

SV

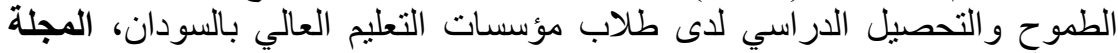

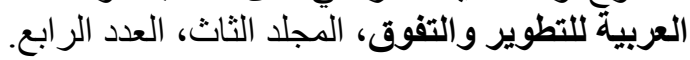

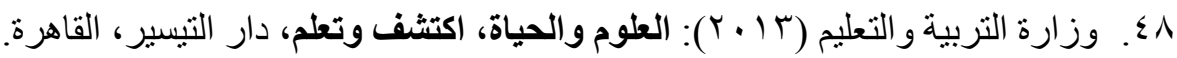

49. Abd-El-Khalick, et.al. (2004): Inquiry in Science Education: International Perspectives, Culture and Comparative Studies, Wiley Periodicals, Inc, pp.397- 418 .

50. Adeyemi, S. (2012): Developing Critical Thinking Skills in Students: A Mandate for Higher Education in Nigeria, European Journal of Educational Research, 1 (2), pp.155-161.

51. Anderson, J., et.al. (2004): Arguing to learn: Confronting Cognitions in Computer-Supported Collaborative learning environments, Dordrecht: Kluwer.

52. Bekiroglu, O. \& Aydeniz, M. (2013): Enhancing Pre-service Physics Teachers' Perceived Self-efficacy of Argumentationbased Pedagogy through Modelling and Mastery Experiences, Eurasia Journal of Mathematics, Science \& Technology Education, 9 (3) .

53. Bekiroglu, O., et.al. (2012): Examination of the Relationship between Engagement in Scientific Argumentation and Conceptual Knowledge, International Journal of Science and Mathematics Education, 10 (6), pp.1415-1443 .

54. Berland, K., Hammer, D. (2012): Framing for Scientific Argumentation, Journal of Research in Science Teaching , 49, 1, PP. 68-94 .

55. Berland, L., Reiser, B. (2009). Making sense of argumentation and explanation. Science Education, 93(1), pp. 26-55.

56. Berland, L., Victor R. (2012): In Pursuit of Consensus: Disagreement and Legitimization during Small-Group Argumentation, International Journal of Science Education, 34 (12), pp1857-1882.

57. Bricker, L., Bell, P. (2008): Conceptualizations of Argumentation from Science Studies and the Learning Sciences and their Implications for the Practices of Science Education., Science Education, 92 (3), pp. 473-498. 
العدد الرابع

58. Bybee, R. et.al. (2006): The BSCS 5E instructional model: Origins, effectiveness, and applications, Colorado Springs: BSCS.

59. Çalık, M. (2013): Effect of Technology-Embedded Scientific Inquiry on Senior Science Student Teachers' Self-Efficacy, Eurasia Journal of Mathematics, Science \& Technology Education, 9 (3). pp. 223-232.

60. Chin, C., \& Osborne, J. F. (2010). Students' questions and discursive interaction: Their impact on argumentation during collaborative group discussions in science, Journal of Research in Science Teaching, 47 (7), 883-908.

61. Dawson, V, Venville, G. (2010): The Impact of a Classroom Intervention on Grade 10students' argumentation Skills, Informal Reasoning, and Conceptual Understanding of Science, Journal of Research in Science Teaching, 47(8): pp.952-977.

62. Dewey J, Bento J. (2009): Activating children's thinking skills (ACTS): the effects of an infusion approach to teaching thinking in primary schools. British Journal Education Psychology, 79 (2), pp. 329-351.

63. Donovan, S., Bransford, J. (2005): How Students Learn: Science in the Classroom, Washington, DC., National Academy Press.

64. Dori, Y., et.al. (2003): Teaching biotechnology through case studies-can we improve higher order thinking skills of nonscience majors?, Science Education, 87(6), 768-793.

65. Driver, R., et.al. (2000): Establishing the norms of scientific argumentation in classrooms,Science Education, 83 (3): pp.287312.

66. Duschl, R., Ellenbogen, K. (2009).: Argumentation and Epistemic Criteria: Investigating Learners' Reasons for Reasons, Educacion Quimica, pp., 111-118.

67. Duschl, R., et.al. (2007): Taking science to school: Learning and teaching science in grades K-8. Washington, DC: National Academies Press.

68. Ebenzer, J., et.al. (2010): The Effects of Common Knowledge Construction Model Sequence of Lessons on Science 
العدد الرابع

Achievement and Relational Conceptual

Change, Journal of Research in Science Teaching, 47, (1), pp 2546.

69. Enderle, P., Grooms, J., and Williams, K. (2012). The development of science proficiency in high school chemistry students engaged in argument focused instruction. Paper to be presented at the 2012 Annual Conference of the American Educational Research Association (AERA), Vancouver, BC. (view the paper

70. Enderle, P., Sampson, V., Campbell, H. (2012). The impact of a new instructional model on middle school science writing. Paper to be presented at the 2012 Annual Conference of the American Educational Research Association (AERA), Vancouver, BC. (view the paper)

71. Ford, M. (2008): Disciplinary authority and accountability in scientific practice and learning, Science Education, 92 (3), pp. 404- 423.

72. Garcla-mila', M., et.al. (2013): The Effect of Argumentative Task Goal on the Quality of Argumentative Discourse, Science Education, 97 (4), pp. 497-523.

73. Grooms, J. (2011): Using Argument-Driven Inquiry to Enhance Students' Argument Sophistication When Supporting a Stance in the Context of Socioscientific Issues, Electronic Theses, Treatises and Dissertations. Paper 3950.

74. Grooms, J., Sampson, V., and Carafano, P. (2012). The impact of a new instructional model on high school science writing. Paper to be presented at the 2012 Annual Conference of the American Educational Research Association (AERA), Vancouver, BC. (view the paper)

75. Grooms, J., \& Sampson, V. (2012). Using a Science Laboratory Course to Enhance Undergraduate Students' Arguments related to Socioscientific Issues. Paper presented at the 2011 Annual Conference of the Association of Science Teacher Educators (ASTE). Clearwater, FL.

76. Gunckel, L. (2013): Fulfilling multiple obligations: Preservice elementary teachers' use of an instructional model while learning 
\begin{tabular}{ccc} 
العدد الرابع \\
\hline \hline
\end{tabular}

to plan and teach science, Science Education, 97 (1), pp. 139162.

77. Hall, C., Sampson, V. (2009): Inquiry, argumentation, and the phases of the moon: Helping students learn important concepts and practices. The Science Scope, 32 (7), pp. 30-35.

78. Halliday, M., Martin, J. (1993): Writing Science Literacy and Discursive Power, Pittsburgh, PA, University of Pittsburgh Press.

79. Hanneke, J. (2010): National Curriculum Tests and the Teaching of Thinking Skills at Primary Schools- parallel or paradox? Education 3-13: International Journal of Primary, Elementary and Early Years Education, 38 (1).

80. Hoffman, J. (2010): What we can learn from the first digital generation: Implications for Developing twenty-first century learning and thinking skills in the primary grades, Education 313: International Journal of Primary, Elementary and Early Years Education, (38), 1.

81. Jimenez-Aleixandre, M. \& Erduran, S. (2008): Argumentation in science education: an overview. Chapter in S. Erduran \& M.P. Jimenez-Aleixandre (Eds.), Argumentation in Science Education: Perspectives from Classroom-Based Research. Dordrecht: Springer.

82. Kelly, G., et.al. (1998). Students' reasoning about electricity: Combining performance assessments with argumentation analysis. International Journal of Science Education, 20 (7), 849871.

83. Kelly, G. Bazerman, C. (2003): How students argue scientific claims: A rhetorical semantic analysis, Applied Linguistics, 24 (1), 28-55 .

84. Ketelhut, D., Nelson, B. (2010): Designing for Real-World Scientific Inquiry in Virtual Environments. Educational Research 52 (2), 151-167.

85. Kuhn, D. (2010): Teaching and Learning Science as Argument, Science Education, 94, pp. 810-824.

86. Kuhn, D., Udell, W. (2003): The Development of Argument Skills, Child Development, 74 (5), pp.1245-1260. 


العدد الرابع

87. Lawson, A. (2003): The Nature and Development of Hypothetico-predictive Argumentation with Iimplications for Science Teaching, International Journal of Science Education, 25 (11), pp. 1387-1408.

88. Lee, S. (2011): Writing Activities Embedded in Bioscience Laboratory Courses to Change Students' Attitudes and Enhance their Scientific Writing, EURASIA Journal of Mathematics, Science \& Technology Education, 7 (3), pp 193-202

89. Lehrer, R., schwable. L. (2009): Images of learning, Images of progress, Journal of Research in Science Teaching, 46 (6), pp. 605-737.

90. Linn, M. \& Burbules, N. (1993). Construction of knowledge and group learning. In K. G. Tobin (Ed.), The practice of constructivism in science education, (pp. 91-119). Washington, DC: American Association for the Advancement of Science (AAAS) Press.

91. Liu, T, et.al. (2009): The Effects of Mobile Natural-science Learning Based on the 5E Learning Cycle: A Case Study, Educational Technology \& Society, 12 (4), pp. 344-358.

92. Lunetta V, Hofstein A. \& Clough M. (2007): Learning and Teaching in the School Science Laboratory: an Analysis of Aesearch, Theory, and Practice, In Handbook of research on science education, eds Lederman N \& Abel S. pp. 393-441. Mahwah, NJ: Lawrence Erlbaum.

93. Marjoribanks, K. (2005): Family Background, Adolescent, s Educational Aspirations, and Australian Young Adults, s Educational Attainment, International Educational Journal, 6 (1), pp. $104-112$.

94. Mayer, R. (2003): Learning and Instruction, Laboratery of Congress Cataloging Publication Data, New Jersy.

95. McNeill, K., Knight, A, (2013): Teachers' Pedagogical Content Knowledge of Scientific Argumentation: The Impact of Professional Development on K-12 Teachers, Science Education, 97 (6), pp. 936-972.

96. Muijs, D., Reynolds, D. (2011): Effective Teaching Evidence and Practice, SAGE Publications Ltd, Third Edition. 


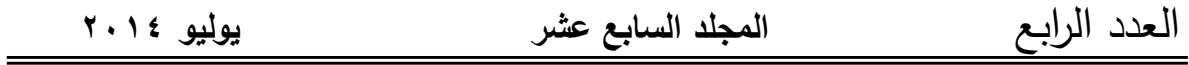

97. Murphy C, et.al. (2004): Students as catalysts in the classroom: the impact of co-teaching between science student teachers and primary classroom teachers on children's enjoyment and learning of science, International Journal of Science Education, 26 (8), pp.1023-1035.

98. Nelon, S. (2003): Learning environment, motivation, and achievement in high school science, Journal of Research in Science Teaching, 40 (4,) pp 347-368.

99. Nussbaum, E., et.,al. (2008): Role of epistemic beliefs and scientific argumentation in science learning, International Journal of ScienceEducation 30 (15): pp.1977-1999.

100. Odgen, L, (2000): Collaborative tasks During peer interaction at key stage, British Education Research Journal, 26 (2), pp. 211- 226 .

101. Osborne, J. et.al. (2013): Learning to argue: A study of four schools and their attempt to develop the use of argumentation as a common instructional practice and its impact on students, Journal of Research in Science Teaching, 50 (3), pp.315-347.

102. Parkinson, J. (2004): Learning through Writter and Oral Work, in Improving Secondary Science Teaching, London and New York.

103. Raths, E. (1991): Teaching For Thinking, Second Edition, Teacher College, Columbia University, New York.

104. Salih, M. (2010): Developing Thinking Skills in Malaysian Science Students via an Analogical Task, Journal of Science and Mathematics Education in Southeast Asia, 33 (1), pp110128 .

105. Sampson, V. (2009): Argument-Driven Inquiry and the development of science proficiency in the laboratory. Paper presented at the 2009 Biannual International Meeting of the European Science Education Research Association, Istanbul, Turkey.

106. Sampson, V., \& Clark, D. (2011): A comparison of the collaborative scientific argumentation practices in two high and two low performing groups. Research in Science Education, 41 (1), pp. 63-97. 
العدد الرابع

107. Sampson, V., et.al.. (2012): Using laboratory activities that emphasize argumentation and argument to help high school students learn how to engage in scientific inquiry and understand the nature of scientific inquiry, Paper to be presented at the 2012 Annual Conference of the National Association of Research in Science Teaching (NARST)

108. Sampson, V., et.al. (2013). Writing to learn and learning to write during the school science laboratory: Helping middle and high school students develop argumentative writing skills as they learn core ideas. Science Education, 97(5), 643-670.

109. Sampson, V., Enderle, P., Grooms, J. (2013). Argumentation in science and science education. The Science Teacher, 80 (5), 3033.

110. Sampson, V. Gleim, L. (2009): Argument-Driven Inquiry To Promote the Understanding of Important Concepts \& Practices in Biology, The American Biology Teacher, 71 (8): 465-472.

111. Sampson, V. and Grooms, J. (2008,): Science as ArgumentDriven Inquiry: The impact on students' conceptions of NOS. Paper presented at the 2009 Annual International Conference of the National Association of Research in Science Teaching (NARST). Baltimore, MD.

112. Sampson, V. and Grooms, J. (2009). Promoting and supporting scientific argumentation in the classroom: The evaluate alternatives instructional model. The Science Scope, 33 (1).

113. Sampson, V., Grooms, J. and Walker, J. (2009). Argumentdriven inquiry to promote learning and interdisciplinary work in science classrooms. The Science Teacher, 76 (8).

114. Sampson, V., Grooms, J., \& Walker, J. (2011). ArgumentDriven Inquiry as a way to help students learn how to participate in scientific argumentation and craft written arguments: An exploratory study, Science Education, 95 (2), 217-257.

115. Sampson, V., Hester, M., Enderle, P. (2012). The development of science proficiency through argument focused lab instruction in high school biology. Paper to be presented at the 2012 Annual Conference of the American Educational Research Association (AERA), Vancouver, BC. (view the paper) 
العدد الرابع

116. Sandoval, W. and Reiser, B. (2004). Explanation driven inquiry: Integrating conceptual and epistemic scaffolds for scientific inquiry, Science Education, 88 (3): 345-372.

117. Sampson, V., \& Walker, J. (2012). Argument-Driven Inquiry as a way to help undergraduate students write to learn by learning to write in chemistry. International Journal of Science Education, 34 (9-10), 1443-1486.

118. Singh, Y. (2011): Astudy of Educational Asbiration in secondary school students, International Referred research Journal, 25 (3) .

119. Torres, T., et.al. (2013): Generating Students' Information Seeking Questions in the Scholar Lab: What Benefits Can We Expect From Inquiry Teaching Approaches?, EURASIA Journal of Mathematics, Science \& Technology Education, 9 (3) .

120. vin, M.. (2011). Relationship of school context to rural youth's educational achievement and aspirations. Journal of Youth and Adolescence, 40, pp.1225-1242.

121. Walker, J. (2011): Argumentation in undergraduate chemistry laboratories, electronic theses, florida state university.

122. Walker, J., et.al. (2010): Argument-Driven Inquiry: An instructional model for use in undergraduate chemistry labs. Paper presented at the 2010 Annual International Conference of the National Association of Research in Science Teaching (NARST). Philadelphia,

123. Walker, J. and Sampson, V. (2013). Learning to argue and arguing to learn in science: Argument-Driven Inquiry as a way to help undergraduate chemistry students learn how to construct arguments and engage in argumentation during a laboratory course, Journal of Research in Science Teaching, 50 (50), 561596

124. Walker, J. and Sampson, V. (2013). Learning to argue and arguing to learn in science: Argument-Driven Inquiry as a way to help undergraduate chemistry students learn how to construct arguments and engage in argumentation during a laboratory course. Journal of Research in Science Teaching, 50 (50), $561-596$ 
العدد الرابع

125. Wallace, C.,. Hand, B., Prain, V. (2004): Writing and Learning in the Science Classroom, Kluwer Academic Publishers.

126. Walters, et.al. (2009): An Investigation of the Incorporation of Information and Communication Technology and Thinking Skills with Year 1 and 2 Students, Australian Journal of Language and Literacy, 32 (3).

127. Yeh, T. (2012): Major Strands in Scientific Inquiry through Cluster Analysis of Research Abstracts, International Journal of Science Education. 34 (18), pp.2811-2842.

128. Yerrick, R. (2000). Lower track science students' argumentation and open inquiry instruction, Journal of Research in Science Teaching, 37, pp. 807-838.

129. Zohar, A., Nemet, F. (2002): Fostering students' knowledge and argumentation skills through dilemmas in human genetics, Journal of Research in Science Teaching, 39 (1), pp. 35-62. 